Prepared for the U.S. Department of Energy

under Contract DE-AC05-76RL01830

\title{
Pedestrian Friendly Outdoor Lighting
}

NJ Miller

TK McGowan

RN Koltai

December 2013

Pacific Northwest

NATIONAL LABORATORY

Proudly Operated by Battelle Since 1965 


\title{
DISCLAIMER
}

This report was prepared as an account of work sponsored by an agency of the United States Government. Neither the United States Government nor any agency thereof, nor Battelle Memorial Institute, nor any of their employees, makes any warranty, express or implied, or assumes any legal liability or responsibility for the accuracy, completeness, or usefulness of any information, apparatus, product, or process disclosed, or represents that its use would not infringe privately owned rights. Reference herein to any specific commercial product, process, or service by trade name, trademark, manufacturer, or otherwise does not necessarily constitute or imply its endorsement, recommendation, or favoring by the United States Government or any agency thereof, or Battelle Memorial Institute. The views and opinions of authors expressed herein do not necessarily state or reflect those of the United States Government or any agency thereof.

\author{
PACIFIC NORTHWEST NATIONAL LABORATORY \\ operated by \\ BATTELLE \\ for the \\ UNITED STATES DEPARTMENT OF ENERGY \\ under Contract DE-AC05-76RL01830 \\ Printed in the United States of America \\ Available to DOE and DOE contractors from the \\ Office of Scientific and Technical Information, \\ P.O. Box 62, Oak Ridge, TN 37831-0062; \\ ph: (865) 576-8401 \\ fax: $(865)$ 576-5728 \\ email: reports@adonis.osti.gov \\ Available to the public from the National Technical Information Service \\ 5301 Shawnee Rd., Alexandria, VA 22312 \\ ph: (800) 553-NTIS (6847) \\ email: ordersantis.gov <http://www.ntis.gov/about/form.aspx> \\ Online ordering: http://www.ntis.gov
}

This document was printed on recycled paper.

(8/2010) 
PNNL-23085

\section{Pedestrian Friendly Outdoor Lighting}

Final Report prepared in support of the DOE Solid-State Lighting Technology Demonstration GATEWAY Program

Study Participants:

Pacific Northwest National Laboratory

U.S. Department of Energy

NJ Miller ${ }^{1}$

RN Koltai ${ }^{2}$

TK McGowan $^{3}$

December 2013

Prepared for

the U.S. Department of Energy

under Contract

Pacific Northwest National Laboratory

Richland, Washington 99352

\footnotetext{
${ }^{1}$ Senior Staff Scientist, Pacific Northwest National Laboratory, Portland OR

${ }^{2}$ Principal, Koltai Lighting Design, LLC, Stanford, CA

${ }^{3}$ Principal, Lighting Ideas, Cleveland Heights, $\mathrm{OH}$
} 



\section{Preface}

This document is a report of observations and results obtained from a lighting demonstration project conducted under the U.S. Department of Energy (DOE) GATEWAY Demonstration Program. The program supports demonstrations of high-performance solid-state lighting (SSL) products in order to develop empirical data and experience with in-the-field applications of this advanced lighting technology. The DOE GATEWAY Demonstration Program focuses on providing a source of independent, third-party data for use in decision-making by lighting users and professionals; this data should be considered in combination with other information relevant to the particular site and application under examination. Each GATEWAY Demonstration compares SSL products against the incumbent technologies used in that location. Depending on available information and circumstances, the SSL product may also be compared to alternate lighting technologies. Though products demonstrated in the GATEWAY program may have been prescreened for performance, DOE does not endorse any commercial product or in any way guarantee that users will achieve the same results through use of these products.

\section{Acknowledgements}

Reports like this are not possible without contributions from many parties. These include Stanford University and Chautauqua Institution that allowed GATEWAY to learn from their lighting demonstrations and document the process, performance and results. Dr. William Neches and the Chautauqua Property Owners Association contributed experience and use of Dr. Neches' extensive site photographs. Manufacturers such as Acuity/Holophane, Architectural Area Lighting, Xeralux/Sensity, Cree, Acuity/Tersen, Neri, Landscape Forms, Bega, Selux, and others provided sample products (often customized) that advanced the understanding of pedestrian-friendly lighting. 



\section{Executive Summary}

Nighttime outdoor lighting has most often been designed for the vehicle driver, rather than the pedestrian. Metrics such as pavement illuminance or luminance, illuminance uniformity ratios, vertical illuminance on objects or faces, and glare metrics such as Veiling Luminance Ratio or Glare Ratings from the Illuminating Engineering Society (IES) Luminaire Classification System (BUG) have been used as criteria. The U.S. Department of Energy GATEWAY Demonstration Program has followed two pedestrian-focused projects at sites where the pedestrian-scale lighting needed improvement: Stanford University in California and the Chautauqua Institution in upstate New York. The results from these projects reveal that pedestrians may have different criteria and priorities than drivers, especially in areas where cars are subordinate to bicycles and users on foot.

At both sites, an iterative process was used to evaluate luminaires; collect feedback from residents, homeowners, and/or campus facilities groups; and use that feedback to try other options. In both cases, it became clear that users

- cared about the daytime appearance of the luminaire

- found luminaire glare to be a significant factor in luminaire acceptability

- preferred luminaires that produced a soft-edged pattern of light on the ground

- preferred a warm color of light (2700K to $3000 \mathrm{~K})$ given the character of their neighborhood and the fact that they were used to either incandescent sources or high-pressure sodium as a baseline

- found that horizontal illuminances could be at the low end of IES-recommended levels as long as luminaire glare was reduced.

Diffusion was an important characteristic of optical systems deemed less glaring. Light-emitting diodes (LEDs) or clear metal halide arc tubes exhibit high variation of luminance across the face of the luminaire, but diffusion from frosted refractors and flat glass panels was judged as less glaring, even when measured spot luminances were high. Smoothing out the luminance transition from high to low resulted in responses of greater visual comfort, even though glare metrics do not take this into account.

Traditionally, the outdoor luminaire's "glare” angles have been $75^{\circ}$ to $90^{\circ}$ from nadir. These projects gathered observations and responses that suggest that although pedestrians may be affected by glare from these angles when they are far away from a post-top luminaire, they are most uncomfortable when they are walking within the zone from $0^{\circ}$ to $75^{\circ}$, that is, when they are closer to the luminaire and when the highest luminance elements are within or even above the field of view. This may be related to overhead glare that has been studied in interior applications, or it may be related to the fact that pedestrians naturally glance around their surroundings as they walk, putting the luminaire in the field of view as their eyes look upward.

Every outdoor lighting project is different. The needs vary according to the project client, the users, and their activities, and therefore the best lighting solution will also vary from project to project. There are invariably tradeoffs that must be weighed among visual comfort, color, visibility, efficacy, and other factors. There is no glare metric that works reliably for pedestrian lighting, so full-scale mockups are an important step for gathering feedback from users. Not every neighborhood is suited for pedestrian- 
friendly approaches, but where communities are receptive, the following may help mitigate glare, improve visual comfort and visibility, and make outdoor spaces more inviting:

- lower lumen output luminaires and lower illuminances, if luminaire brightness can be controlled

- luminaires that spread luminance (“brightness”) over a larger area

- luminaires with less optical punch and less sharp angular variation in candlepower

- luminaires delivering warmer color light, usually lower than 4000K, and often below 3000K correlated color temperature.

The problems of pedestrian lighting occur with all technologies, but LEDs offer unique optical options and opportunities to the industry. This report is meant to stimulate discussion among specifiers, users, energy specialists, and industry in hopes that new approaches, metrics, and standards can be developed to support pedestrian-focused communities, while reducing energy use. 


\section{Acronyms and Abbreviations}

$\begin{array}{ll}\text { AAL } & \text { Architectural Area Lighting } \\ \text { BUG } & \text { backlight, uplight, and glare } \\ \text { CCT } & \text { correlated color temperature } \\ \text { CFL } & \text { compact fluorescent lamp } \\ \text { CMH } & \text { ceramic metal halide } \\ \text { CPOA } & \text { Chautauqua Property Owners Association } \\ \text { CRI } & \text { color rendering index } \\ \text { CUD } & \text { Chautauqua Utility District } \\ \text { DOE } & \text { U.S. Department of Energy } \\ \text { fC } & \text { footcandle(s) } \\ \text { HPS } & \text { high-pressure sodium } \\ \text { IES } & \text { Illuminating Engineering Society } \\ \text { IP } & \text { Ingress Protection } \\ \text { LCS } & \text { Luminaire Classification System } \\ \text { LED } & \text { light-emitting diode } \\ \text { lx } & \text { lux } \\ \text { SCRL } & \text { Stanford Campus Residential Leaseholders } \\ \text { SSL } & \text { solid state lighting } \\ \text { UGR } & \text { Unified Glare Rating } \\ \text { VCP } & \text { Visual Comfort Probability } \\ \text { VLR } & \text { Veiling Luminance Ratio }\end{array}$





\section{Contents}

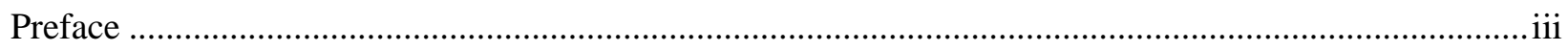

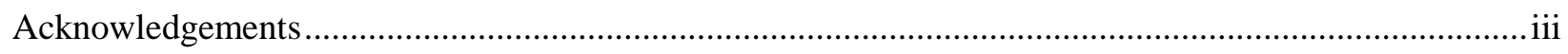

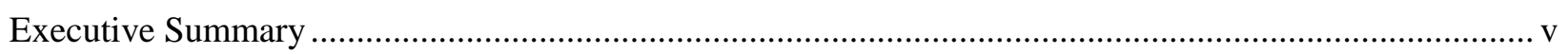

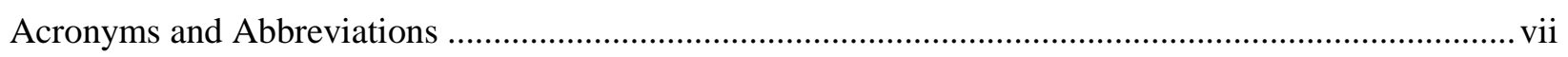

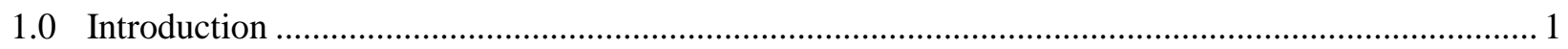

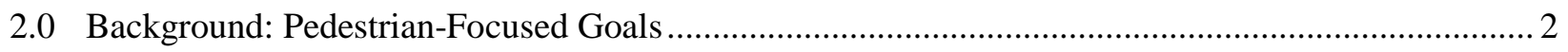

2.1 Safety from Tripping, Slipping, Falling …........................................................................ 2

2.2 Personal Security from Harm, Intimidation ......................................................................... 4

2.3 Unwanted Light in Residential Windows ......................................................................... 4

2.4 Appearance of the Neighborhood or Campus or Area .......................................................... 4

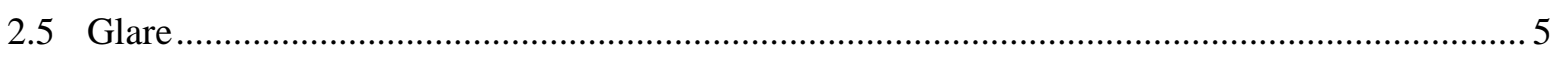

3.0 Where To Consider Pedestrian-Friendly Lighting ................................................................ 7

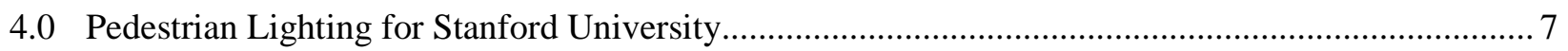

4.1 Options Considered for Improving the Campus Lighting ...................................................... 10

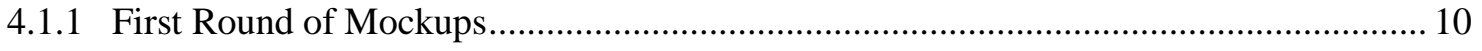

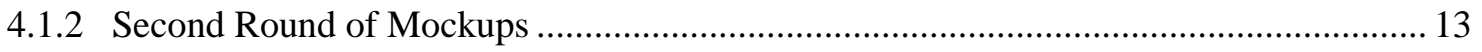

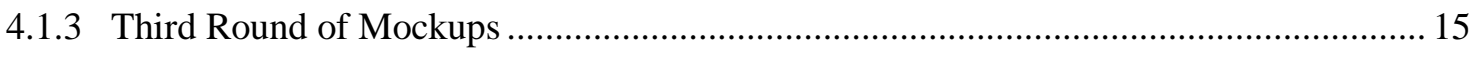

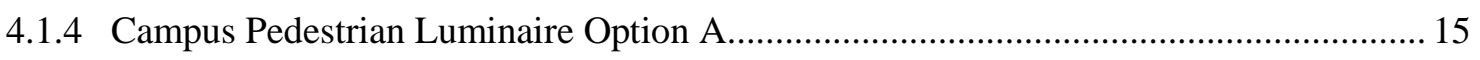

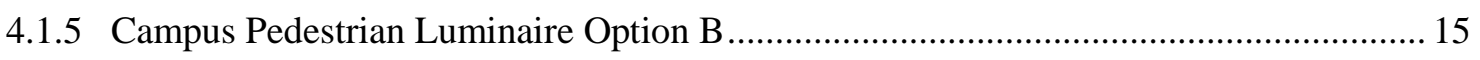

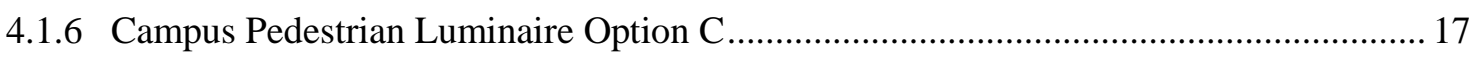

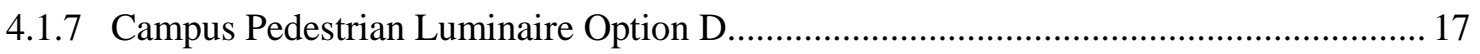

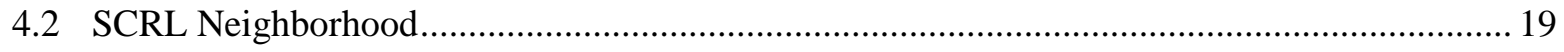

4.2.1 Landscape Forms “Alcott,” 58W 3000K LED .......................................................... 19

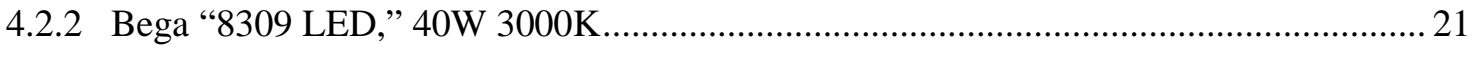

4.2.3 Architectural Area Lighting (AAL) "Providence-Indirect” .......................................... 22

4.2.4 Selux Saturn Cutoff with 60W 2800K “Cosmowhite” CMH lamp (67W input)............ 23

4.2.5 Acuity/Holophane "PUL,” Utility Full-Cutoff Post-Top with 70W 3000K LED Matrix, Ordered with Frosted Lens at the Aperture to Diffuse the View of the

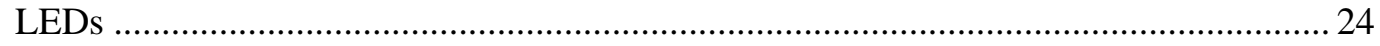

4.3 Lessons Learned from the Stanford University Mockups....................................................... 25

5.0 Pedestrian Lighting for the Chautauqua Institution...................................................................... 25

5.1 Demonstration 1: AAL Providence Post-Top with Indirect Asymmetrical Optics Using

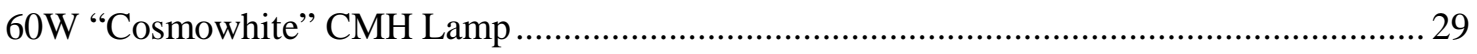

5.2 Demonstration 2: Acuity/Tersen "Resonance” Post-Top with LED Matrix in Cap of Luminaire . 
5.3 Demonstration 3: AAL “Providence Microcore” Post-Top with Round Pattern of LEDs in Aimed Optics . 32

5.4 Demonstration 4: Neri “804” Post-Top Lantern with Linear LED Module............................... 33

5.5 Demonstration 5: Neri “804” Post-Top Lantern with Linear LED Module Dimmed............... 34

5.6 Results of the Five Demonstrations at Chautauqua Institution ................................................ 36

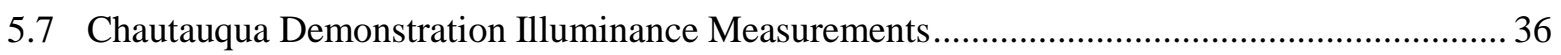

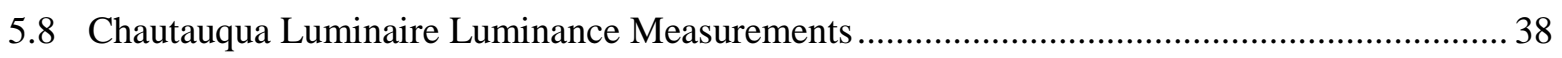

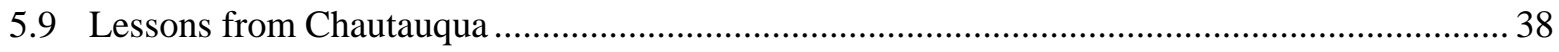

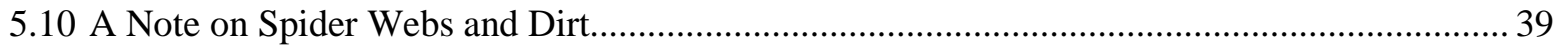

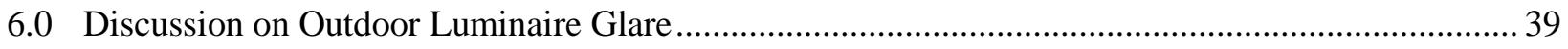

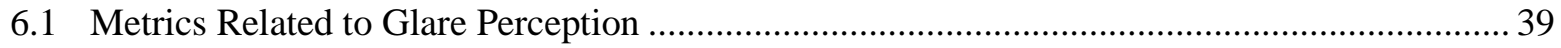

6.1.1 The IES Luminaire Classification System, or BUG (Backlight, Uplight, and Glare)

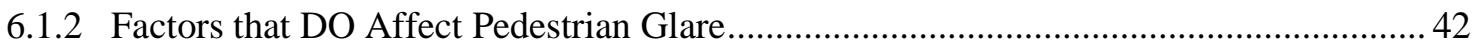

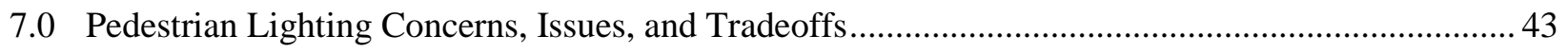

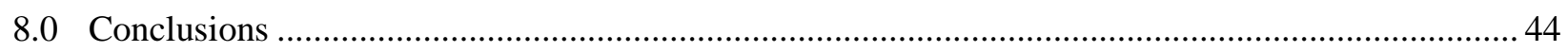

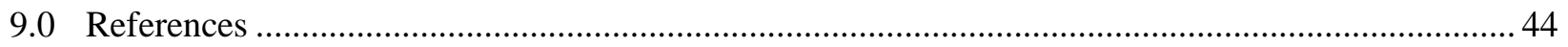

Appendix A : Stanford Community Residential Leaseholders (SCRL) Lighting Survey ...................... A.1

Appendix B : Chautauqua Property Owners Association Outdoor Lighting Survey, 2012.......................1

Appendix C : Chautauqua Property Owners Association Outdoor Lighting Survey, 2013........................1

Appendix D : $\quad$ Photometric Performance for Luminaires on Stanford University and

Chautauqua Institution projects

D.1 


\section{Figures}

Figure 1. Campus pathway at night, showing reflected glare (i.e., veiling reflection) from pavement. The grass areas flanking the path have a more matte reflectance when wet, and the texture difference marks the edge of the pathway. (www.shutterstock.com)

Figure 2. Glare compromises the pedestrian's ability to see details in darker areas of the visual field. In this photo, the wallpack light source is not shielded; therefore, the visual system adapts to the luminance (brightness) of the wallpack’s lens. The bright luminaire is also producing both disability glare and discomfort glare. (Photo courtesy of the International Dark-sky Association.)

Figure 3. Glare compromises the pedestrian's ability to see. In this photo, the glare source is masked, lowering the viewer's adaptation level and making it possible to see details in the darker areas of the scene, revealing a man standing at the gate. (Photo courtesy of the International Dark-sky Association.) ................................................................................ 3

Figure 4. Approximate luminaire angle ranges that contribute to pedestrian glare and driver glare........... 5

Figure 5. Illustration of disability glare, where the bright luminaire is creating scatter within the eye of the viewer, washing out the contrast of the couple in the visual image. (Image courtesy of the International Dark-sky Association.)

Figure 6. Same view, but with luminaire brightness controlled to reduce the disability glare, using an optical element such as a well-engineered lens or reflector for shielding. (Image courtesy of the International Dark-sky Association.)

Figure 7. Stanford University. (Photo from http://www-conf.slac.stanford.edu/pic/.) ............................ 7

Figure 8. Stanford University's typical pedestrian lighting, using 100W HPS in a glass refractor luminaire, $10 \mathrm{ft}$ poles, $70 \mathrm{ft}$ on center, average. (Photo: www.KenRicePhoto.com.)...

Figure 9. Stanford University campus standard pedestrian post-top luminaire (top left); the University’s typical pedestrian post-top, the Acuity/Holophane RSL-350 (right); and closeup of its glass refractor (bottom left). (Photos: Koltai Lighting (top left) and www.KenRicePhoto.com (right, bottom left).)

Figure 10. The Acuity/Holophane PTU, a utility post-top with flat glass instead of lantern glass refractor (left); closeup of the Holophane PTU luminaire showing the $100 \mathrm{~W}$ clear 3000K CMH lamp and clear flat glass at the aperture (right). (Photos: Acuity/Holophane (left) and www.KenRicePhoto.com (right).).

Figure 11. Mockup installation of the Holophane PTU luminaire with 100W clear 3000K CMH lamp and clear glass at the aperture. Note the sharp-edged shadow on the ground around the pole. (www.KenRicePhoto.com)

Figure 12. Retrofit installation of the Xeralux/Sensity 70W 4100K LED lamp product (bottom left), its appearance inside the lantern refractor (top left), and as installed in the mockup luminaire (right).

Figure 13. The Cree 57W 2700K LED retrofit lamp (top left), partially installed in RSL-350 luminaire (bottom left), and lighted at night (right). 
Figure 14. Option A for Stanford's campus pedestrian lighting mockups: 60W 2800K, 70CRI (“Cosmowhite”) CMH lamp (right); closeup of Option A (left). Spider webs are a familiar sight on all post-top luminaires. (www.KenRicePhoto.com)

Figure 15. Option B for Stanford's campus pedestrian lighting mockups: Holophane "PUL" utility series full-cutoff post-top with 70W 3000K LED optics with diffusing glass in luminaire cap. (www.KenRicePhoto.com).

Figure 16. Closeup photo of Option B luminaire (left); Option B: Holophane PUL luminaire (right). (Photos: www.KenRicePhoto.com (left) and Acuity/Holophane (right).) .

Figure 17. Two campus luminaires retrofitted with frosted glass refractor and 50W 2700K LED optical replacement kit by Holophane. This was ultimately the most widely supported pedestrian lighting solution for the Stanford University campus.

(www.KenRicePhoto.com).

Figure 18. Closeup photo of 50W 2700K LED optical replacement kit with frosted glass refractor (left) and detail of frosted glass refractor (right). (Photos: www.KenRicePhoto.com (left) and Koltai Lighting Design (right).)

Figure 19. Manufacturer's catalog illustration of LED optical replacement kit. (Photo courtesy of Acuity/Holophane Lighting.) .....

Figure 20. Mockup installation of Landscape Forms streetlight for Stanford neighborhood.

(www.KenRicePhoto.com).

Figure 21. Landscape Forms Inc. Alcott luminaire (left); close-up photos of Landscape Forms (type 3 distribution) luminaire taken from sidewalk (center) and street (right). (Images:

Landscape Forms (left) and www.KenRicePhoto.com (center, right).) 20

Figure 22. Mockup installation of Bega "8309 LED” indirect post-top, with 40W 3000K LEDs. (www.KenRicePhoto.com)

Figure 23. Bega “8309 LED” luminaire (left); closeup of luminaire with 40W 3000K indirect lamp (right). (Courtesy of Bega-US (left) and www.KenRicePhoto.com (right).)

Figure 24. Mockup installation of the AAL "Providence Indirect" luminaire with 60W 2800K 70CRI CMH lamp (“Cosmowhite”). (www.KenRicePhoto.com).

Figure 25. AAL Providence Indirect luminaire (left); closeup of luminaire with 60W 2800K CMH indirect lamp. (Photos: AAL (left) and www.KenRicePhoto.com (right).).

Figure 26. Mockup installation of the Selux Saturn Cutoff luminaire using 60W 2800K 70 CRI CMH lamp. (www.KenRicePhoto.com)......

Figure 27. Selux Saturn Cutoff luminaire (left image courtesy of Selux; right image www.KenRicePhoto.com).

Figure 28. Mockup of the Holophane PUL luminaire with 70W 3000K LED matrix and frosted glass diffusing lens. Note the diffused shadow at the base of the pole.

(www.KenRicePhoto.com).

Figure 29. Acuity/Holophane PUL utility post-top luminaire (left) closeup of luminaire with 70W 3000K LED matrix and frosted diffusing lens to mitigate glare and soften the distribution of light. (Photos: Acuity/Holophane (left) and www.KenRicePhoto.com (right)). 25

Figure 30. Photos of the Chautauqua community. (Photos courtesy of www.ciweb.org) 26 
Figure 31. Sign posted at the entrance to the Chautauqua Institution grounds restricting traffic speed.

Figure 32. Nighttime view of Chautauqua street where $175 \mathrm{~W}$ mercury vapor carriage lanterns (blue-white color appearance) are starting to be replaced by 100W HPS carriage lanterns (yellow color appearance) when older equipment fails. (Photo: Dr. William Neches.)

Figure 33. These six photos illustrate luminaires on the grounds of Chautauqua that have been modified with paint or opaque shielding to minimize glare and light trespass. (Photos: Dr. William Neches.).

Figure 34. Daytime and evening views of AAL "Providence" indirect luminaire with 60W 2800K 70 CRI CMH (“Cosmowhite”) lamp. (Photos: Dr. Williams Neches.).

Figure 35. AAL “Providence Indirect” luminaire (left); closeup of asymmetrical indirect optical system (right). (Photos: AAL (left) and Dr. William Neches (right).)

Figure 36. Daytime photo of the Acuity/Tersen Resonance post-top luminaire with prismatic glass to diffuse brightness of individual LEDs (left); closeup of luminaire with LED matrix and glass diffuser. (Photos: Dr. William Neches.)

Figure 37. Nighttime photo of Acuity/Tersen Resonance luminaire mockup (on left). (Photo: Terry McGowan.)

Figure 38. AAL Providence Microcore LED luminaire (top left); luminaire with diffusing glass, daytime appearance (right) and closeup (bottom left). (Photos: AAL (top left) and Dr. William Neches (bottom left; right).)....

Figure 39. Daytime appearance of Neri 804 post-top lantern with 37W LED module.

Figure 40. Closeup of Neri 804 optical system showing remote-phosphor LED module behind clear glass (left); closeup of system with diffusing glass (center); LED module used in Neri 804 post-top luminaire, showing its large remote-phosphor surface (right)

Figure 41. Neri post-top LED luminaire with 1800 lumen output, viewed from above to show light pattern on street. (Photo: Dr. William Neches.)

Figure 42. Photo of Chautauqua street with dimmed Neri 804 luminaire on mockup pole in the foreground, right. (Photo: Terry McGowan.).... 35

Figure 43. Nighttime illuminance measurements at Chautauqua Institution. 37

Figure 44. Three-dimensional illustration of the LCS model.

\section{Tables}

Table 1. Measured luminaire luminance values from Chautauqua mockup luminaires. 38 



\subsection{Introduction}

Outdoor lighting contributes to safety of nighttime travel along streets and roadways, in parking lots, at building entrances, in parks and entertainment venues, and along pedestrian pathways. Conventional lighting design has rightly focused on visibility, as well as economic and environmental goals for these applications. These include, in no specific order

- illuminance or luminance on pavement

- contrast of irregular paving and objects in the path of travel

- uniformity (e.g., maximum-to-minimum illuminance or average-to-minimum illuminance)

- vertical illuminance on faces and targets

- pole spacing and mounting height for economy and uniformity

- luminaire distribution (“Cutoff” or BUG (backlight, uplight, glare) system ratings) for dark-sky considerations and some degree of glare control

- lighting system efficacy.

This approach works pretty well for vehicle drivers, but what about pedestrians? Pedestrians do not have the roof of a vehicle to block the view of the pole-mounted light, and they move much slower, often in their own neighborhoods. While drivers primarily look straight ahead, pedestrians often have complex sight lines as they look around the surrounding environment. Pedestrian-scale luminaires typically are mounted at much lower pole heights than streetlighting luminaires, and so are more likely to be in the field of view. The goals for pedestrian-scale lighting may include

- safety from tripping/falling

- safety from being hit by vehicles, bicycles, or skateboarders

- personal security from harm or intimidation by others

- minimizing unwanted light in residential windows

- appearance of the neighborhood/campus/area

- minimizing glare that causes discomfort, is disabling, or affects viewer adaptation level.

Previous reports on outdoor lighting projects featured in the U.S. Department of Energy GATEWAY Demonstration Program have focused on light-emitting diode (LED) applications for street and area lighting, including parking lots and parking garages. Recognizing that pedestrian lighting has different criteria for success, GATEWAY has followed two projects in recent years to gain insight into what those criteria might be, how they differ from street and area lighting applications, and how solid-state lighting can be better applied in pedestrian applications.

Unlike many previous GATEWAY reports, which focus on in-depth analyses of a single application, this report presents carefully evaluated survey data and the evolution of thinking involving the products appropriate for two pedestrian-scale lighting projects that underwent multiple mockups. It reports on formal and informal surveys and observations from neighborhood residents and pedestrians, feedback from experienced facility design and engineering professionals, personal observations and discussions of 
lighting designers and engineers, and input from researchers and scientists. The results are not meant to present a solution for nighttime pedestrian lighting for all neighborhoods and campuses, but to encourage informed discussion among lighting specialists, researchers, and luminaire manufacturers who recognize that good lighting must satisfy human needs that are still difficult to quantify.

\subsection{Background: Pedestrian-Focused Goals}

This section describes issues that affect pedestrian goals, through the eyes of a nighttime pedestrian.

\subsection{Safety from Tripping, Slipping, Falling}

Objects in the pathway, chipped concrete, icy patches, or sidewalk buckling due to tree roots are obstacles that the pedestrian needs to navigate. These are made more visible when the angle of light increases the contrast between an obstacle and the background, either by putting the obstacle in silhouette against the lighted background, or highlighting obstacle relative to the darker background.

Illuminance uniformity along the path helps to minimize dark patches where people or objects are not visible. Lighting the edge of the path (including the surface beyond the path) can help pedestrians navigate the route more confidently, especially when pavement is wet and becomes a specular surface (Figure 1). Controlling glare from luminaires delivers multiple benefits. First, the pedestrian's eye adapts quickly to the brightest object in the field of view, and the visual system can only resolve details within a limited range of luminances. A viewer who is adapted to that bright source cannot resolve details in areas darker than about $1 / 1000^{\text {th }}$ of that luminance, ${ }^{1}$ making obstacles, signs, and facial details in dimmer areas essentially invisible (Figure 2 and Figure $3^{2}$ ). Additional benefits are discussed in section 2.5 (Glare).

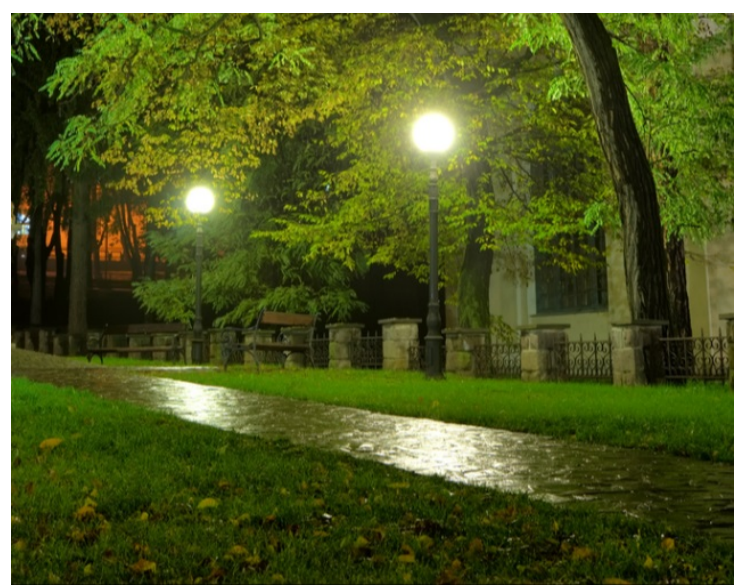

Figure 1. Campus pathway at night, showing reflected glare (i.e., veiling reflection) from pavement. The grass areas flanking the path have a more matte reflectance when wet, and the texture difference marks the edge of the pathway. (www.shutterstock.com)

\footnotetext{
${ }^{1}$ Based on an email exchange between Dr. Peter Boyce and the chief author in 2013, the dark-adapted eye is unable to resolve luminance contrasts outside of a range of approximately 1000 to 1 at night. This is an approximate value and will vary according to the individual's adaptation level. This is also supported by Figure 2.11 from Boyce 2003.

${ }^{2}$ These photos illustrate how the eye sees, but a camera cannot reproduce how the eye sees with complete accuracy.
} 


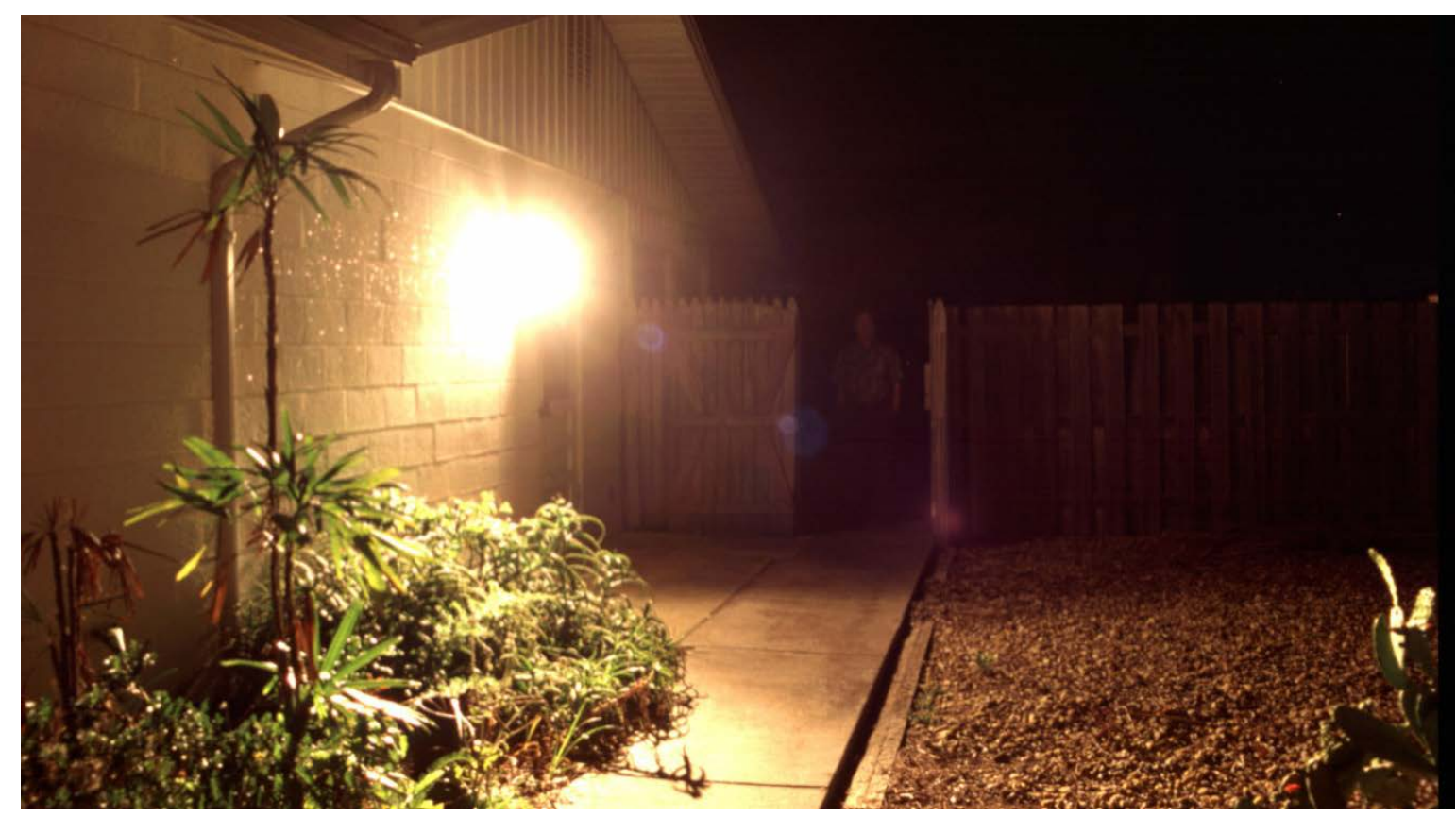

Figure 2. Glare compromises the pedestrian's ability to see details in darker areas of the visual field. In this photo, the wallpack light source is not shielded; therefore, the visual system adapts to the luminance (brightness) of the wallpack's lens. The bright luminaire is also producing both disability glare and discomfort glare. (Photo courtesy of the International Dark-sky Association.)

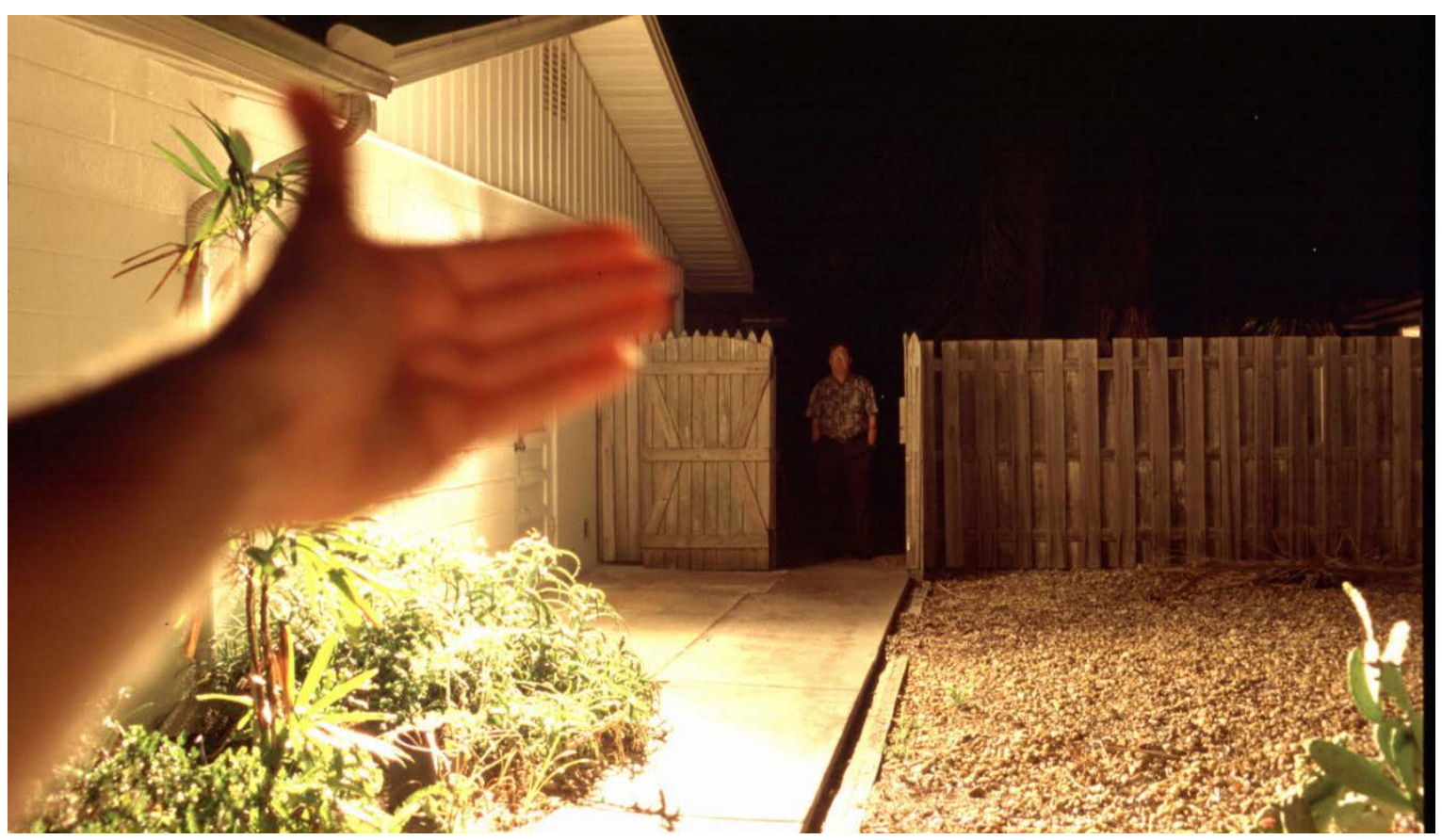

Figure 3. Glare compromises the pedestrian's ability to see. In this photo, the glare source is masked, lowering the viewer's adaptation level and making it possible to see details in the darker areas of the scene, revealing a man standing at the gate. (Photo courtesy of the International Darksky Association.) 


\subsection{Personal Security from Harm, Intimidation}

The pedestrian is likely to perceive an area as safer if he or she can see the faces and bodies of people nearby. Soft or reflected light (i.e., not strongly directional or casting harsh shadows) helps the pedestrian see faces and clothing of others, which helps with identifying whether individuals are a friend or potential foe, and whether they have malicious postures or gestures or weapons. Soft light is more attractive for people and environments such as outdoor cafes or festivals, and often what makes a space feel safe is safety in numbers: seeing other people enjoying outdoor activities or even casually walking their dogs.

Dr. Peter Boyce has promulgated two principles for pedestrian perception of safety: (1) seeing at sufficient distance to identify danger in time to react, and (2) seeing where to go for safety or refuge if needed (Boyce 2003). The soft lighting on faces and bodies supports these principles by making people and objects more visible. Similarly, some degree of uniformity on the ground provides reassurance that there is no danger hiding in the shadows between the observer and the place of refuge.

\subsection{Unwanted Light in Residential Windows}

Light from sources such as streetlights or wallpacks can be a nuisance for residents. Although some of the light can illuminate paths and building entrances, the stray light and glare may disrupt sleep and create ugly patterns in interior living spaces. When caused by streetlights, this annoying stray light is usually emitted between $60^{\circ}$ and $120^{\circ}$ from the luminaire's nadir, toward the house side.

\subsection{Appearance of the Neighborhood or Campus or Area}

Different neighborhoods have different characters and histories, and pedestrian lighting often supports that character, either through its daytime appearance (e.g., decorative carriage lantern post-tops in the North End of Boston or the French Quarter of New Orleans) or its lighted appearance at night. Glaringly bright luminaires may unintentionally communicate that the neighborhood is unsafe, scaring away the very residents and outdoor activities that would make the streets feel safer at night. The light patterns on grounds and buildings can attract or deter pedestrians, depending on whether the patterns are visually attractive and provide enough uniformity to reduce dark shadows where criminals can hide. The lighting color may also affect how inviting the spaces and paths are. In certain neighborhoods, warm color light with moderate to excellent color rendering is considered more appealing than very cool, bluish light or orange light with an unnatural spectrum. This color preference may change according to the culture and climate of the area. 


\subsection{Glare}

Pedestrians are subject to glare from different angles than the vehicle driver is, and for a longer period because pedestrians move more slowly. Because the driver's field of view is limited by the opaque top of the vehicle, only the $75^{\circ}$ to $90^{\circ}$ zone from the luminaire is usually contributing to driver glare. ${ }^{1}$ However, the pedestrian can sense brightness from almost the whole downward emission of the luminaire, with the worst exposure within the zones of maximum candelas, approximately $0^{\circ}$ to $75^{\circ}$ from nadir ${ }^{2}$ (Figure 4 ). Discomfort from very bright luminaires may cause pedestrians to shield their eyes with their hands.

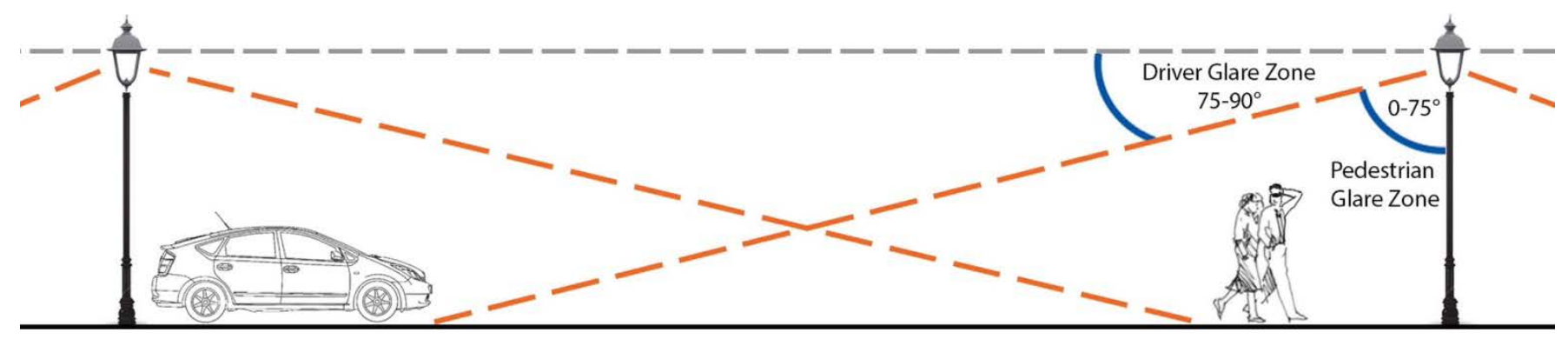

Figure 4. Approximate luminaire angle ranges that contribute to pedestrian glare and driver glare.

Disability glare may also cause discomfort, but it is defined as very high luminance (measured "brightness") that is close to the line of sight that affects the viewer's ability to resolve details because it superimposes a veil of light, washing out the contrast in the visual image. Illustrated in Figure 5 and Figure 6, this is a concern because the glare may reduce the pedestrian's ability to see faces and objects at a distance. This may be more of a problem for pedestrian-scale lighting because the luminaire is mounted lower to the ground, closer to eye height than is normal for taller roadway lighting.

Whether producing discomfort or disability glare, the bright light source shifts the viewer's adaptation level higher, reducing the pedestrian's ability to see details in darker areas of the field of view, making the space feel less safe.

Glare can also lead to afterimages on the retina that take time to dissipate, since it takes time for the rods or cones to recover from bleaching of their photopigment. The afterimage can mask the detection and identification of surroundings and people, and this effect grows more pronounced with age.

\footnotetext{
${ }^{1}$ IES Recommended Practice 8 (RP-8-00) cites unpublished studies by Adrian et al. that indicate "75 percent of drivers of 1980's style autos are shielded by the windshield from luminaires above 20 degrees above horizontal," which means the driver is able to see the luminaire's output only from $70^{\circ}$ to $90^{\circ}$ from nadir. IES Technical Memorandum 15 (TM-15-07 Revised) lists the "glare angles" as $80^{\circ}$ to $90^{\circ}$ from luminaire nadir. The $75^{\circ}$ to $90^{\circ}$ range illustrated here represents an average of the two ranges.

${ }^{2}$ Glare formulae such as Visual Comfort Probability (VCP) and Unified Glare Rating (UGR) have assumed that light sources outside the direct field of view do not contribute to the glare response. However, more recent glare research has shown that individuals also sense discomfort from luminaires above the field of view, up to $85^{\circ}$ above horizontal when the light source luminance is very high relative to the adaptation luminance (Ngai and Boyce 2000; Boyce et al. 2003). Those angles are measured from a fixed horizontal line of sight. It is fair to assume that pedestrians may glance upward in their travels just as drivers do (Gibbons et al. 2012), especially when a glaring luminaire is spotted; thus, the full range of $0^{\circ}$ to $75^{\circ}$ from the luminaire's nadir is likely to contribute to discomfort.
} 


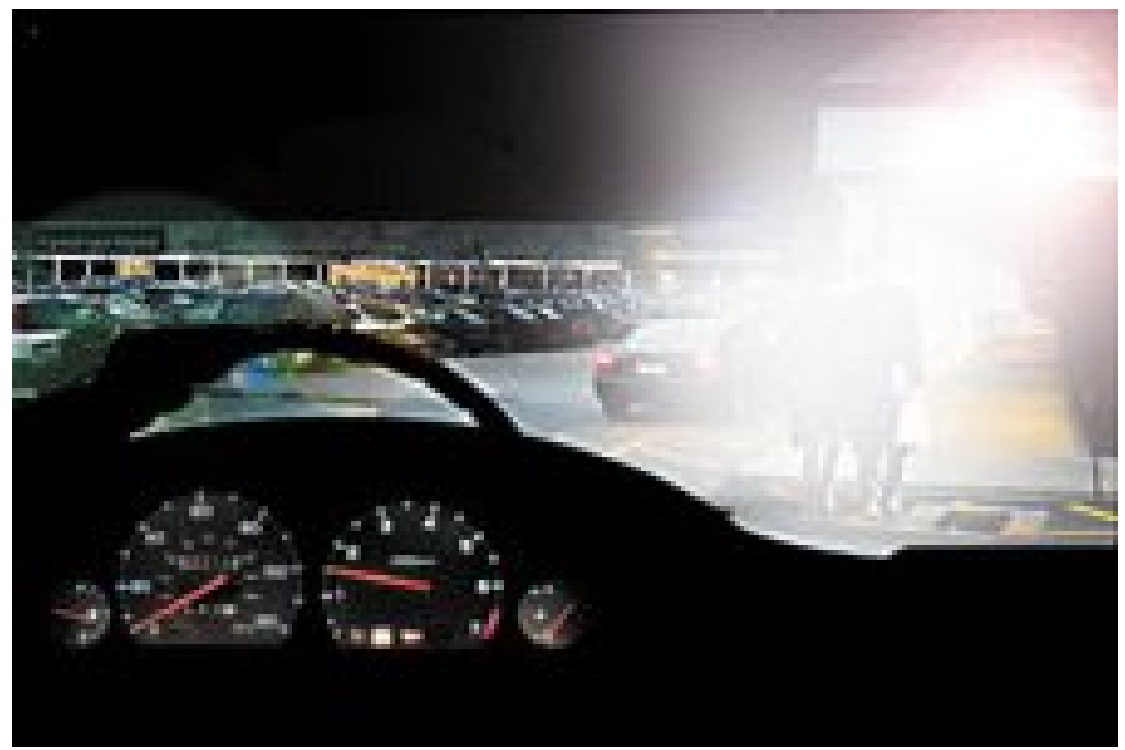

Figure 5. Illustration of disability glare, where the bright luminaire is creating scatter within the eye of the viewer, washing out the contrast of the couple in the visual image. (Image courtesy of the International Dark-sky Association.)

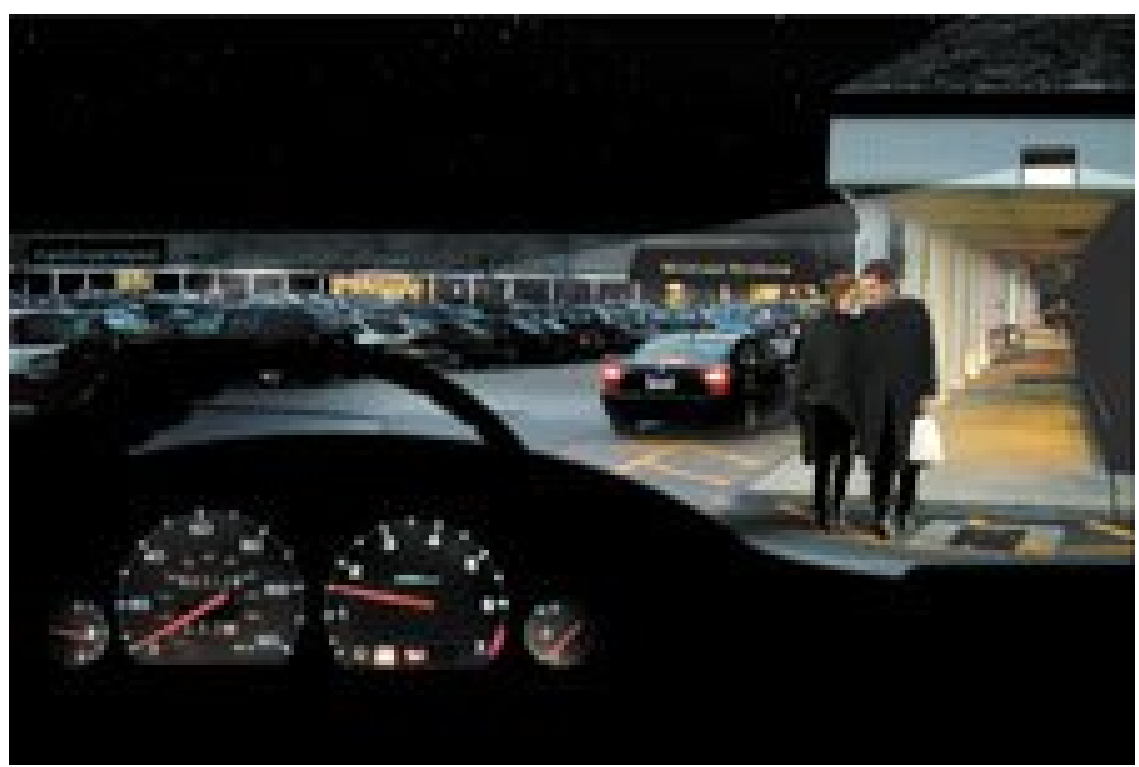

Figure 6. Same view, but with luminaire brightness controlled to reduce the disability glare, using an optical element such as a well-engineered lens or reflector for shielding. (Image courtesy of the International Dark-sky Association.) 


\subsection{Where To Consider Pedestrian-Friendly Lighting}

Pedestrian areas are located in urban, suburban, and rural areas. Every site has different needs, depending on factors such as traffic density and speeds, pedestrian and economic activity levels, need for security, community philosophy, and space types. Some of the following types of facilities and spaces may be appropriate places to consider visual comfort and appearance as principal criteria:

- summer camps, private clubs, retreats, and cultural institutions

- college campuses

- private schools and boarding schools

- parks, cafes, and some outdoor festivals

- quiet residential neighborhoods where neighbors know each other, spend time outdoors, and walk dogs on the street, and where crime is less of a major concern.

Two site lighting projects have been monitored by the GATEWAY program for the last 2 years, and both projects have solicited input from pedestrians, neighbors, visitors, and facilities staff. Although both projects are still underway, they have already yielded insight into what improves acceptance of outdoor lighting for pedestrians, especially when using energy-efficient LED sources. The two sites, Stanford University and Chautauqua Institution, are described in the sections that follow.

\subsection{Pedestrian Lighting for Stanford University}

Located in the foothills of the San Francisco's peninsula region, Stanford University has a long history of academic scholarship. The university maintains an exemplary reputation, and the appearance and ambiance of the campus is important for attracting high quality students, faculty, and staff, as well as donors and collaborators. Many campus buildings exhibit a warm adobe wall finish with red Spanish tile roofs (Figure 7), and the university architects and facilities group choose to extend that warmth to the campus outdoor lighting systems.

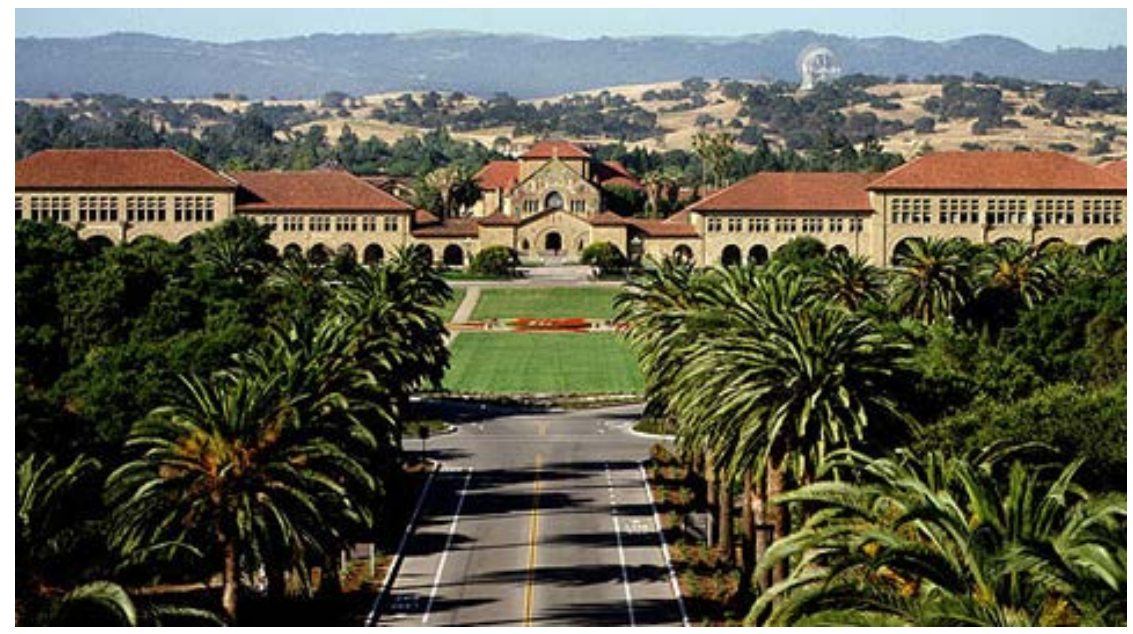

Figure 7. Stanford University. (Photo from http://www-conf.slac.stanford.edu/pic/.) 
Stanford's campus includes student housing, sports and activity centers, and academic buildings. Transportation on campus is primarily by foot or bicycle, and this activity continues into the early hours of the morning. Vehicle traffic is minimized, with limited access and controlled speeds. Although the outdoor lighting is not completely consistent, the predominant pedestrian lighting system currently uses 100W high-pressure sodium (HPS) lamps in a glass refractor post-top luminaire (Holophane RSL-350 utility series), mounted on a $10 \mathrm{ft}$ pole. The HPS lamps have a yellow-orange color of light (2200K) with a poor color rendering index (CRI) of 22. The poles are spaced approximately $70 \mathrm{ft}$ apart. See Figure 8 and Figure 9. The HPS baseline, measured at a location with two poles spaced $71 \mathrm{ft}$ apart, produces an average of 16.5 lux (lx) [1.53 footcandles (fc)] at grade $6 \mathrm{ft}$ from the poles, and $5.8 \mathrm{~lx}$ [0.54 fc] between the poles. ${ }^{1}$

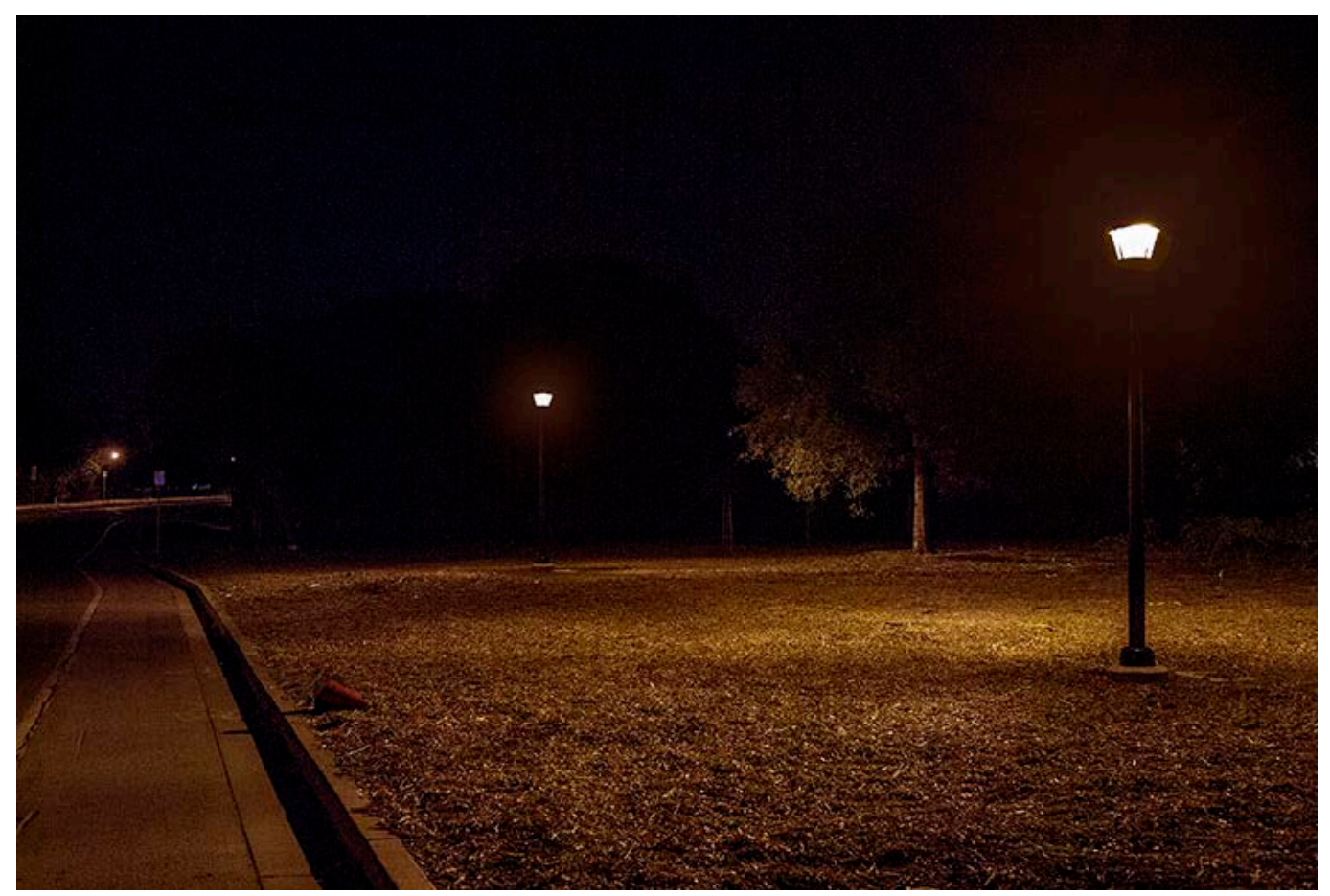

Figure 8. Stanford University's typical pedestrian lighting, using 100W HPS in a glass refractor luminaire, $10 \mathrm{ft}$ poles, $70 \mathrm{ft}$ on center, average. (Photo: www.KenRicePhoto.com.)

\footnotetext{
${ }^{1}$ All measurements quoted for the Stanford project are approximate. Measurements were taken at grade. Maximum illuminances were measured $6 \mathrm{ft}$ from the pole (to avoid the shadow cast immediately below the luminaire) in four cardinal directions and averaged. Minimum illuminances were measured on the sidewalk halfway between the pair of poles, but because pole spacing varied at the mock-up site, the numbers should not be closely compared. Also, contribution of light from post-top luminaires located across the street was not controlled.
} 

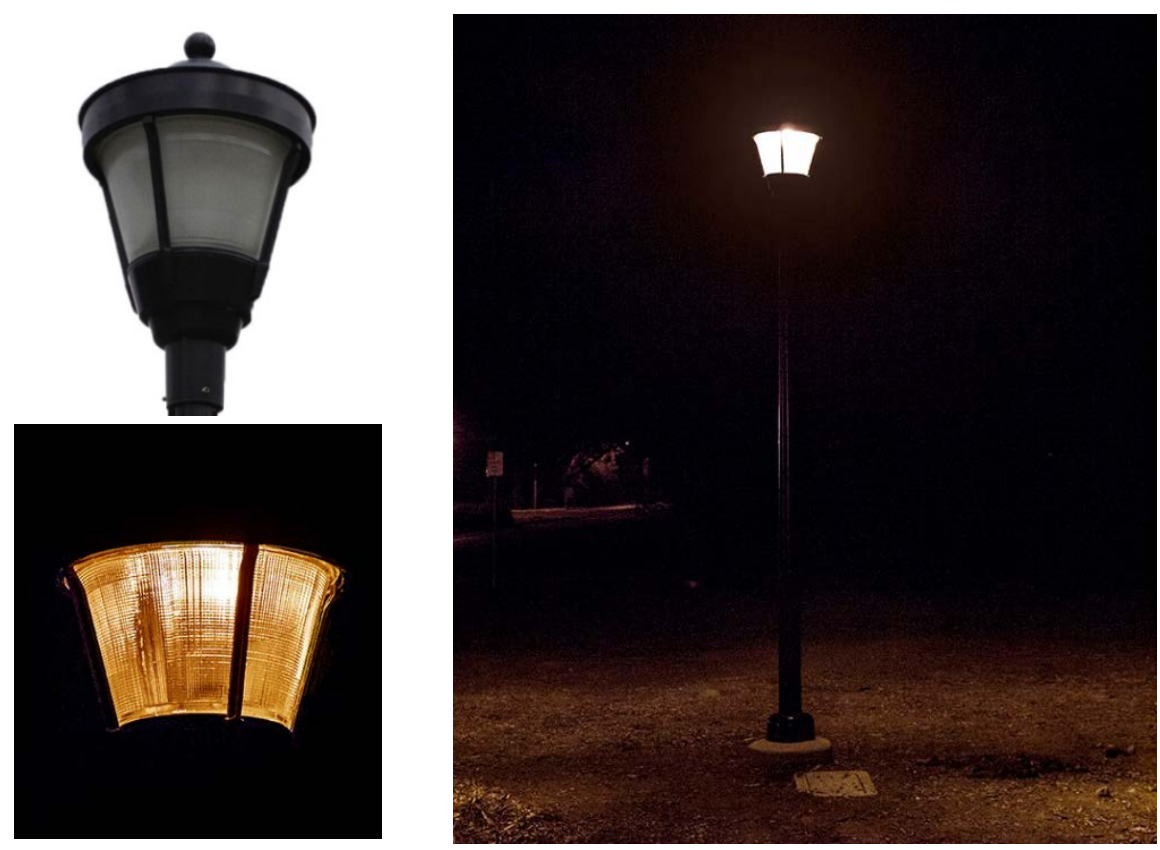

Figure 9. Stanford University campus standard pedestrian post-top luminaire (top left); the University's typical pedestrian post-top, the Acuity/Holophane RSL-350 (right); and closeup of its glass refractor (bottom left). (Photos: Koltai Lighting (top left) and www.KenRicePhoto.com (right, bottom left).)

A number of Stanford faculty and staff are allowed to purchase homes as leaseholders, in a neighborhood adjacent to the campus. That neighborhood, built up over many years, currently has six different luminaire styles installed, including the campus standard pedestrian light in a few areas. Neighborhood residents maintain an active lifestyle, and use the neighborhood paths and streets for walking to and from campus, as well as for exercise. A 2008 survey conducted by Stanford University of Stanford Campus Residential Leaseholders (SCRL) revealed concerns about the existing street lighting in terms of safety, visibility, glare control, and light trespass.

From the outset Stanford set out to develop new standards for both areas that equally met three goals:

1. Safety

2. Energy Conservation

3. Aesthetics

The core team consisted of representatives of the University Architect/Campus Planning and Design Office, Public Safety, and the Office of Sustainability and Energy Management. The university hired Rita Koltai of Koltai Lighting Design, LLC to evaluate the situation and advise on lighting options. As the project proceeded, the lighting objectives for pedestrian lighting in both areas became clearer:

- use soft-edged, warm color lighting with better color rendering than the current HPS

- reduce energy use and frequency of maintenance

- improve campus appearance and make streets and paths more inviting for pedestrians

- reduce glare for pedestrians 
- unify luminaire appearance on campus and residential neighborhoods with somewhat traditional luminaire style

- reuse existing poles and spacing, if possible

- achieve a payback on the investment of 10 years or less (Stanford blended electric rate for nighttime services is $\$ 0.1066 / \mathrm{kWh})$.

\subsection{Options Considered for Improving the Campus Lighting}

More than a dozen alternatives were studied over 3 years. The most promising options were mocked up on existing poles along Oak Road so that university staff and users could evaluate them in person and provide feedback. Luminaire options were mocked up in adjacent pairs, so that observers could see the light distribution from more than one luminaire, and so that light levels could be measured on the ground between poles. While this report does not go into detail on most of the trials, the following sections do briefly summarize the process that led to the final set of mockup options. The judgments were based on a combination of reactions from the Stanford facilities group and surveyed users (see Appendix A for user survey questions).

\subsubsection{First Round of Mockups}

The original poles along Oak Road all had Holophane RSL-350 post-top luminaires with prismatic glass "lantern" and 100W HPS lamps. Pairs of poles were modified with retrofit options reusing the glass refractor, or with new luminaire heads. All retrofit options required disconnecting the existing ballast and rewiring the luminaire for the required replacement light sources and their ballasts or drivers. (See Appendix D for performance data and light levels, where available.) New luminaire options required complete replacement of the existing luminaire. The first four listed options were rejected and were replaced with other options before photographs could be taken.

The options and results are summarized as follows:

- New replacement RSL-350 luminaire called the RPE, but with 70W 4000K LEDs and driver. This was the warmest color option available from Holophane at the time, but observers considered it too white, and the LED lighting produced a distracting and glaring pattern on the lantern glass.

- Retrofit of existing RSL-350 luminaire, with Philips 85W induction lamps in 3000K. Observers found these adequate in color, but light levels delivered to the ground plane were considered by surveyed individuals to be at the low end of acceptable. Long-term availability of the induction lamp was a question.

- Retrofit of existing RSL-350 luminaire, with Philips 90W 2800K 70 CRI ceramic metal halide $(\mathrm{CMH})$ lamps (Philips "Cosmowhite”) with electronic ballasts. These received a neutral rating because the color temperature was considered good but the luminaire appeared somewhat bright and glaring when viewed from a short distance (i.e., approximately $20 \mathrm{ft}$ from the pole).

- Retrofit of existing RSL-350 luminaires, with 100W 4000K 85 CRI CMH lamp and electronic ballast. Observers found the light to be harsh, too glaring, and too white. 
- New Acuity/Holophane "PUL" utility series full-cutoff luminaires in 70W 3000K LED. The LEDs, with a CRI of 80+, are all contained in the cap of the luminaire, shining downward through a flat, frosted lens (a custom feature specifically requested for this project). There was no vertical or "lantern" glass in this luminaire, but the diffusion from the flat glass reduced glare and softened the shadow on the ground around the pole. This option was popular among observers, even though it was the most costly because it involved a complete replacement of the luminaire head. This option advanced to the third round of evaluation.

- New Acuity/Holophane "PTU" utility post-top luminaire, identical to the outward appearance of the RSL-350, but without the lantern glass. This luminaire was equipped with a 100W 3000K 85 CRI $\mathrm{CMH}$ lamp and electronic ballast in the cap of the luminaire, full cutoff distribution, and clear flat glass. Observers strongly disliked this option, primarily because it produced a large-diameter, sharpedged dark shadow around the base of the pole (Figure 10 and Figure 11). 

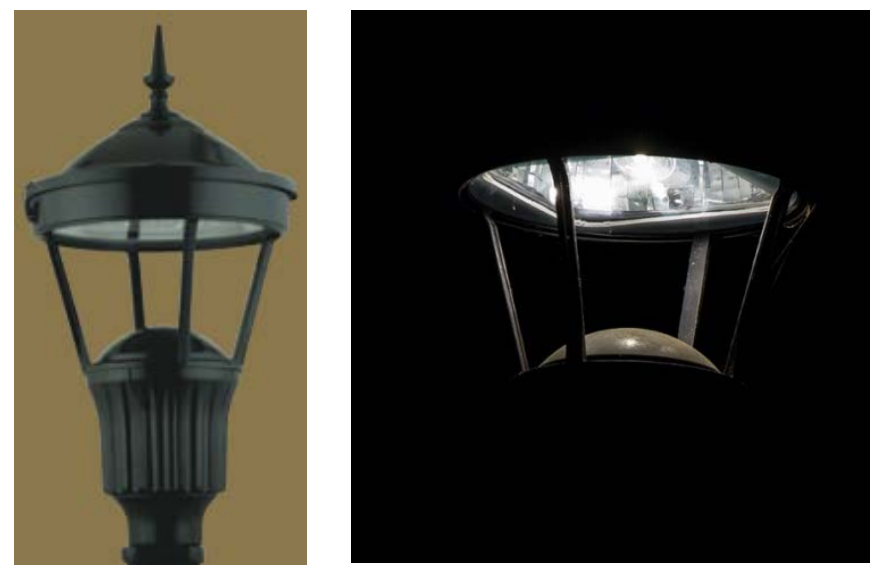

Figure 10. The Acuity/Holophane PTU, a utility post-top with flat glass instead of lantern glass refractor (left); closeup of the Holophane PTU luminaire showing the 100W clear 3000K CMH lamp and clear flat glass at the aperture (right). (Photos: Acuity/Holophane (left) and www.KenRicePhoto.com (right).)

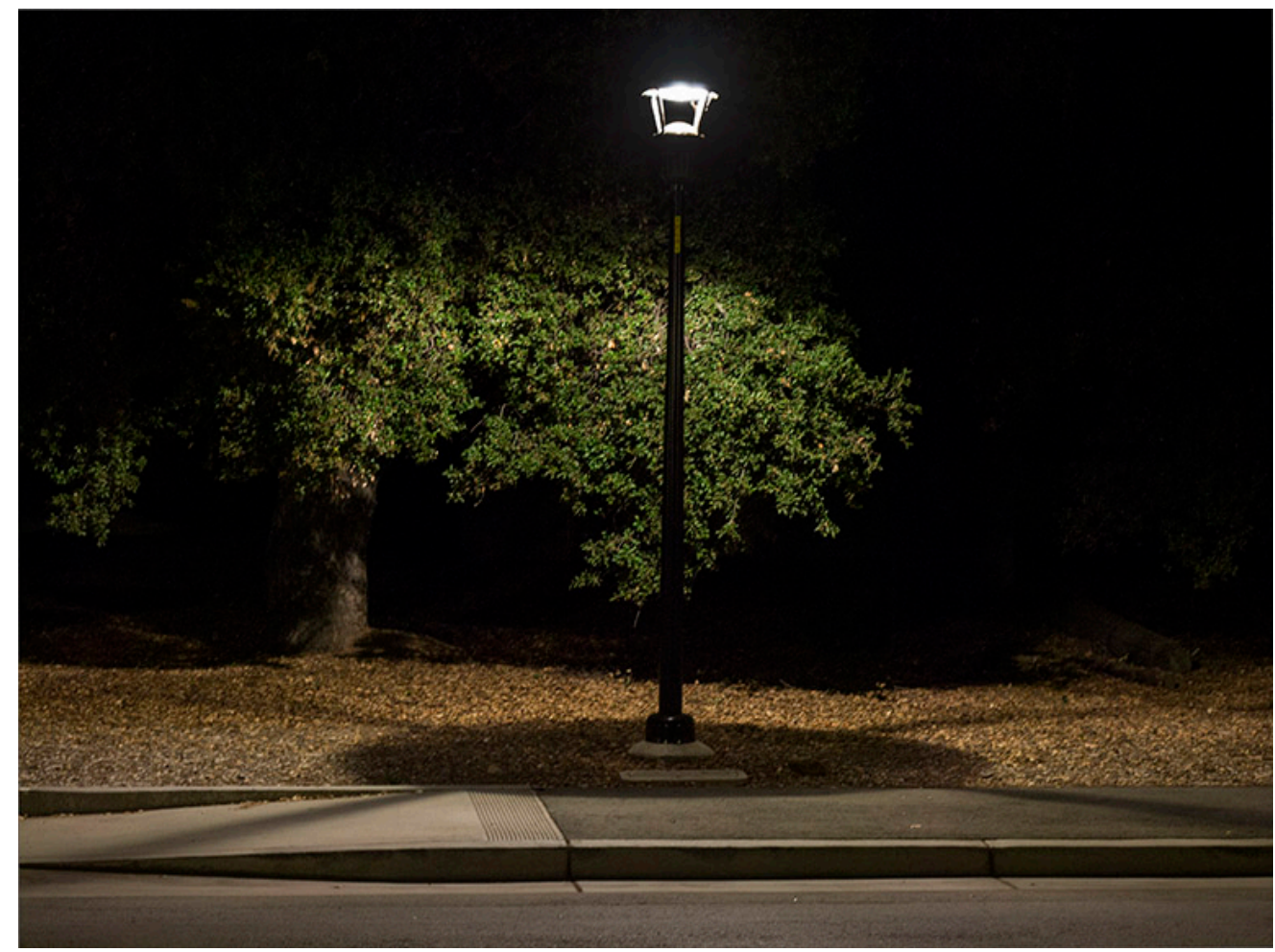

Figure 11. Mockup installation of the Holophane PTU luminaire with 100W clear 3000K CMH lamp and clear glass at the aperture. Note the sharp-edged shadow on the ground around the pole. (www.KenRicePhoto.com) 


\subsubsection{Second Round of Mockups}

The least successful options from the first round were replaced with four new options, all of which reused the existing glass refractor. (See Appendix D for performance data and light levels, where available.)

- Retrofit of the existing RSL-350 with the 60W version of the Philips 2800K 70 CRI CMH lamp ("Cosmowhite"). Observers appreciated the warm color and found the lantern glass brightness to be more comfortable. This product advanced to the third round of evaluation.

- Two LED lamp replacement attempts that were pursued but considered unsuccessful: Both Xeralux (now Sensity) and Cree provided retrofit “lamp” kits, specifically built for the RSL-350 structure and optical system. Xeralux/Sensity's product was a 70W 4100K LED that received poor reviews because of its blue-white color and its uneven lighting of the lantern glass. Cree's product was a 57W 2700K LED kit that produced well-liked color, but also caused pronounced, glaring vertical stripes of light on the lantern refractor from the vertical lines of LEDs. The Cree unit had a unique feature allowing the contractor to dial the light output up or down, but it was difficult to access this dial to adjust it after installation. The university decided that the difficulty involved in setting the level for each luminaire offset the benefit it offered. Neither of these options was considered further for this application. Figure 12 and Figure 13 show the retrofit kits installed in the respective prismatic refractor lanterns and a photo of the mockup pole.

- Retrofit of the existing RSL-350 with a 50W 3000K LED optical replacement kit from Acuity/Holophane. This product was specifically designed for the RSL-350, replacing all luminaire parts except the lantern glass and ballast housing. LEDs are mounted in the cap of the luminaire, lighting downward. This product showed promise, except that the LED pattern through the refractor glass was too bright, too white, and very distracting. In response to complaints about glare, the manufacturer suggested frosting the interior of the prismatic glass lantern to diffuse the brightness. That effort was successful, and this product advanced to the third round of evaluation.

The positive outcome of this series of mockups was that, although the $4000+\mathrm{K}$ color was deemed too cool (irrespective of light source) and the $3000 \mathrm{~K}$ unit in the second round was deemed too white, the 2700K to 2800K color was judged "just right": It set the right color tone for the campus.

Another lesson learned was that clear arc-tube lamps in optical systems with no diffusion created harsh, sharp-edged shadows on the ground. Visibility and perceived light uniformity on the pathway were compromised as a result.

Stanford University decided to look for two types of pedestrian luminaires: a retrofitted Holophane RSL-350 for the 3000 to 4000 existing post-top luminaires on campus, and a downward-only (full cutoff) luminaire that would be dark-sky friendly for park-like areas on the campus. 

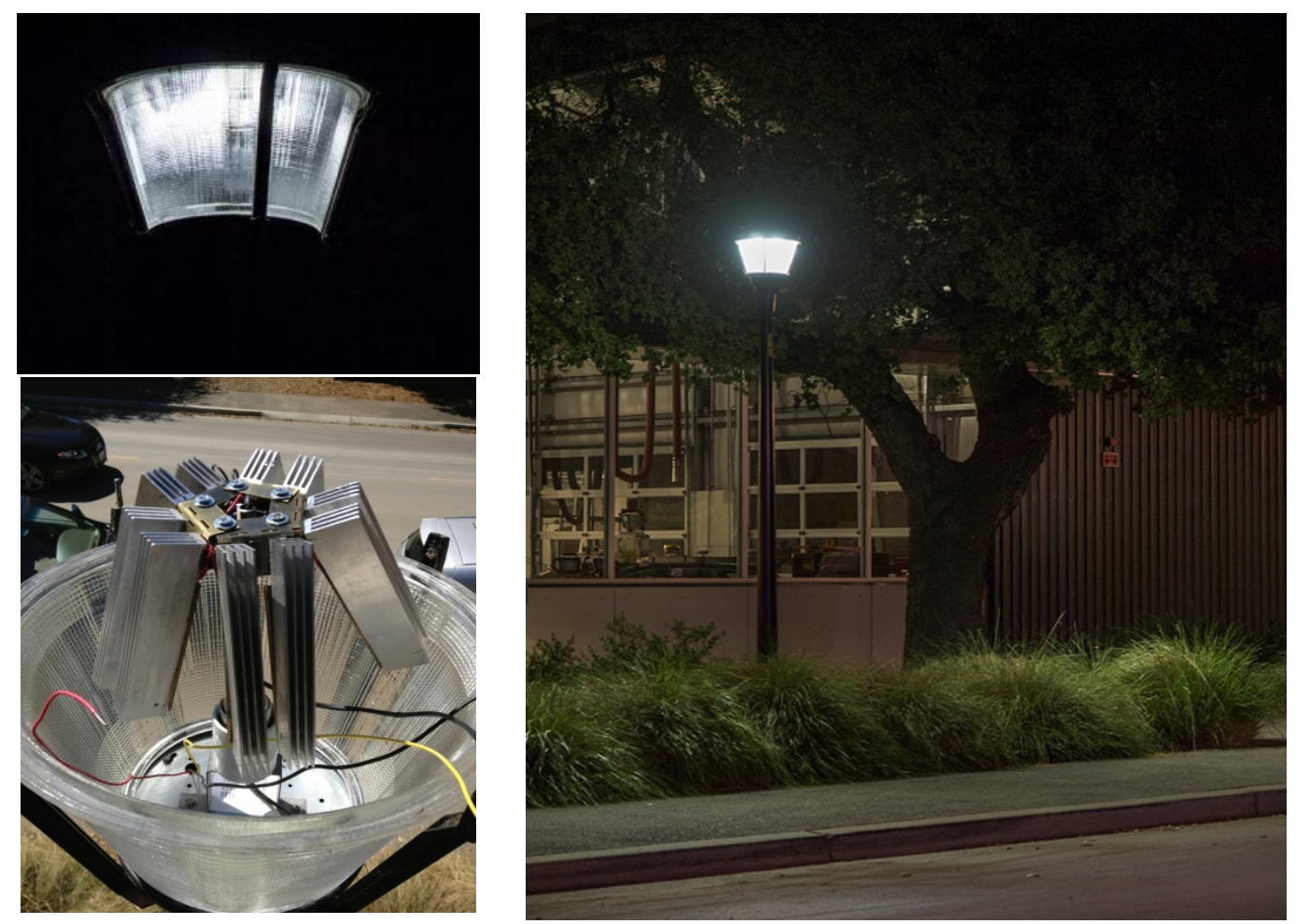

Figure 12. Retrofit installation of the Xeralux/Sensity 70W 4100K LED lamp product (bottom left), its appearance inside the lantern refractor (top left), and as installed in the mockup luminaire (right).
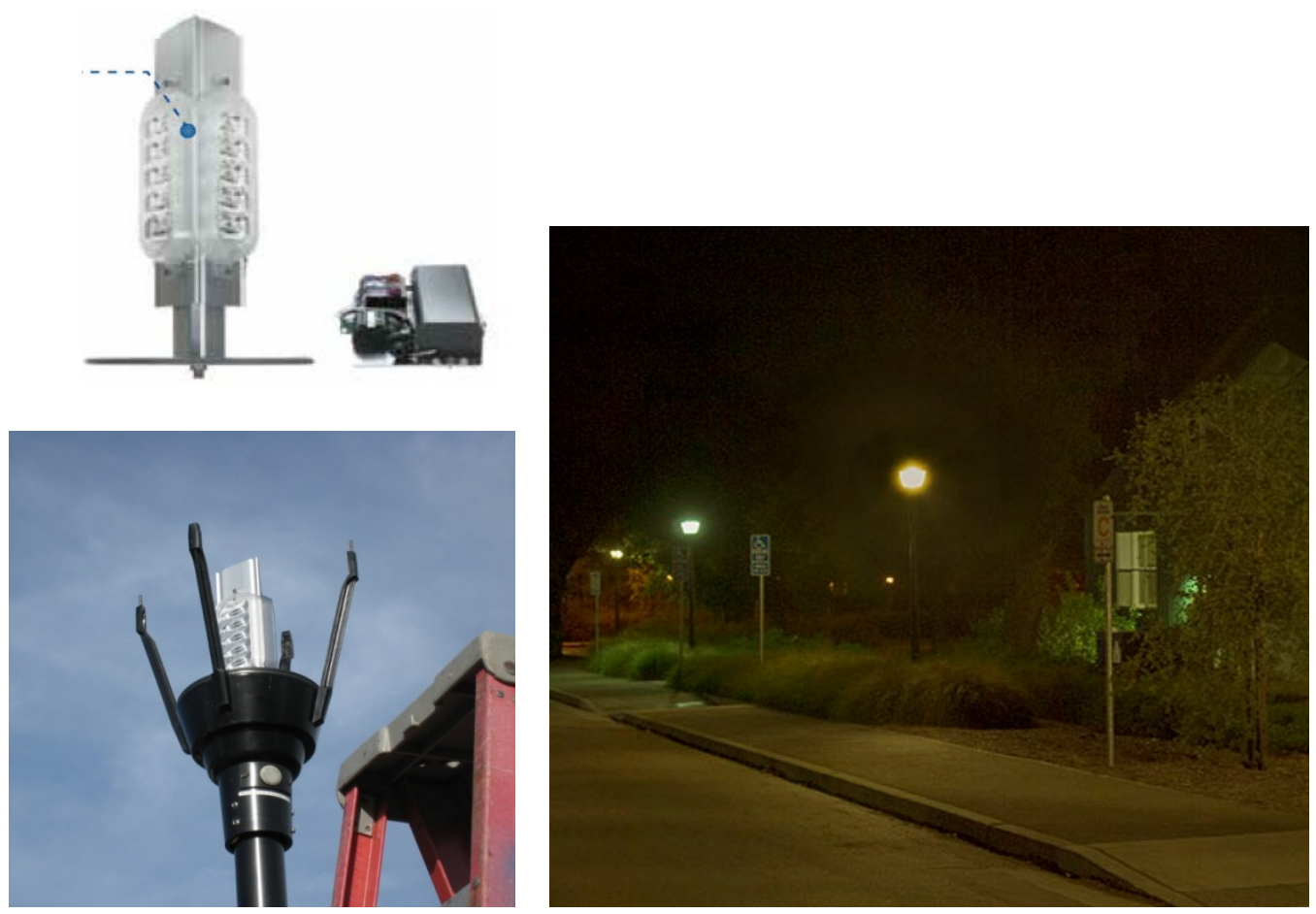

Figure 13. The Cree 57W 2700K LED retrofit lamp (top left), partially installed in RSL-350 luminaire (bottom left), and lighted at night (right). 


\subsubsection{Third Round of Mockups}

In the third round of mockups, the best luminaire options from the first two rounds were left in place, and the interior of the glass lantern was frosted (sand-etched) to diffuse the lantern appearance of the Acuity/Holophane optical replacement kit. Additionally, a custom version of the Acuity/Holophane LED optical replacement kit using 2700K LEDs was added in two existing luminaires, frosting the glass refractors. To simplify the evaluation and results, this report has summarized the four best options as A, $\mathrm{B}, \mathrm{C}$, and $\mathrm{D}$, as described in the following subsections.

\subsubsection{Campus Pedestrian Luminaire Option A}

Option A used the existing Acuity/Holophane RSL-350 luminaire modified for the 2800K 70 CRI 60W CMH ("Cosmowhite") lamp and electronic ballast (Figure 14). Total power draw is approximately $67 \mathrm{~W}$. The Stanford University architects and facilities group very much preferred the warm color and improved color rendering compared to standard HPS. User feedback suggested that the glass lantern lens had an acceptable brightness, and the amount of light on the path seemed appropriate (average illuminances were $15.7 \mathrm{~lx}$ [1.46 fc] measured $6 \mathrm{ft}$ from the pole, and $0.9 \mathrm{~lx}$ [0.08fc] measured between two poles spaced $95 \mathrm{ft}$ apart). The downsides of this option were the 4 to 8 minute restrike time in the event of a brief power failure, and a comparatively short 18,000 hour rated lamp life with the lamp in the vertical position.
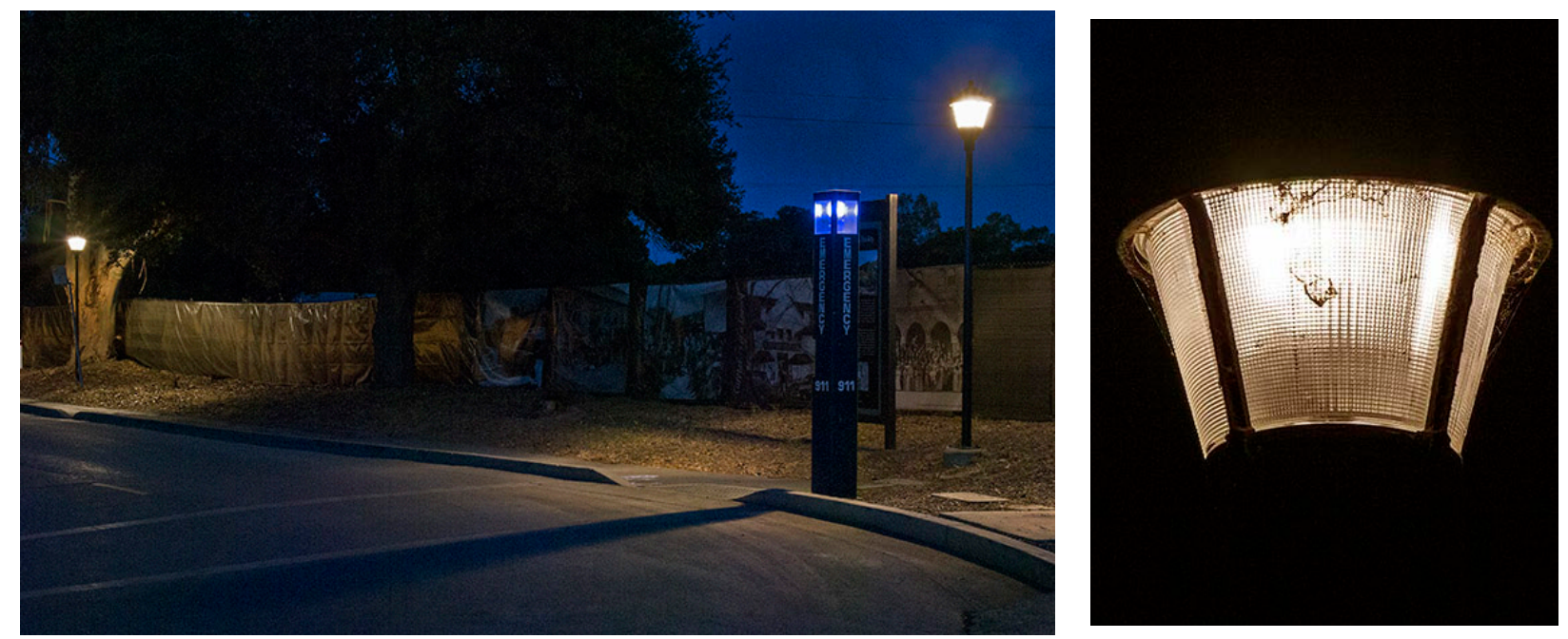

Figure 14. Option A for Stanford's campus pedestrian lighting mockups: 60W 2800K, 70CRI ("Cosmowhite”) CMH lamp (right); closeup of Option A (left). Spider webs are a familiar sight on all post-top luminaires. (www.KenRicePhoto.com)

\subsubsection{Campus Pedestrian Luminaire Option B}

Option B used new Acuity/Holophane "PUL" utility series full-cutoff luminaires in 70W 3000K LED (CRI value not available), with flat diffusing glass at the aperture. Ideally, observers would prefer a color temperature slightly warmer than $3000 \mathrm{~K}$, and would prefer a round pattern of LEDs in the round aperture, rather than square (Figure 15 and Figure 16). The lighting designer's and campus facilities group's high opinion of the luminaire led them to recommend it for the mockups on the SCRL neighborhoods. 
Average illuminances were $28.1 \mathrm{~lx}$ [2.62 fc] on the sidewalk $6 \mathrm{ft}$ from the pole, and $8.1 \mathrm{~lx}$ [0.75 fc] between poles, although these numbers should not be compared to other luminaires because the two poles were only $41.5 \mathrm{ft}$ apart. This product was very well received, and the university thought this could be the campus standard for new park-like areas of the campus.

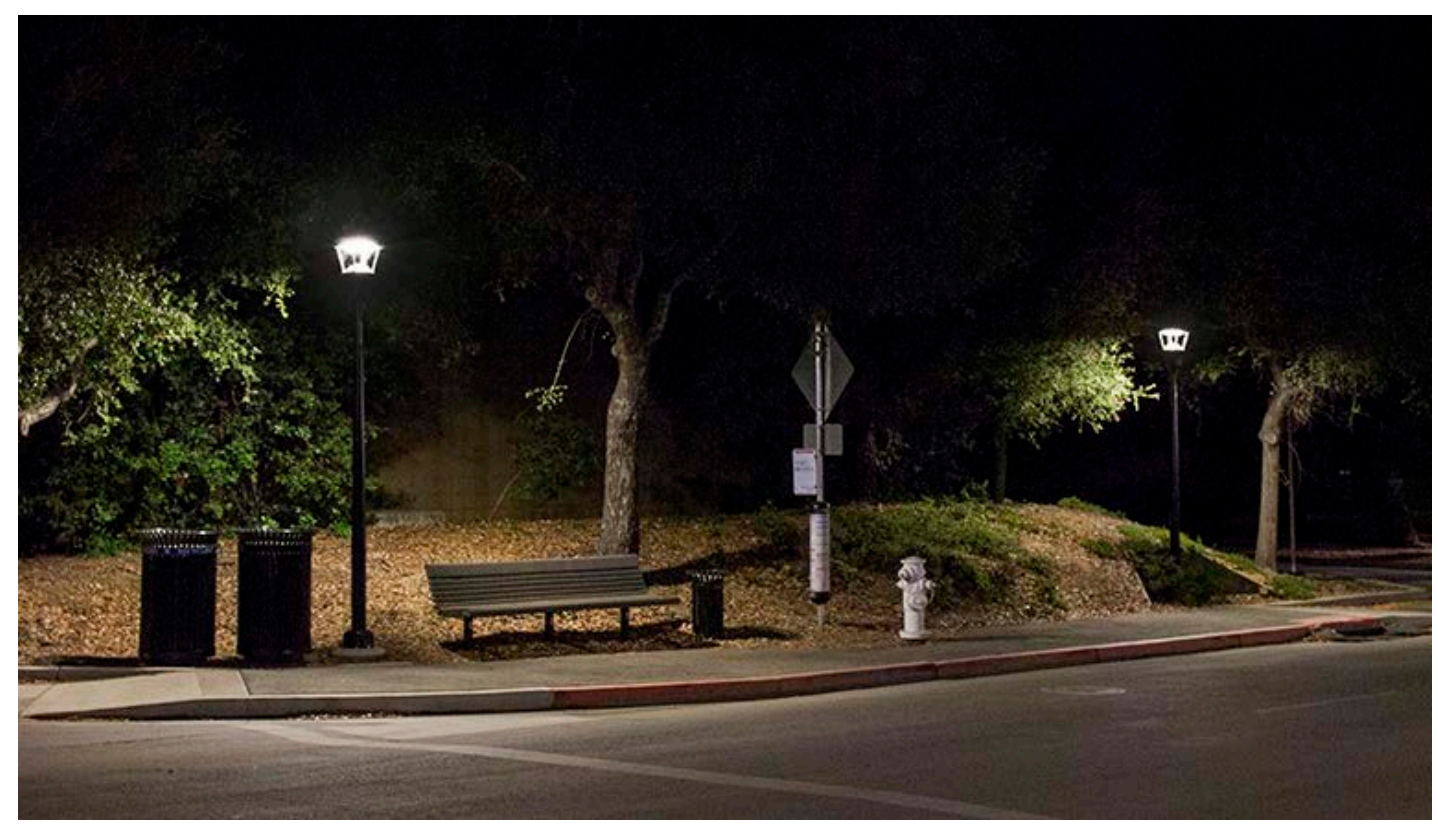

Figure 15. Option B for Stanford's campus pedestrian lighting mockups: Holophane "PUL" utility series full-cutoff post-top with 70W 3000K LED optics with diffusing glass in luminaire cap. (www.KenRicePhoto.com)
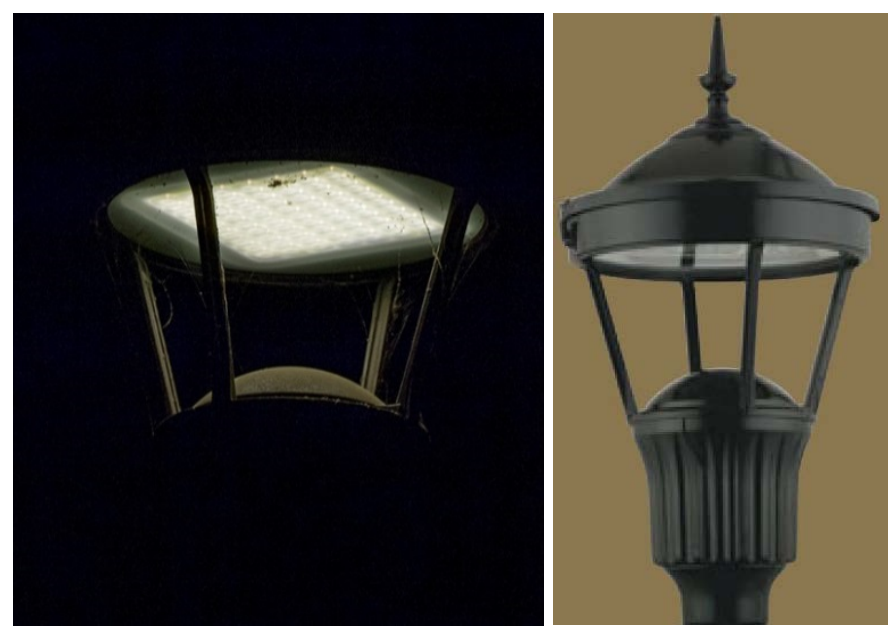

Figure 16. Closeup photo of Option B luminaire (left); Option B: Holophane PUL luminaire (right). (Photos: www.KenRicePhoto.com (left) and Acuity/Holophane (right).) 


\subsubsection{Campus Pedestrian Luminaire Option C}

Option C was to retrofit the existing RSL-350 with a 50W 3000K 70 CRI LED optical replacement kit from Acuity/Holophane. The product was specifically designed for the RSL-350, replacing almost all luminaire parts except the lantern glass and ballast housing. The interior of the lantern refractor was frosted for this third round, and observers thought the glare was considerably reduced as a result. Average illuminances on the sidewalk $6 \mathrm{ft}$ from the pole measured $10.1 \mathrm{~lx}$ [0.94 fc], and $3.2 \mathrm{~lx}$ [0.30 fc] between poles with pole spacing of $70 \mathrm{ft}$. Observers commented to the lighting designer and facilities staff that they liked this product a great deal, but preferred a slightly warmer color of light. Images of Option C are identical to those for Option D (Figure 17, Figure 18, and Figure 19) except that the color temperature is $3000 \mathrm{~K}$ rather than $2700 \mathrm{~K}$.

\subsubsection{Campus Pedestrian Luminaire Option D}

The last set of options reviewed for retrofitting existing post-top luminaires was informed by the previous LED options that delivered the desired warm color of light (2700K) and long-life LEDs, but dealing with the objectionable glare and spotty glass refractor appearance. Similar to Option C, the Holophane LED optical replacement kit was combined with the existing glass refractor, but with a frosted finish on the interior of the lantern glass to spread and soften the odd brightness. This was ultimately the most widely supported solution for the standard campus luminaires (Figure 17, Figure 18, and Figure 19). The sand-etching was done locally by the electrical contractor, at a cost of about $\$ 50$ per luminaire. To the eye of the survey respondents, the light distribution and light levels on the ground are equivalent to the original HPS solution, glare is considered acceptable, and the luminaire has an appropriate traditional appearance. Measured illuminances for a pair of mockup poles spaced $73 \mathrm{ft}$ apart average $11.5 \mathrm{~lx}$ [1.07 $\mathrm{fc}] 6 \mathrm{ft}$ from the pole, and $2.7 \mathrm{~lx}$ [0.25 fc] between poles. Pending life-cycle cost analysis from Stanford University, this is the likely approach for the campus as a retrofit for existing HPS RSL-350 luminaires.

No photometry is available for the final post-top recommended luminaire, but the frosted interior will invariably deliver some light skyward, as did the original HPS luminaire. However, given that the 2700K 50W LED product delivers an estimated 3000 luminaire lumens compared to about 6000 luminaire lumens from the 100W HPS lamp, it is likely fewer lumens will contribute to skyglow. 


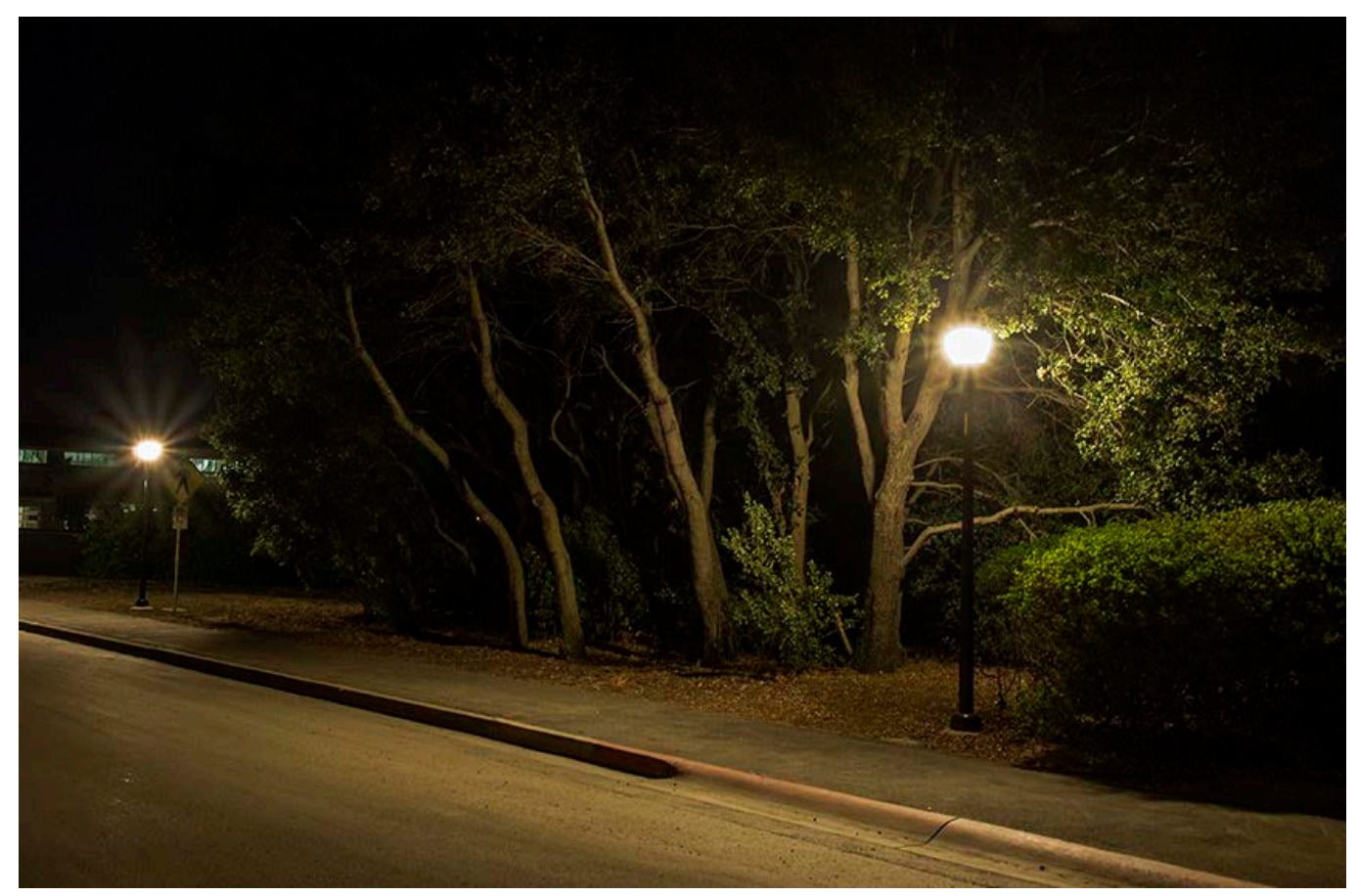

Figure 17. Two campus luminaires retrofitted with frosted glass refractor and 50W 2700K LED optical replacement kit by Holophane. This was ultimately the most widely supported pedestrian lighting solution for the Stanford University campus. (www.KenRicePhoto.com)
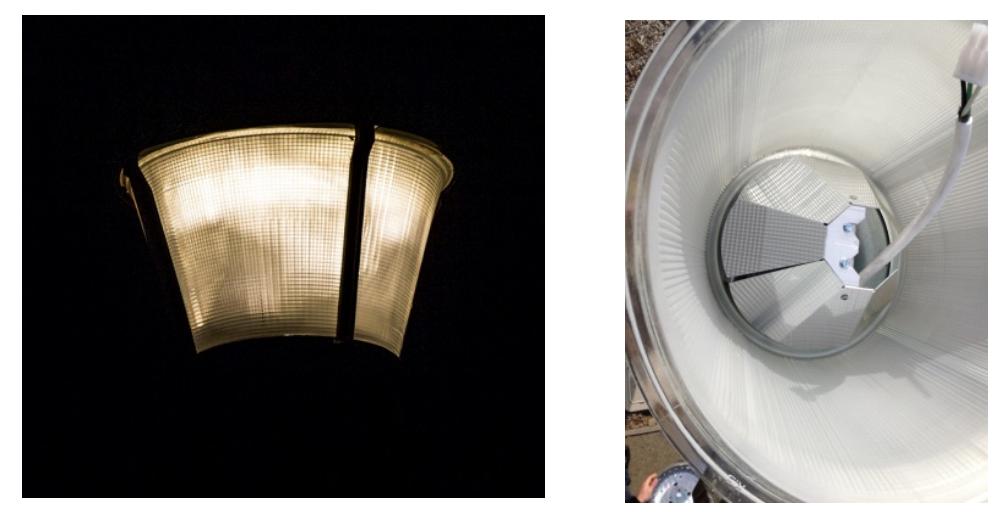

Figure 18. Closeup photo of 50W 2700K LED optical replacement kit with frosted glass refractor (left) and detail of frosted glass refractor (right). (Photos: www.KenRicePhoto.com (left) and Koltai Lighting Design (right).) 


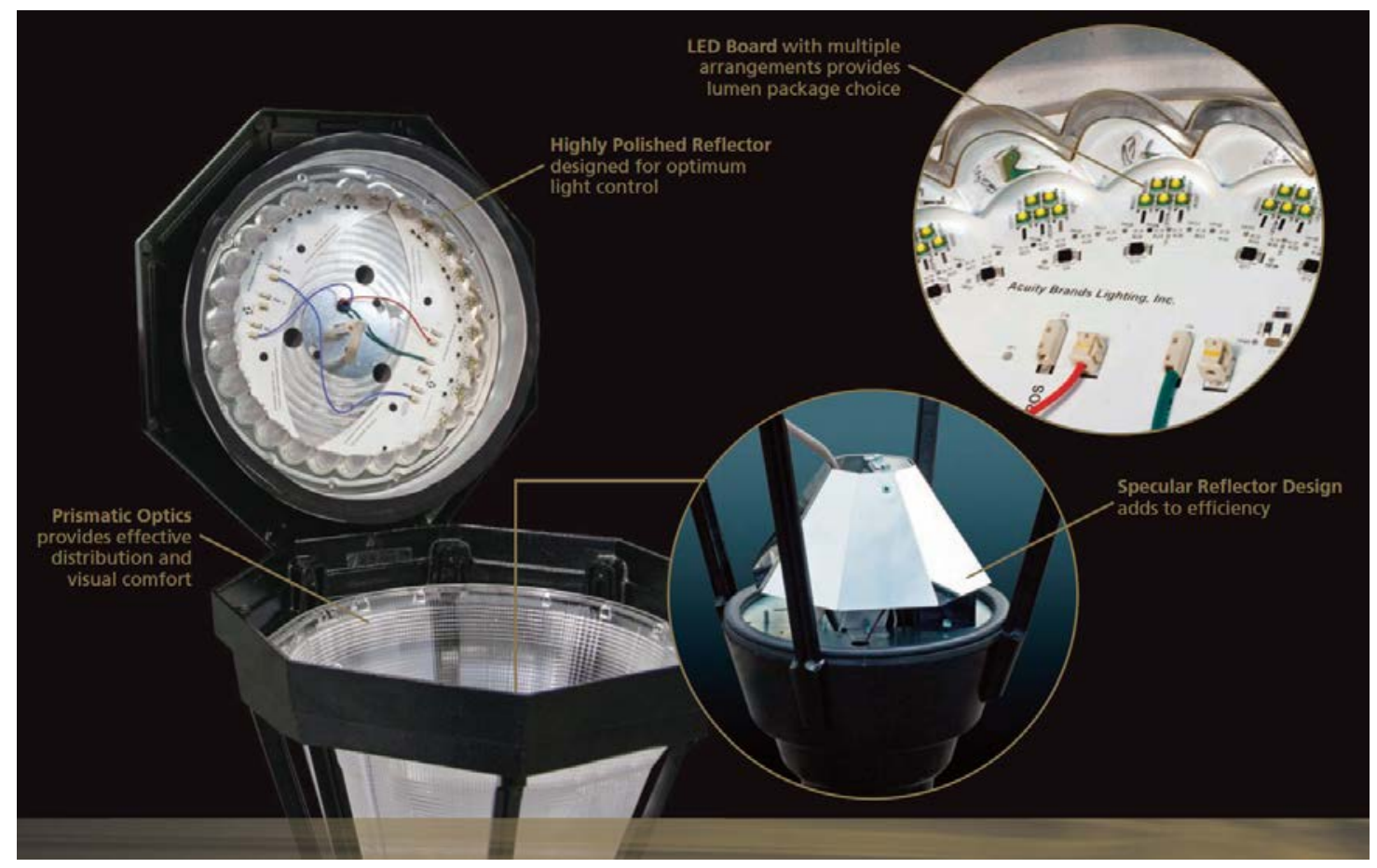

Figure 19. Manufacturer's catalog illustration of LED optical replacement kit. (Photo courtesy of Acuity/Holophane Lighting.)

\subsection{Stanford Campus Residential Leaseholders (SCRL) Neighborhood}

The process of selecting a pedestrian-scale luminaire for the Stanford SCRL neighborhood involved finding a replacement luminaire and pole to improve the visual environment at night and bring consistency of style to the neighborhood during the day. Most of the luminaires currently installed use a 100W HPS lamp, mounted on a $10 \mathrm{ft}$ pole. Glare, light trespass, color of light, and visual appearance are the chief concerns expressed by residents. Many different aesthetic options for luminaires were considered, and six mockup luminaires were installed along one street of the neighborhood, although to minimize cost, only one of each style was installed. A list follows with descriptions of the mockup luminaires and the responses from residents. ${ }^{1}$

\subsubsection{Landscape Forms "Alcott," 58W 3000K LED}

The optical system for this product was designed with LEDs aimed to achieve a widespread asymmetrical distribution suitable for street lighting, with a concave frosted lens or diffuser below the LEDs (Figure 20 and Figure 21). Although this diffusion considerably reduced the glare of the bare LED, residents commented that when they were standing in the directed beam of the LEDs, the LED brightness was still glaring. Ultimately, this luminaire and pole, although appreciated for its style, was deemed too contemporary for the neighborhood.

\footnotetext{
${ }^{1}$ Stanford, like most communities, is home to an industrious spider population. Almost all exterior luminaires were covered with webs. These are especially visible in luminaire designs with open sides and decorative support arms.
} 


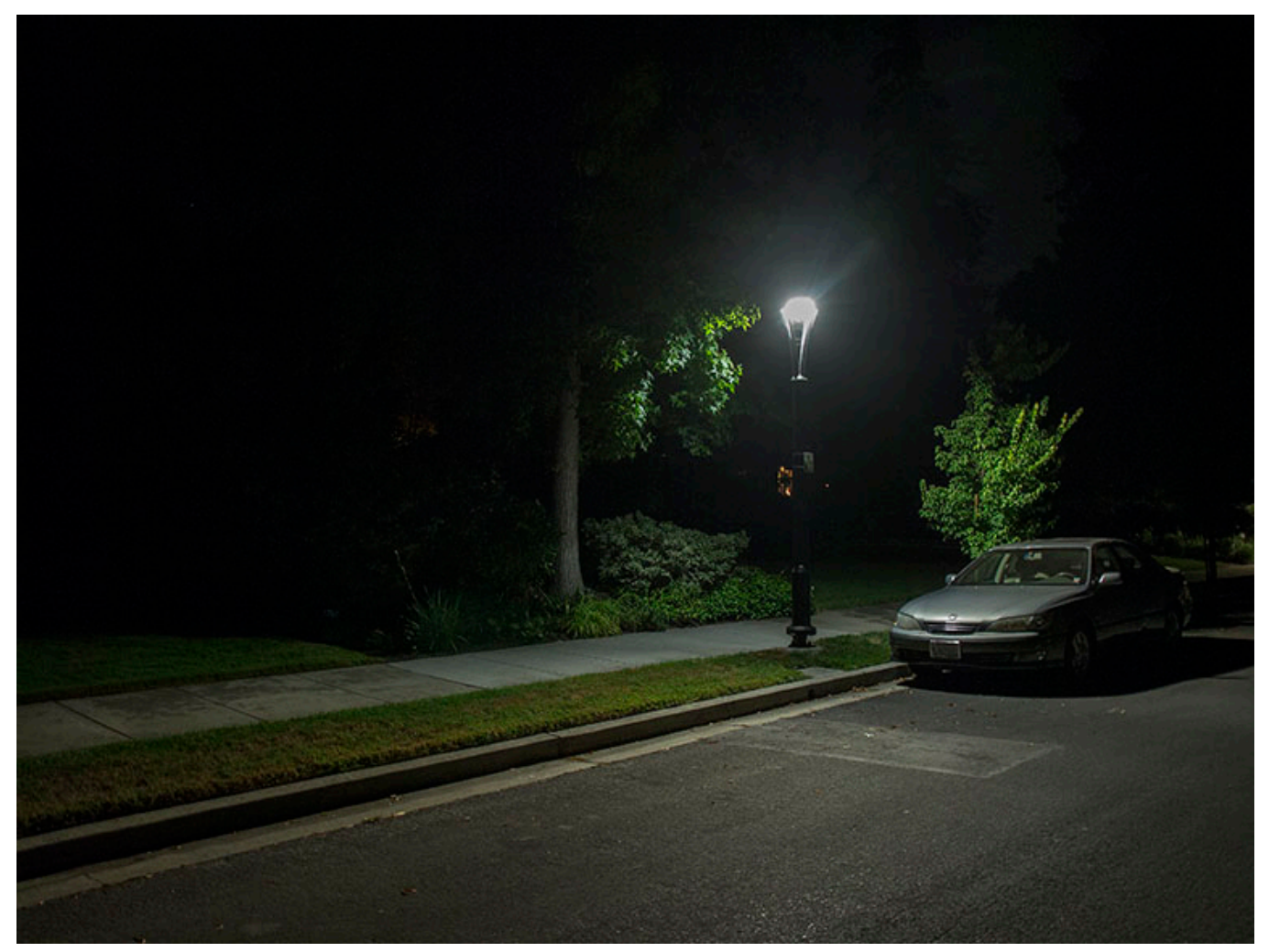

Figure 20. Mockup installation of Landscape Forms streetlight for Stanford neighborhood. (www.KenRicePhoto.com)
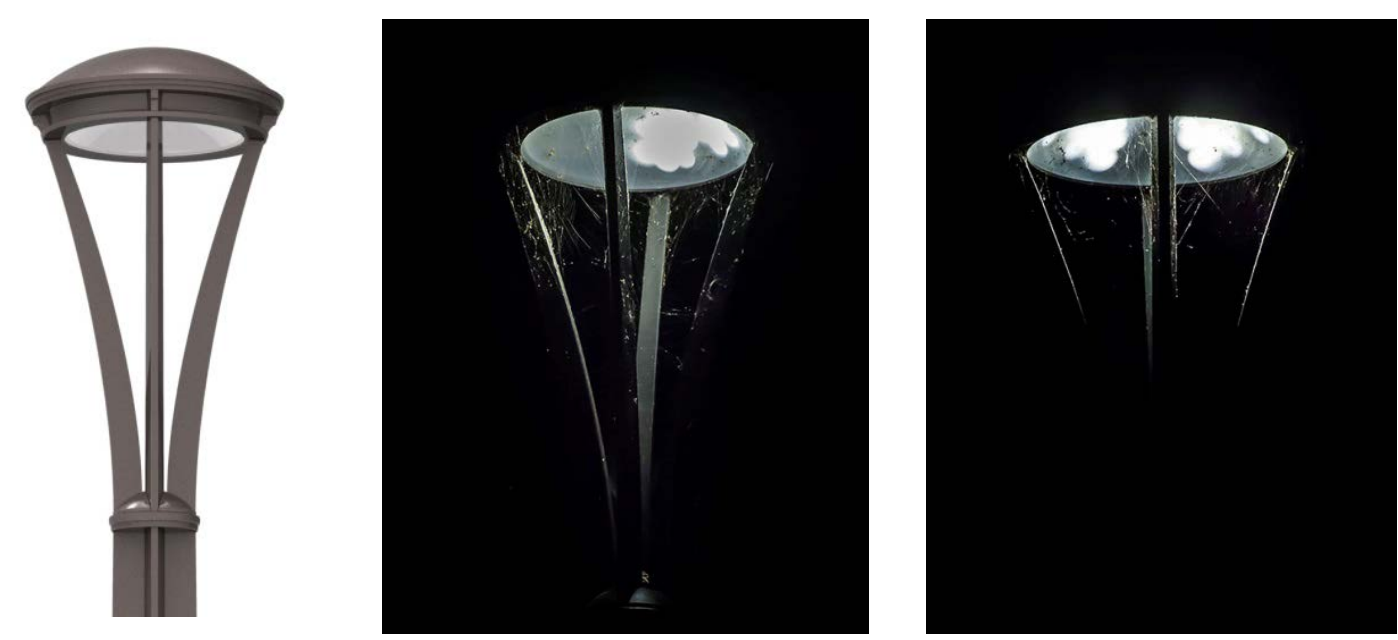

Figure 21. Landscape Forms Inc. Alcott luminaire (left); close-up photos of Landscape Forms (type 3 distribution) luminaire taken from sidewalk (center) and street (right). (Images: Landscape Forms (left) and www.KenRicePhoto.com (center, right).) 


\subsubsection{Bega "8309 LED," 40W 3000K}

This luminaire (Figure 22 and Figure 23) received the best reviews for its soft, even distribution of light and lack of glare. Its efficiency is low because of the indirect optics, although the product is very dark-sky friendly because no light escapes around the edge of the "hat" that captures and redirects the light. Stylistically it was rejected for the SCRL neighborhood because of its contemporary appearance. However, this luminaire is currently one of the Stanford University campus standards, considered the "living room light," for areas where people gather for informal meetings and events.

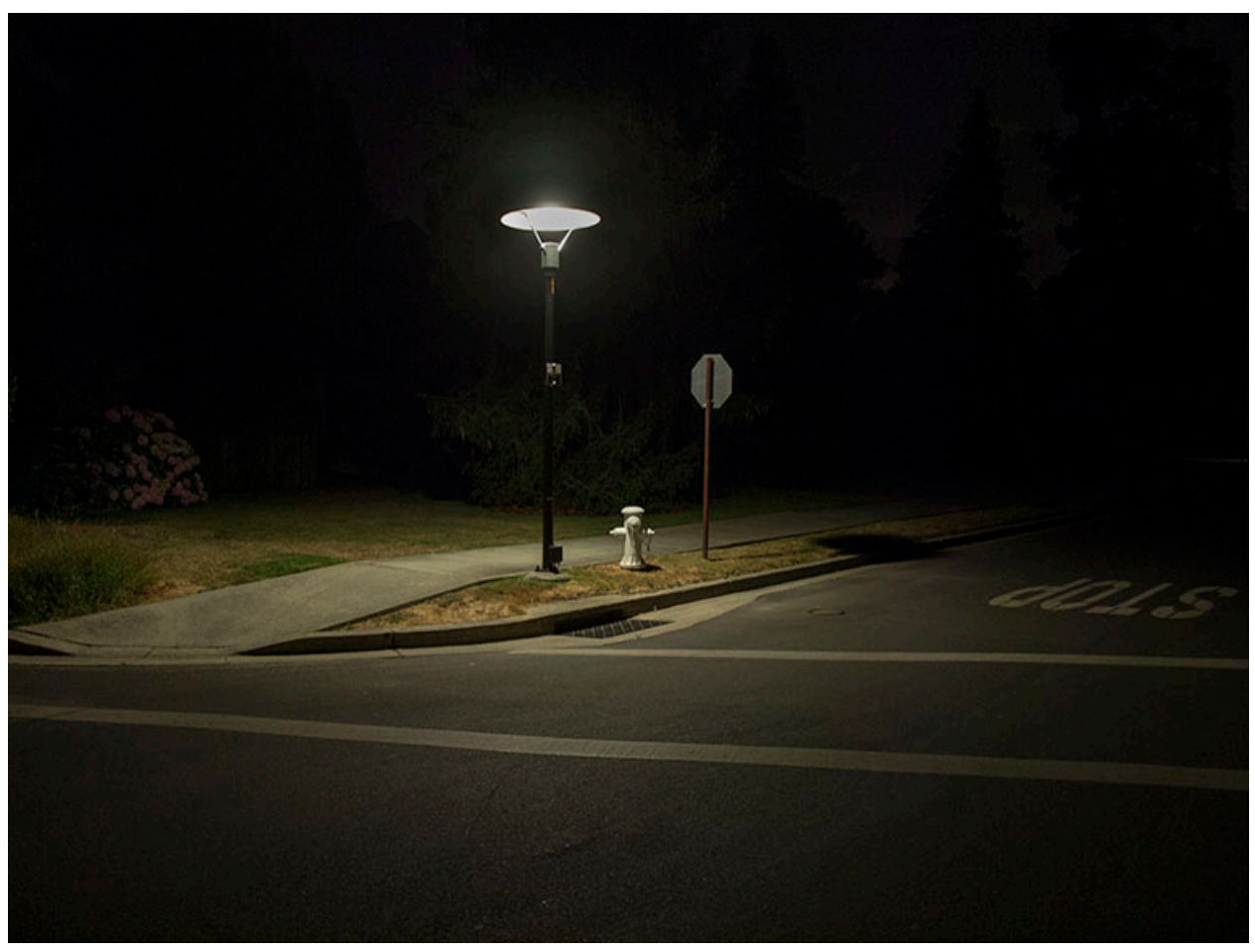

Figure 22. Mockup installation of Bega “8309 LED” indirect post-top, with 40W 3000K LEDs. (www.KenRicePhoto.com)
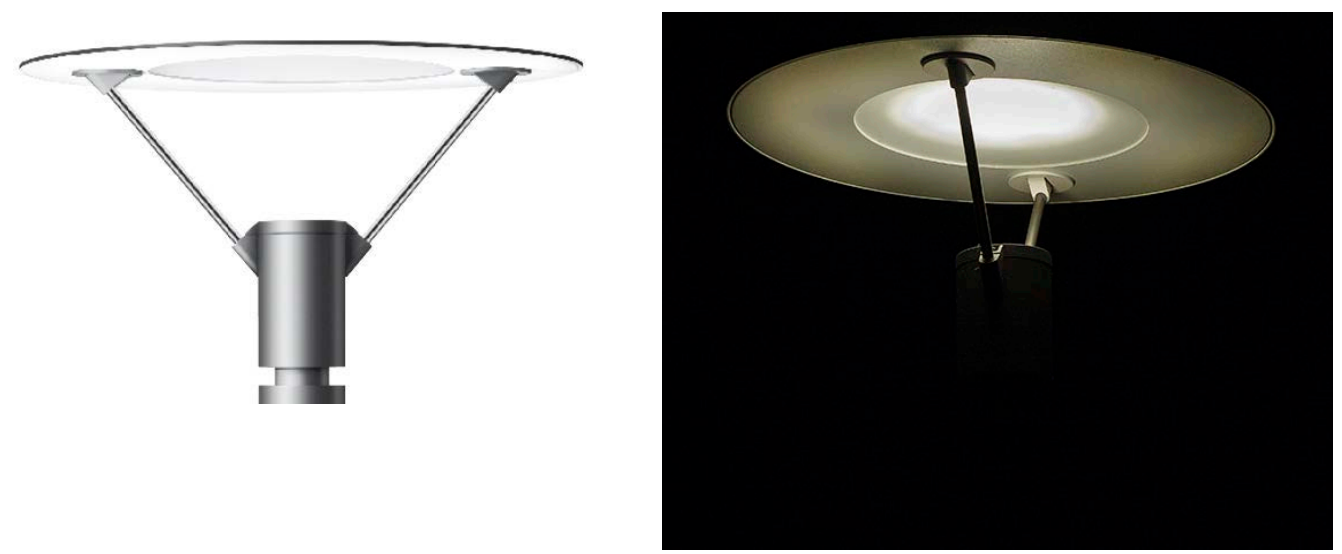

Figure 23. Bega “8309 LED” luminaire (left); closeup of luminaire with 40W 3000K indirect lamp (right). (Courtesy of Bega-US (left) and www.KenRicePhoto.com (right).) 


\subsubsection{Architectural Area Lighting (AAL) "Providence-Indirect"}

Using the Philips “Cosmowhite” 60W 2800K 70 CRI CMH lamp (67W input), this was the option most observers initially preferred because the light appears so soft and the luminaire looks more traditional. Ultimately, however, it was not selected because the lamp's expected life of 18,000 hours in vertical position was too short compared to expected LED life, potentially resulting in much greater maintenance cost for Stanford. Although light levels at the ground level are expected to be low (because of the luminaire's low efficiency), no observers complained about low light levels, although with only one luminaire it was hard to judge light levels along the length of the sidewalk and street. See Figure 24 and Figure 25.

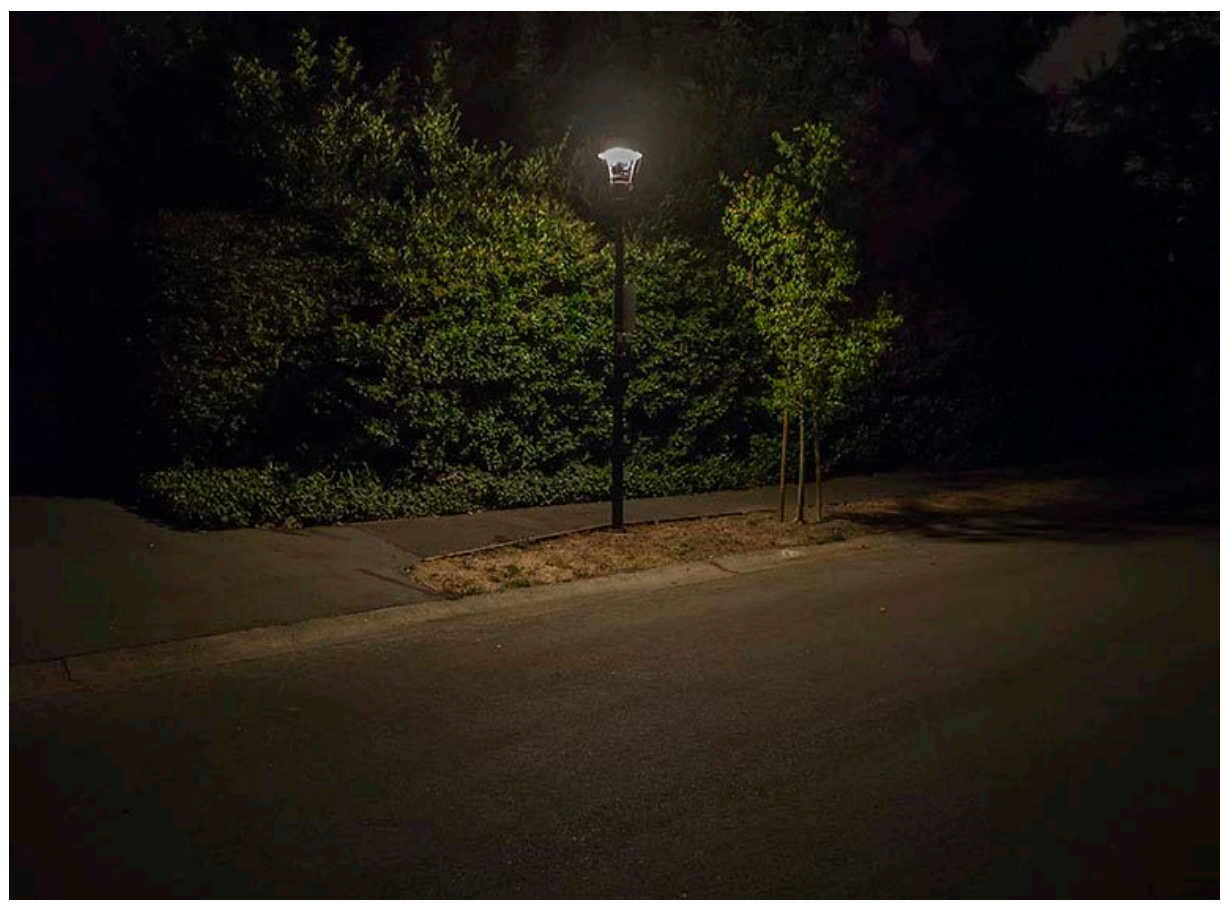

Figure 24. Mockup installation of the AAL "Providence Indirect" luminaire with 60W 2800K 70CRI CMH lamp (“Cosmowhite”). (www.KenRicePhoto.com)
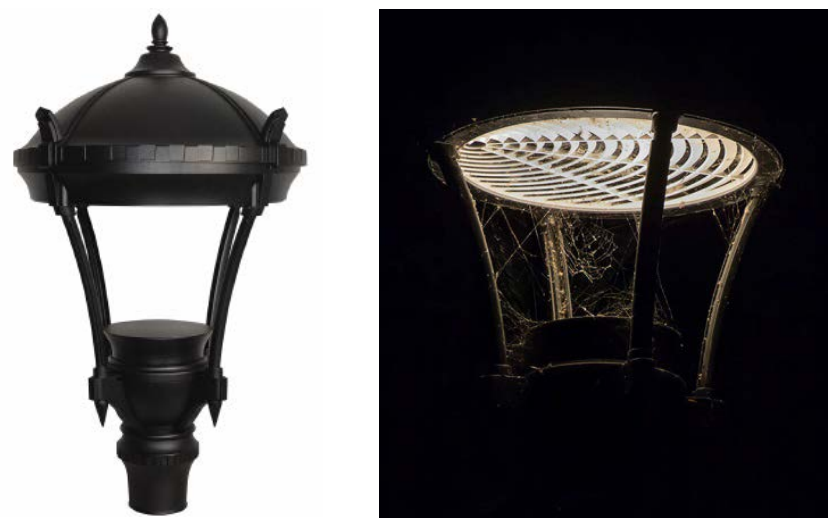

Figure 25. AAL Providence Indirect luminaire (left); closeup of luminaire with 60W 2800K CMH indirect lamp. (Photos: AAL (left) and www.KenRicePhoto.com (right).) 


\subsubsection{Selux Saturn Cutoff with 60W 2800K "Cosmowhite" CMH lamp (67W input)}

This luminaire is similar in appearance to the Bega luminaire, but the lamp is located in the cap of the "hat" reflector and aimed downward through a frosted lens. A small amount of light is directed onto the surrounding brim of the hat, which softens the shadow on the ground around the base of the pole. See Figure 26 and Figure 27. This option produced the most light on the sidewalk. Observers commented that glare is well shielded until the pedestrian moves close enough to the pole that the lamp becomes directly visible inside the reflector, when it becomes very bright. In spite of its celebrated features, it was rejected because of glare, and for its contemporary appearance.

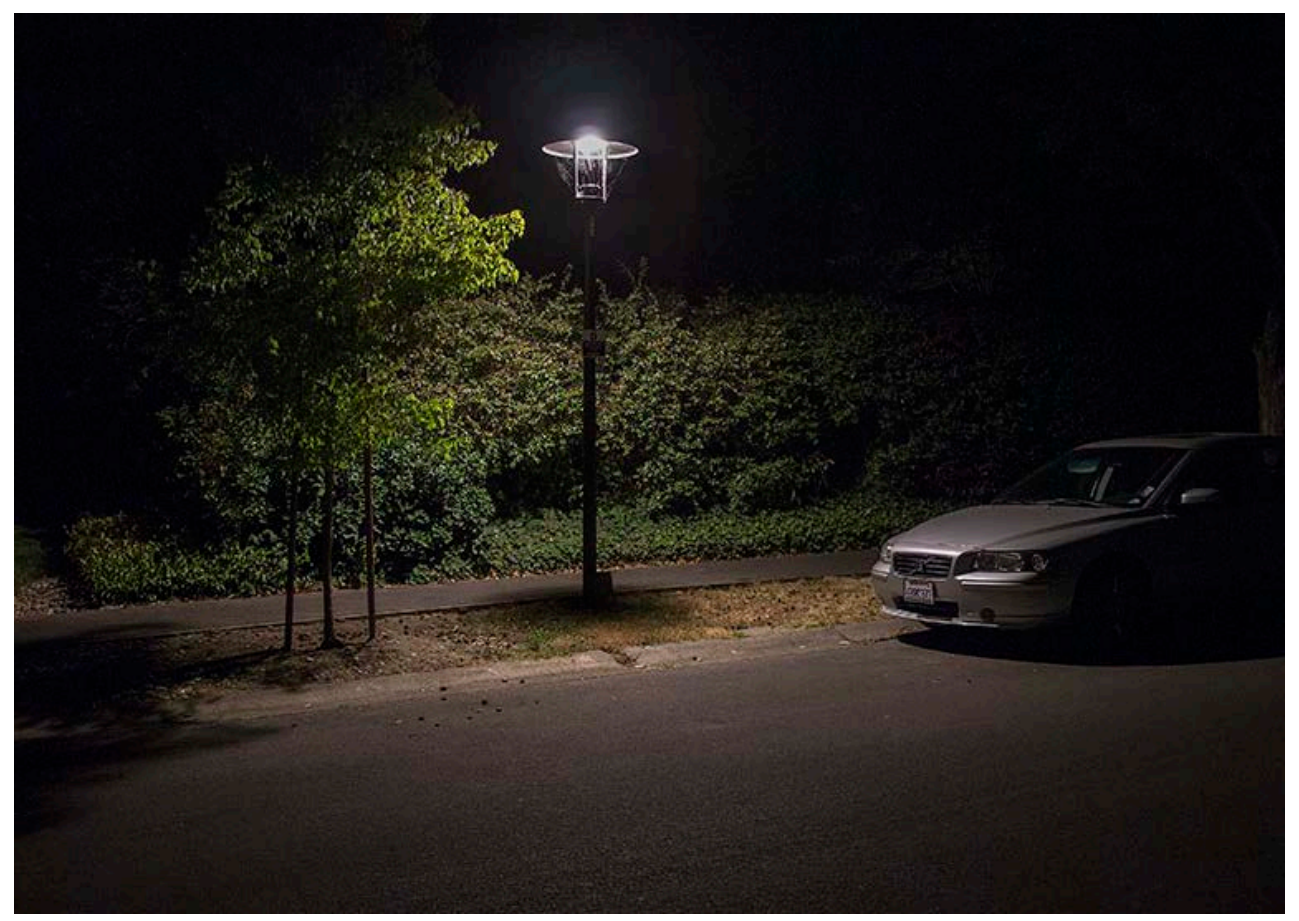

Figure 26. Mockup installation of the Selux Saturn Cutoff luminaire using 60W 2800K 70 CRI CMH lamp. (www.KenRicePhoto.com)
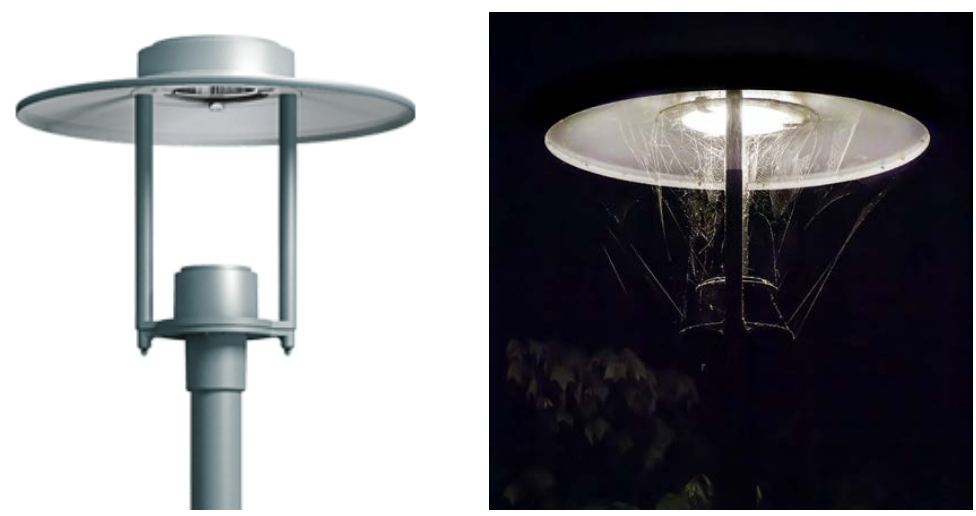

Figure 27. Selux Saturn Cutoff luminaire (left image courtesy of Selux; right image www.KenRicePhoto.com). 


\subsubsection{Acuity/Holophane "PUL," Utility Full-Cutoff Post-Top with 70W 3000K LED Matrix, Ordered with Frosted Lens at the Aperture to Diffuse the View of the LEDs}

There were two last mockup luminaires installed, one was supplied with a Type 3 (asymmetrical) distribution, and one with a Type 5 (symmetrical) distribution (Figure 28 and Figure 29). These luminaires were selected after it became clear that campus residents preferred a more traditional daytime appearance, and when this model of luminaire received good reviews from its installation on Oak Road. The LED optical system is contained in the roof of the luminaire and directs all light downward. Neighborhood residents received this model enthusiastically because of the traditional appearance reminiscent of the campus pedestrian luminaire, the warm color, limited glare, softened shadows, and long estimated LED life that would reduce future maintenance costs.

The lighting designer learned through these and other mockups that once the diffuser was installed, there was little difference between the Type 3 (asymmetrical) and Type 5 (symmetrical) distribution products, whether looking at the light pattern on the ground or looking directly at the luminaire aperture. The diffusion reduces the precision of the optical system. As a result, the designer intends to simplify the specification by recommending Type 5 distribution only. This will also make it easier for the installers, since determining the proper orientation of the luminaires is challenging in the daytime.

Pending life-cycle cost analysis, the Type 5 version of this full cut-off (i.e., no uplight) decorative LED post-top luminaire in 3000K LED with diffusing lens is the preferred solution for the SCRL neighborhoods.

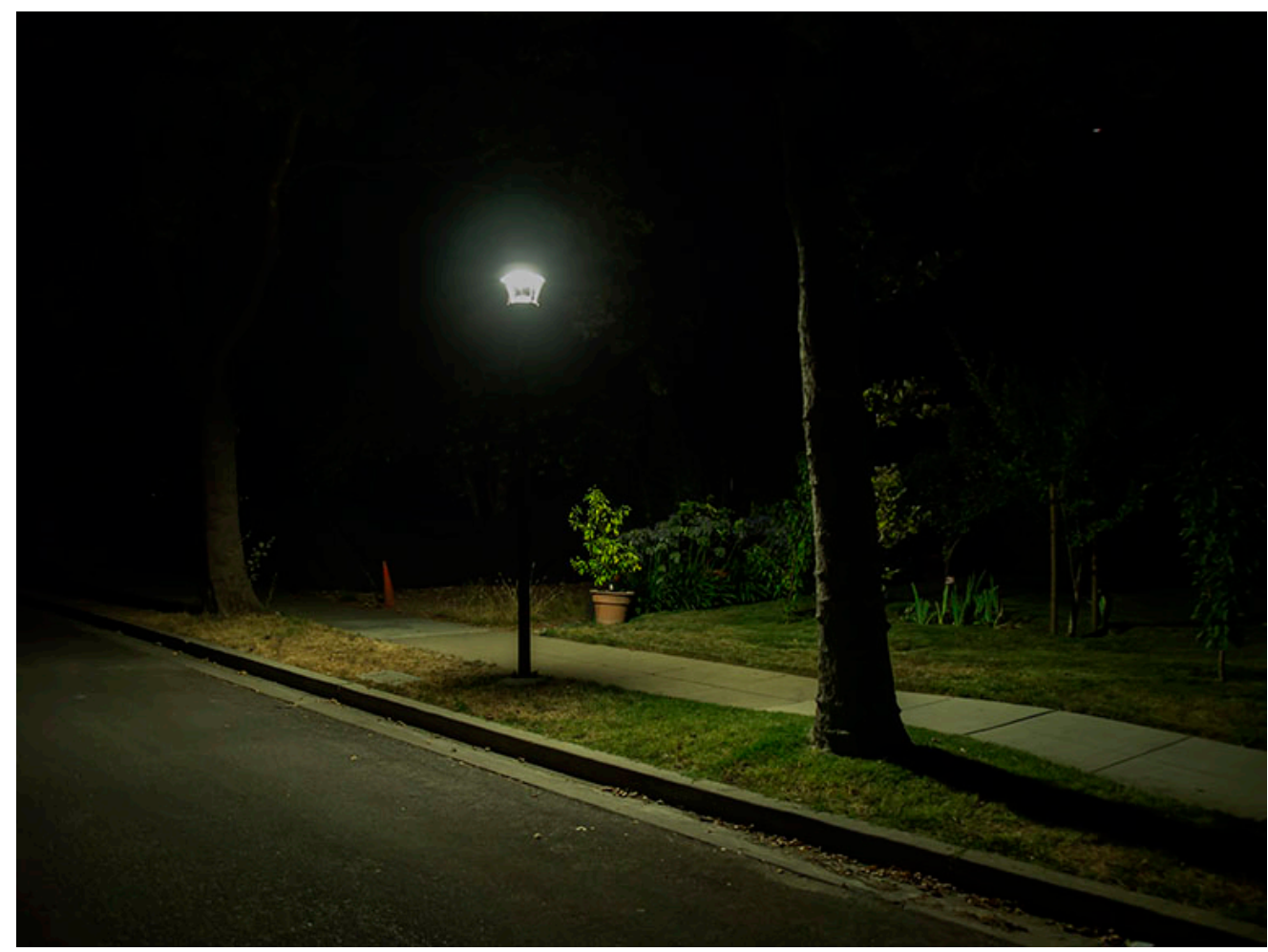

Figure 28. Mockup of the Holophane PUL luminaire with 70W 3000K LED matrix and frosted glass diffusing lens. Note the diffused shadow at the base of the pole. (www.KenRicePhoto.com) 

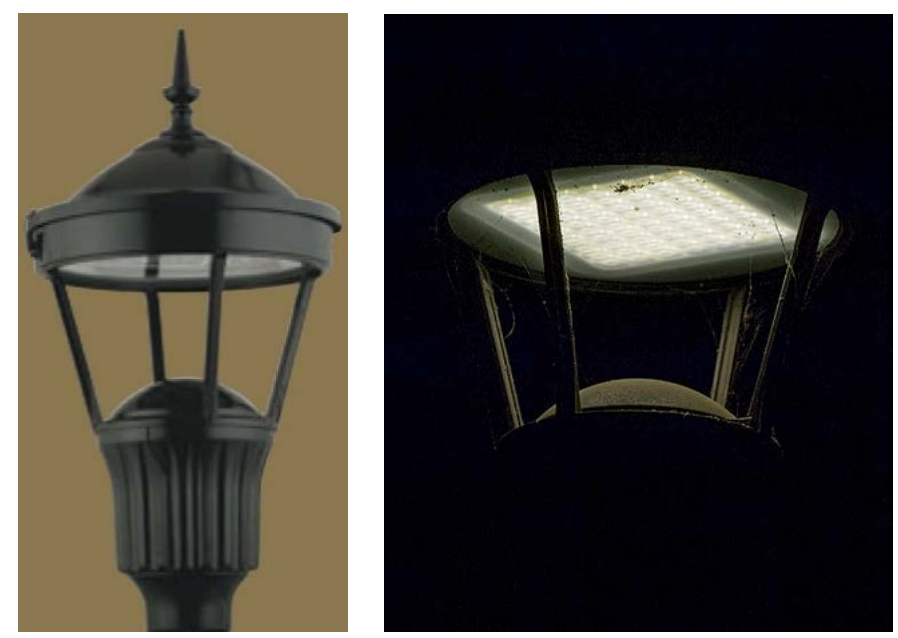

Figure 29. Acuity/Holophane PUL utility post-top luminaire (left) closeup of luminaire with 70W 3000K LED matrix and frosted diffusing lens to mitigate glare and soften the distribution of light. (Photos: Acuity/Holophane (left) and www.KenRicePhoto.com (right)).

\subsection{Lessons Learned from the Stanford University Mockups}

Ultimately, the lessons drawn from the Stanford pedestrian mockups showed that users cared about the daytime appearance of the luminaire. At night, they found lower illuminances than delivered by their existing post-top lights to be acceptable, providing there was little glare, a soft-edged distribution of light, and a warm color (2700K to $3000 \mathrm{~K}$ ) with CRI of 70 or higher. Diffusion was an important characteristic of optical systems that were deemed less glaring. LEDs or clear metal halide arc tubes exhibit an extreme spatial gradient of luminance. That is, the maximum luminance is very high over a very small visual angle, flanked by a sharp-edged drop to much lower luminance. Diffusion that smoothed out that luminance transition was described as less glaring.

\subsection{Pedestrian Lighting for the Chautauqua Institution}

The Chautauqua Institution is an arts, music, performance, interfaith religion, and cultural community founded in 1874 and located on the shore of Lake Chautauqua in western upstate New York (Figure 30). In the summer, it hosts a 9-week program of lectures, entertainment, recreation, theater, worship, and dance. Guests typically live on the grounds for a week; many are in residence for the whole season. It is a compact, pedestrian-focused community. Bicycles are also widely used. During the season, cars and other motorized vehicles are only allowed on the grounds to pick up and drop off passengers and to make deliveries. Those vehicles are restricted to a speed limit of 12 miles per hour (Figure 31). There is a small year-round community of residents, and outside of the summer program weeks vehicles are allowed on the grounds, but speed limits are still enforced. 

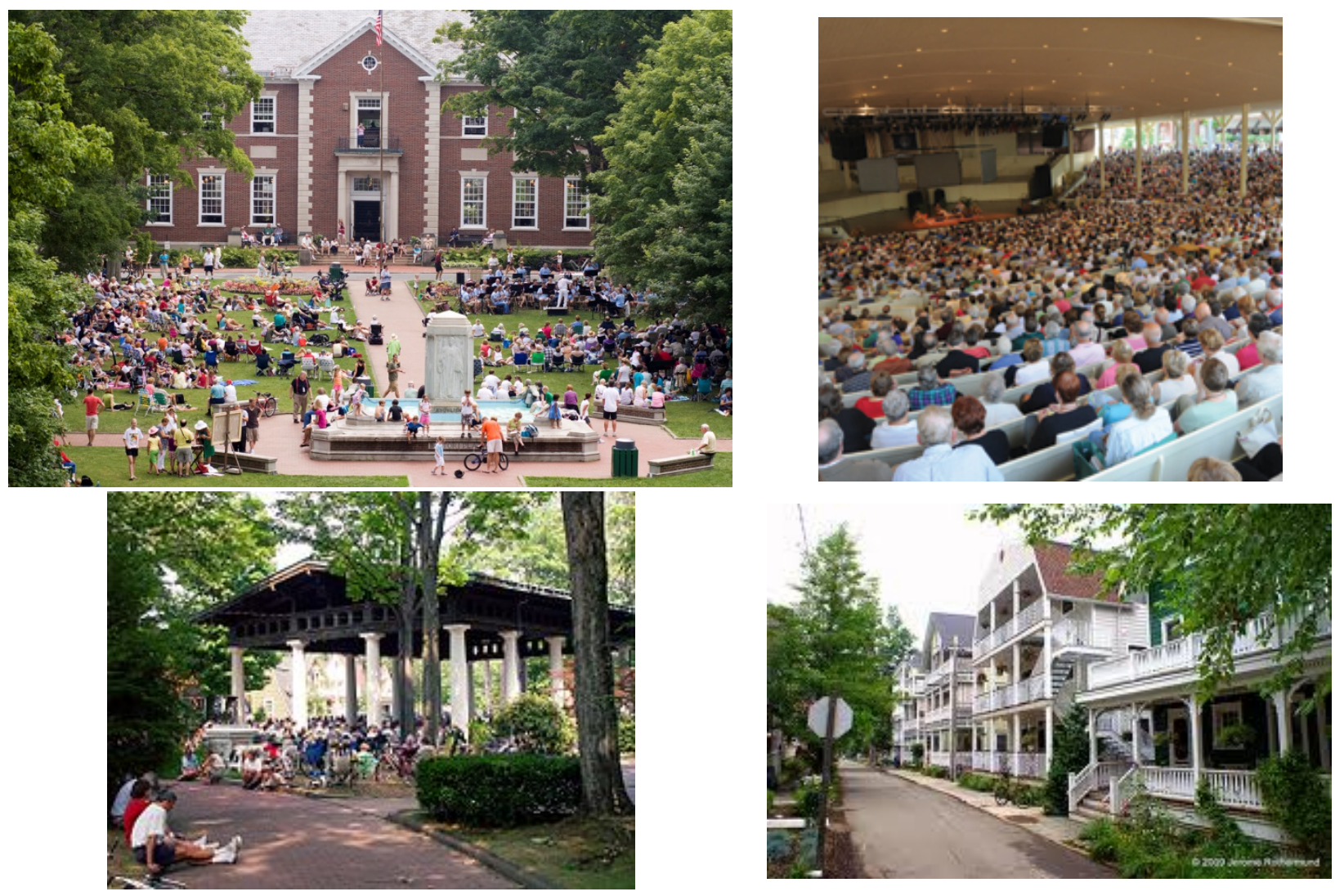

Figure 30. Photos of the Chautauqua community. (Photos courtesy of www.ciweb.org)

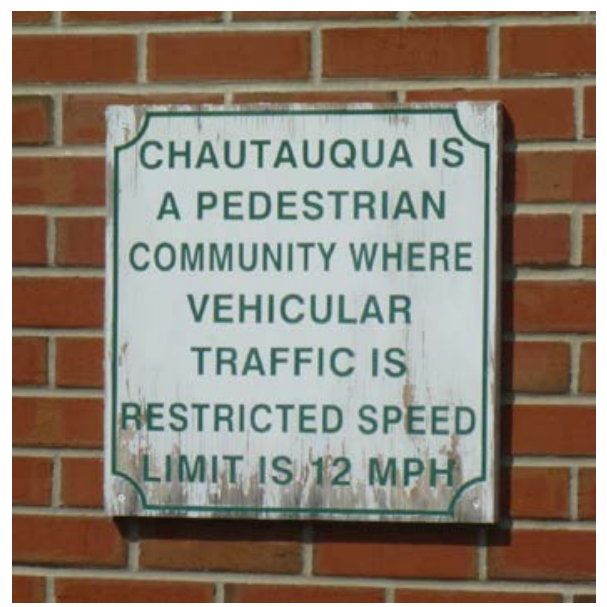

Figure 31. Sign posted at the entrance to the Chautauqua Institution grounds restricting traffic speed.

Housing at Chautauqua is very dense and destinations on the grounds are typically a few minutes' walk. The community is environmentally conscious, bat conscious (for insect control), and concerned about preserving night skies. Glare and light trespass into bedroom windows are topics that arise in conversations about comfort and appearance of the grounds, and darkness and quiet are recognized ingredients for restorative sleep. 
The existing street and pathway lighting systems vary widely, having been installed over a period of almost 100 years. For streetlighting, most poles and luminaires were supplied by the local electric utility and include radial-wave reflectors with incandescent lamps, cobra-head dropped-refractor luminaires with mercury lamps, and post-top carriage-style lanterns with mercury lamps along streets and paths. As these luminaires fail or are damaged, the utility replaces them with 100W to 250W HPS luminaires (Figure 32).

Summer visitors and property owners on the grounds are concerned about the high light output, increased glare, and poor color appearance of the HPS luminaires, and would prefer something that matches the color and light output of the incandescent lamps that lighted the grounds for most of the last century. In 2008, the Chautauqua Property Owners Association (CPOA) formed a committee to study outdoor lighting options; this committee has been exploring options with the electric utility (National Grid), the Chautauqua Utility District (CUD), and the Chautauqua Institution Board of Directors. Some lighting is owned and serviced by the Institution; but most of the street and walkway lighting is owned and serviced by the utility through the CUD. The effort to replace and upgrade the lighting involves not only the groups listed above but also the full-year and seasonal residents who participate via polls and lighting demonstrations. The CPOA outdoor lighting committee established the following goals:

- Provide soft (i.e., non-glaring), warm-color lighting for pedestrians.

- Provide lighting on pavement and pathway surfaces for safety and visibility, with particular attention to the visibility of tripping hazards due to curbs, obstacles, or uneven pavement surfaces.

- Minimize light trespass in windows and onto porches so that it doesn’t interfere with evening gatherings and nighttime sleep.

- Select a luminaire style that suits the traditional early-1900s appearance of Chautauqua, and pole heights that are appropriate for the residential scale of the Chautauqua Community. The committee selected a $12 \mathrm{ft}$ pole (plus luminaire) for the walking paths and deemed a $20 \mathrm{ft}$ mounting height to be suitable for luminaires mounted on utility poles along streets.

- Reduce energy use and maintenance, year-round (nighttime blended electric rates are around $\$ 0.11 / \mathrm{kWh})$.

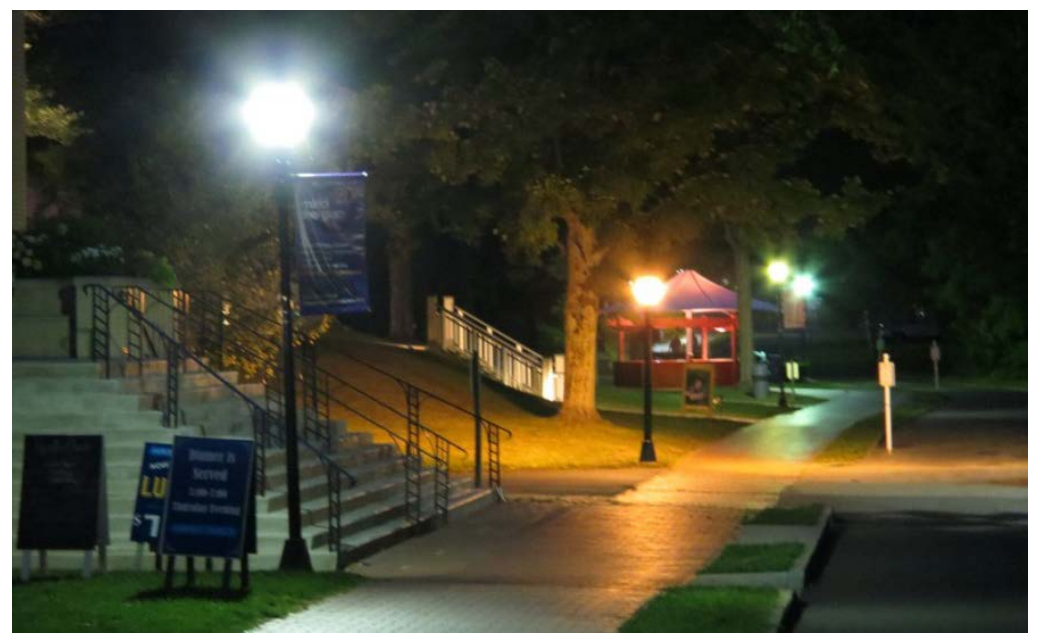

Figure 32. Nighttime view of Chautauqua street where $175 \mathrm{~W}$ mercury vapor carriage lanterns (bluewhite color appearance) are starting to be replaced by 100W HPS carriage lanterns (yellow color appearance) when older equipment fails. (Photo: Dr. William Neches.) 
It is easy to see evidence of concern over glare and stray light. The following photos (Figure 33) show luminaires that were modified by the Institution or the utility at the request of property owners and residents. The photos were taken at various locations on the grounds of Chautauqua Institution.
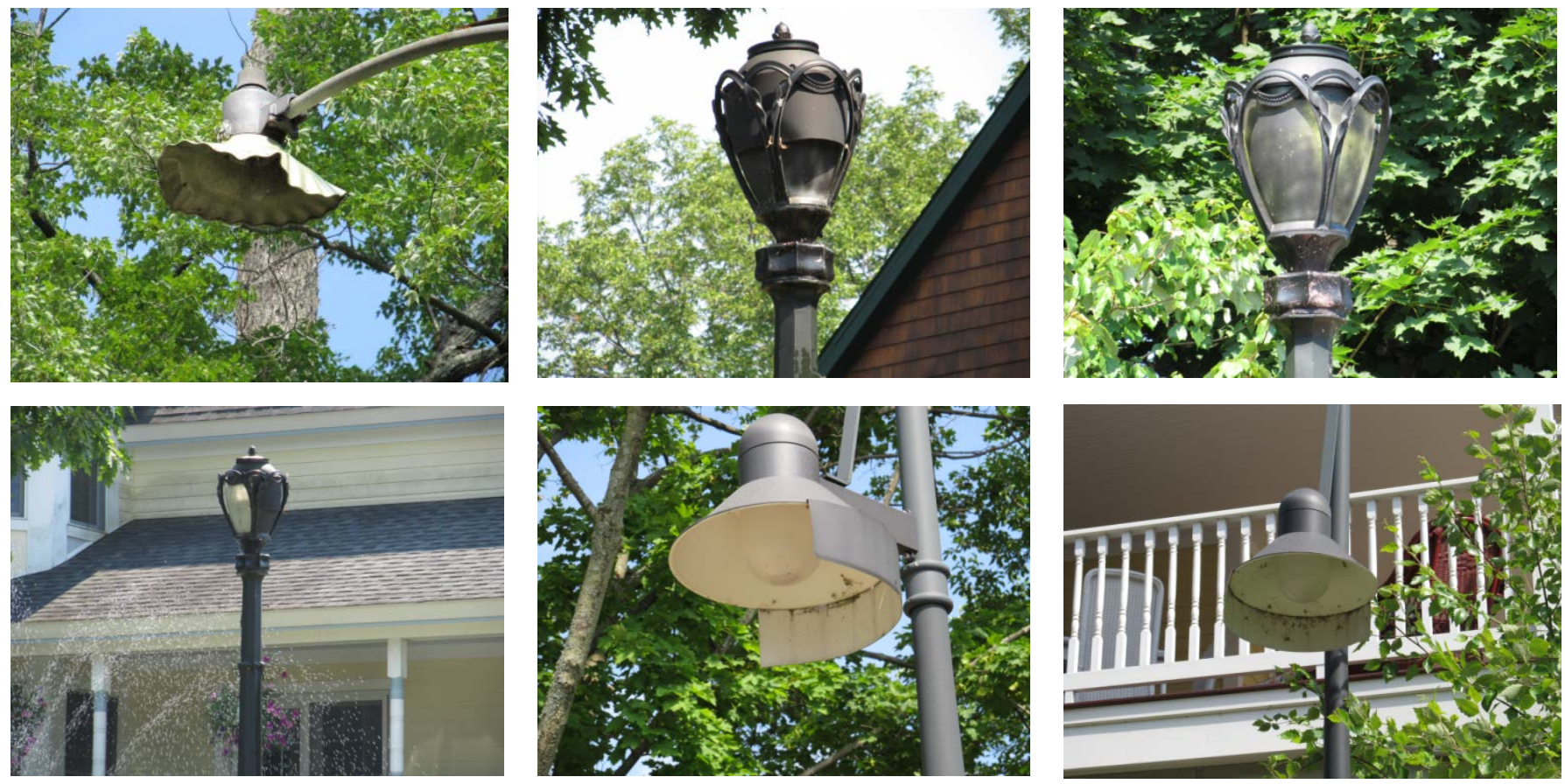

Figure 33. These six photos illustrate luminaires on the grounds of Chautauqua that have been modified with paint or opaque shielding to minimize glare and light trespass. (Photos: Dr. William Neches.)

As the committee searched for suitable luminaires and light sources, they found that nothing meeting the criteria and, particularly, nothing in warm colors (2700K to $3000 \mathrm{~K})$ was available in the utility's catalog of street lighting product offerings. Therefore, they considered the option of Chautauqua Institution and the CUD purchasing and maintaining their own lighting systems. They would then pay the utility only for the power used, plus a charge for maintaining power distribution and other infrastructure, in addition to the charges for mounting some of the luminaires on utility-owned poles.

The CPOA researched outdoor lighting options that seemed to meet their criteria, based on available technical literature. With the help of lighting-savvy members of the committee, outdoor luminaire manufacturers were contacted for samples of post-top luminaires for installation on the Institution grounds for demonstration and evaluation. The CPOA delivered lectures and wrote newspaper articles to build interest in the project, raise awareness about glare and dark sky concerns, and encourage feedback. It also developed a paper and online survey for Chautauqua residents and summer program attendees, making survey forms available in the Chautauqua library with instructions for completing and returning them. Because the number of available poles was limited, only one to two luminaires were available for nighttime viewing at any given time. These mockups took place over two summer seasons at Chautauqua, and they are described in the following subsections. 


\subsection{Demonstration 1: AAL Providence Post-Top with Indirect Asymmetrical Optics Using 60W "Cosmowhite" CMH Lamp}

The first mockup erected in June 2012 was a single luminaire with early 20th century ambiance, using a 60W Philips "Cosmowhite" CMH lamp (2800K, 70 CRI, 67W system watts) that automatically dimmed by $25 \%$ late at night (Figure 34 and Figure 35 ). It was temporarily mounted to an $11 \mathrm{ft}$ wooden pole, but was remounted to a $12 \mathrm{ft}$ metal pole later that summer. Lamp lumens were 6900, but the luminaire efficiency was low, delivering 1230 luminaire lumens. Expected lamp life was 15,000 to 20,000 hours (3.5 to 5 years, based on 4000 estimated annual hours of use). A total of 331 summer program attendees responded to the survey on this luminaire (Appendix B), with the following results for the overall satisfaction question:

- Positive responses $=86 \%($ Strongly agree $=68 \%$, Agree $=18 \%)$

- Neutral $=3 \%$

- Negative responses $=11 \%($ Disagree $=4 \%$, Strongly disagree $=7 \%)$

Survey comments suggested the vast majority of respondents liked the aesthetic appearance and the lack of glare, and appreciated the warm, incandescent-like color. Although delivered light levels were relatively low —about $0.5 \mathrm{fc}$ on average - in the lighted area surrounding the pole, there were no complaints about light levels being either too high or too low. Note: The $5.4 \mathrm{~lx}$ [0.5 fc] from the AAL Providence/Cosmowhite system compares to an average of $1 \mathrm{~lx}$ [0.1 fc] provided by traditional whiteglobe post-top lighting in an adjacent village green area. See Figure 43. (The traditional lighting consists of simple post-tops using either 100W incandescent A-lamps or 23W 2700K compact fluorescent lamps (CFLs) inside white glass globes.) 

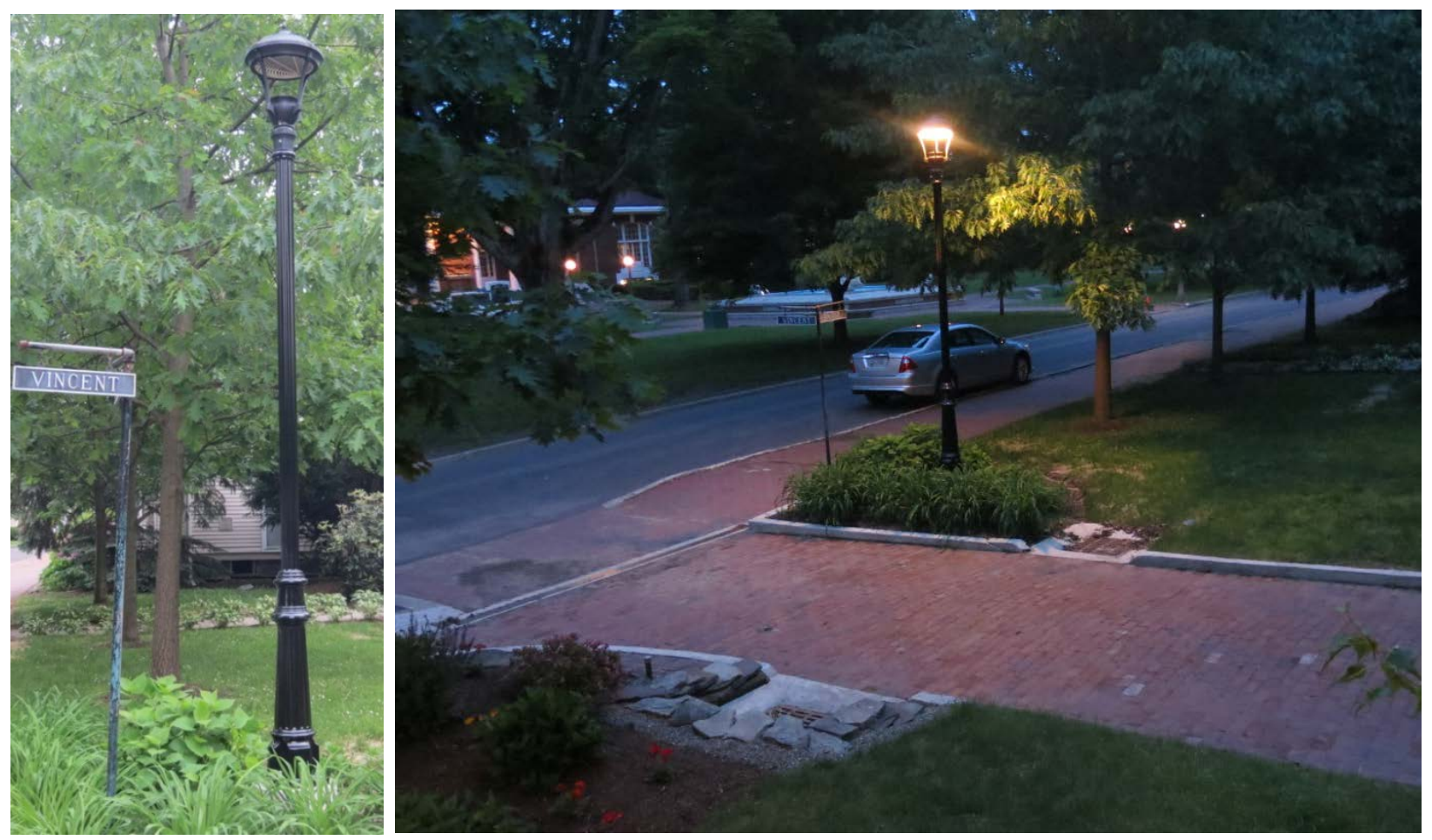

Figure 34. Daytime and evening views of AAL "Providence" indirect luminaire with 60W 2800K 70 CRI CMH (“Cosmowhite”) lamp. (Photos: Dr. Williams Neches.)
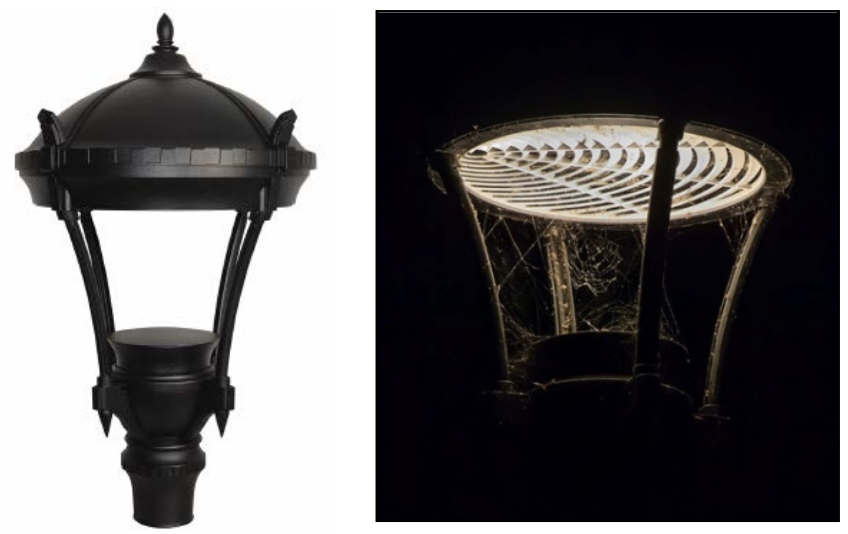

Figure 35. AAL “Providence Indirect” luminaire (left); closeup of asymmetrical indirect optical system (right). (Photos: AAL (left) and Dr. William Neches (right).)

Although this luminaire received excellent reviews, the committee was concerned about whether there was an option that would use LEDs to reduce maintenance frequency and cost, and perhaps deliver the same or better light levels at lower power input. This led to a demonstration of three different LED luminaires in 2013, all with the LEDs located in the hood of the housing so that they would support darksky principles of delivering all of their light downward.

The 2013 summer season luminaire options were evaluated more informally until the committee was confident about its recommendation to the full Chautauqua community. The surveys were distributed to the members of the outdoor lighting committee and a number of other Chautauquans, for a total of about 
30 people for each luminaire. The chair of the CPOA reported that these survey results indicated that each of the luminaires were considered appropriate for Chautauqua's architectural ambiance, produced a pleasant color of light, and produced a good light distribution on the ground with dark-sky compliant optics. Details follow. At the conclusion of the 2013 summer season, a second survey was widely distributed to the Chautauqua community to get feedback on the acceptability of the option proposed by the CPOA (see Appendix C).

\subsection{Demonstration 2: Acuity/Tersen "Resonance" Post-Top with LED Matrix in Cap of Luminaire}

Installed in May 2013 on a $13 \mathrm{ft}$ pole, this product was provided by the manufacturer with a 7 by 7 matrix of LEDs in the cap of the luminaire, enclosed with a flat clear glass. The Committee quickly asked the manufacturer to replace this glass with a small-prism glass lens to diffuse the brightness of the LEDs. Drawing 58 system watts, the luminaire delivered 3000 lumens downward in a Type 3 distribution, with warm 3000K, 65 CRI color. Manufacturer-estimated LED life was 70,000 hours (17 years at 4000 hours per year). Feedback from the outdoor lighting committee and informally distributed surveys indicated that even with the glass diffuser, this product produced unacceptable glare for pedestrians. One committee member commented, "The glare control is fine once you're 50 feet or so away from the fixture because the cut-off angle of the fixture shields your eye from the LED array. As you move closer, however, the glare is substantial. The problem is that the fixture is emitting too many lumens for the size of the light-emitting array and the mounting height. But, I believe the glare could be made acceptable if the light output were reduced.” Illuminances measured $16 \mathrm{~lx}$ [1.5 fc] at the curb next to the pole; and 4 to $11 \mathrm{~lx}$ [0.4 to $1.0 \mathrm{fc}$ ] within a $29 \mathrm{ft}$ radius of the pole. See Figure 36 and Figure 37.
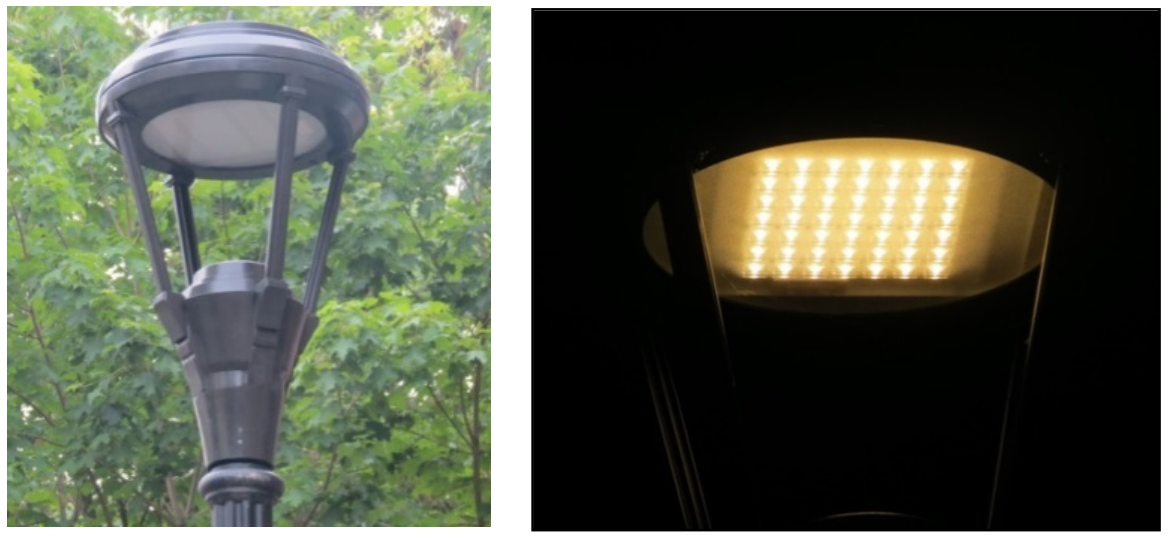

Figure 36. Daytime photo of the Acuity/Tersen Resonance post-top luminaire with prismatic glass to diffuse brightness of individual LEDs (left); closeup of luminaire with LED matrix and glass diffuser. (Photos: Dr. William Neches.) 


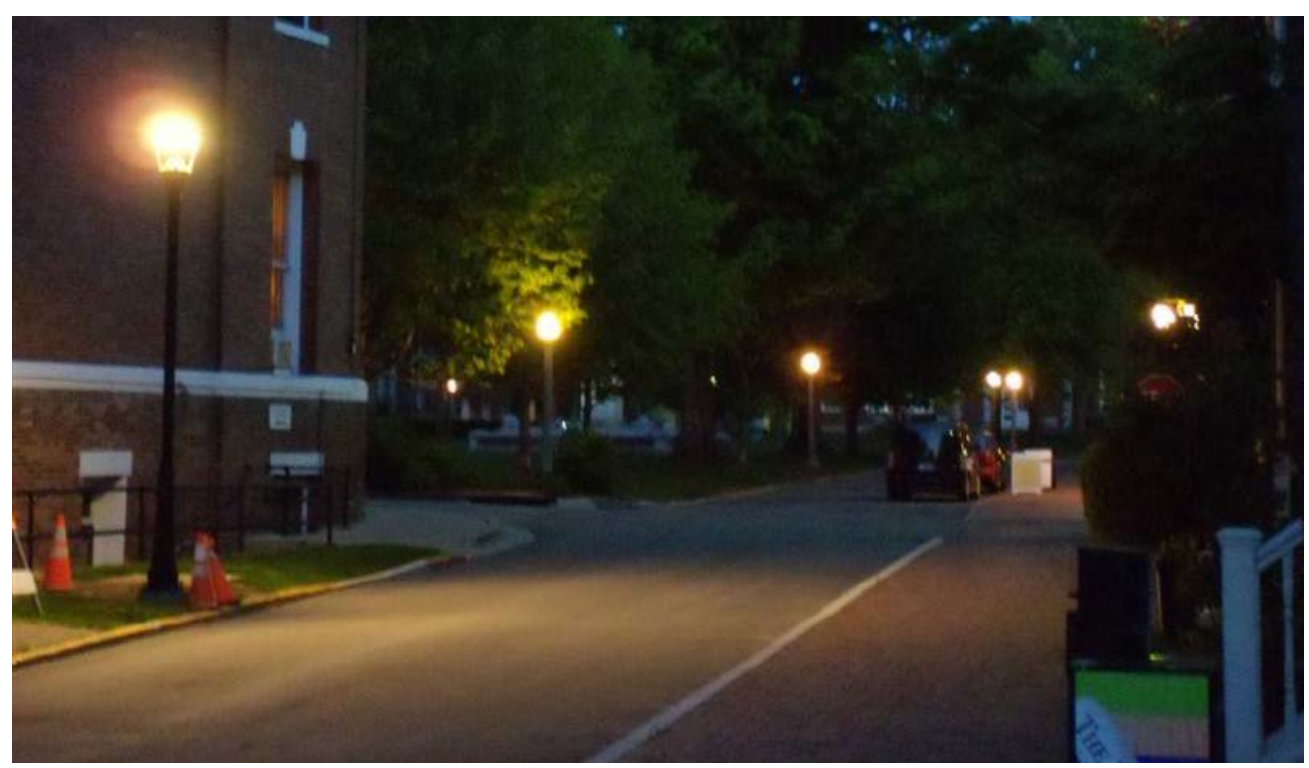

Figure 37. Nighttime photo of Acuity/Tersen Resonance luminaire mockup (on left). (Photo: Terry McGowan.)

\subsection{Demonstration 3: AAL "Providence Microcore" Post-Top with Round Pattern of LEDs in Aimed Optics}

The Acuity/Tersen luminaire was replaced in late June 2013 with an AAL "Providence Microcore" luminaire, equipped with 32 LEDs in a round configuration. It drew $76 \mathrm{~W}$, delivering 3500 luminaire lumens downward in a Type 3 distribution, with a warm $3000 \mathrm{~K}$ color. The manufacturer claimed an expected life of 100,000 hours (24 years at 4000 hours per year). The luminaire was originally provided by the manufacturer with a small-prism lens to diffuse the LED glare. The committee asked the manufacturer for a frosted glass diffuser instead, hoping that would appear less glaring. Even with that change, the informally surveyed residents and the outdoor lighting committee found the glare unacceptable, and the luminaire was removed before illuminance measurements could be taken. This optical system has individual LEDs aimed in specific directions, and those LEDs aimed away from the pedestrian's direction of view were comfortable to view, but the LEDs aimed toward the viewer were inevitably glaring even if the pedestrian wasn't specifically looking at the luminaire. However, many noted that they liked the aesthetics of the round pattern of LED in the round luminaire head, since the two previous options had had a square optical system in a round housing. See Figure 38. 

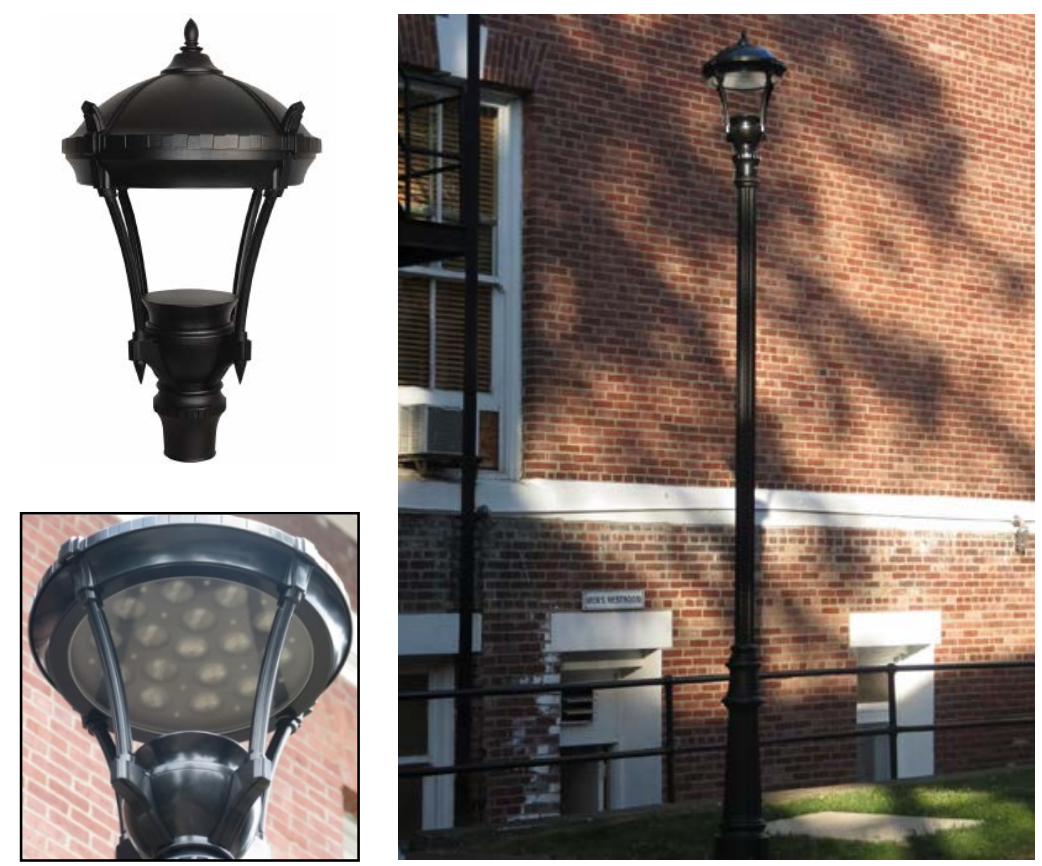

Figure 38. AAL Providence Microcore LED luminaire (top left); luminaire with diffusing glass, daytime appearance (right) and closeup (bottom left). (Photos: AAL (top left) and Dr. William Neches (bottom left; right).)

\subsection{Demonstration 4: Neri "804" Post-Top Lantern with Linear LED Module}

This mockup luminaire, temporarily installed in late June of 2013, was aesthetically acceptable because of its traditional carriage lantern appearance (Figure 39 and Figure 40). Similar to the other darksky friendly options, this luminaire has its optics in the cap of the luminaire, using a linear LED module with a large-area remote phosphor panel (Philips Fortimo LLM module). The surface area of the remote phosphor spreads the brightness of the LED chips over a larger area, reducing the luminance of any given point. This product was originally provided with a clear, flat glass in the aperture, which was subsequently replaced with a frosted glass diffuser to counteract glare, upon request by the outdoor lighting committee. The luminaire draws 37W, delivers approximately 3000 luminaire lumens in a warm 3000K, 80 CRI color, and the manufacturer publishes an expected life of 70,000 hours (17 years at 4000 hours per year). Its light is directed downward for dark sky considerations. The committee and informally surveyed residents preferred this option among the three LED products installed in 2013, and in late July 2013 the committee had the AAL Microcore product removed and this luminaire moved to a $12 \mathrm{ft}$ metal pole in a more prominent location on the grounds. However, group opinion was that the LED module brightness was too high. Fortunately, this product had been supplied with a dimmable driver, so the next demonstration used this same luminaire, but dimmed to lower light output. 


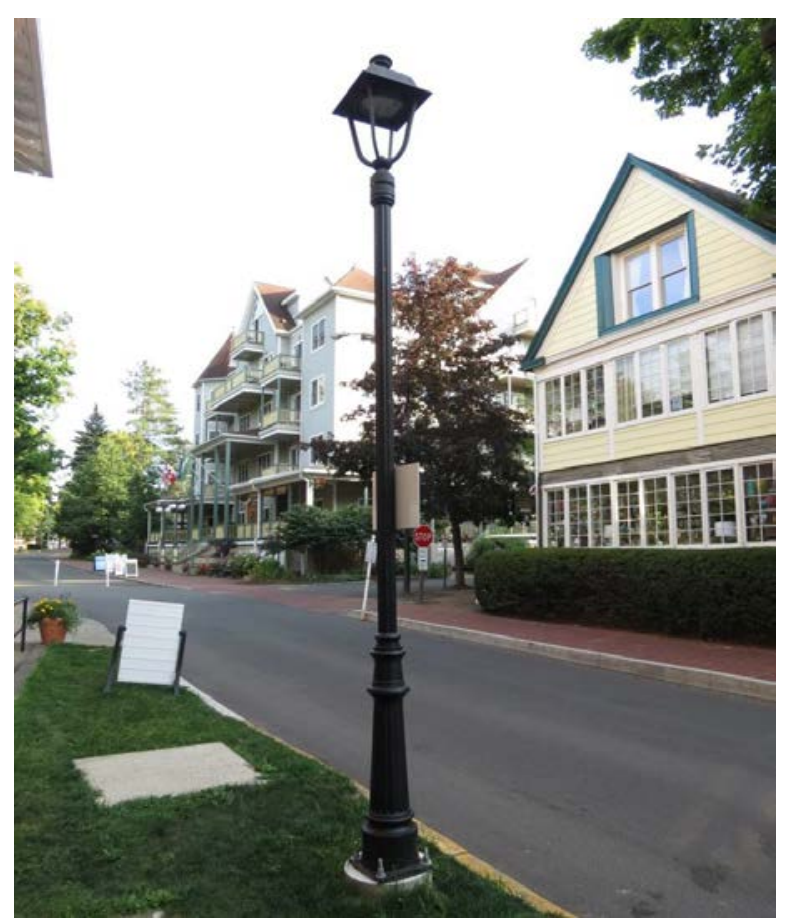

Figure 39. Daytime appearance of Neri 804 post-top lantern with 37W LED module.
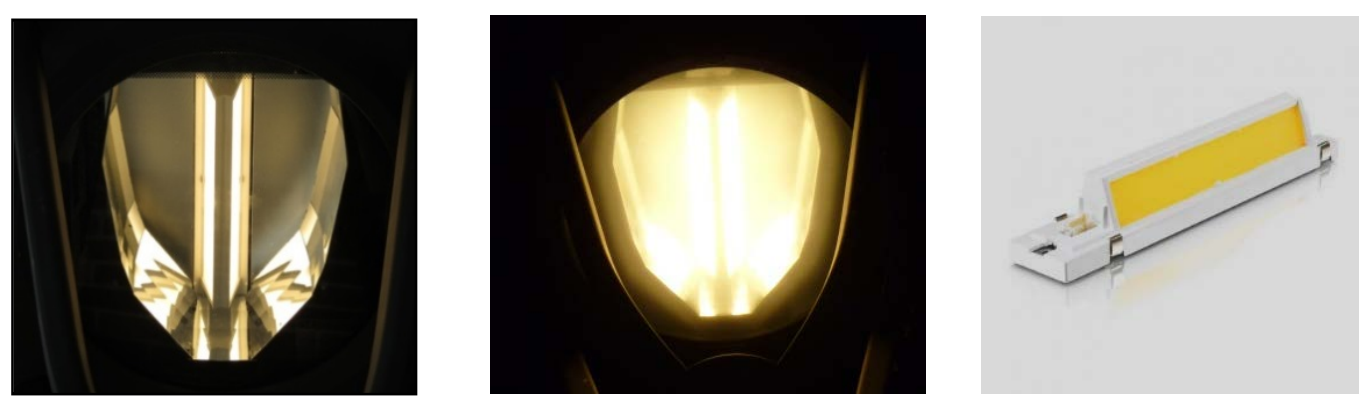

Figure 40. Closeup of Neri 804 optical system showing remote-phosphor LED module behind clear glass (left); closeup of system with diffusing glass (center); LED module used in Neri 804 post-top luminaire, showing its large remote-phosphor surface (right).

\subsection{Demonstration 5: Neri "804" Post-Top Lantern with Linear LED Module Dimmed}

On August 14, 2013, a 0-10V dimmer was wired into the pole and luminaire, as described in Demonstration 4 discussion above. With the outdoor lighting committee and interested summer residents in attendance, the luminaire output was dimmed and lowered to a variety of levels. Ultimately, the 3000 lumen luminaire was dimmed to $60 \%$ of its full output as measured by ground plane illuminance, or approximately 1800 lumens. This produced a light distribution that was deemed acceptable, delivering a light pattern that was visually judged to extend about $37 \mathrm{ft}$ along the street in either direction from the $12 \mathrm{ft}$ pole. Within that range, illuminances from 1.1 to $9.7 \mathrm{~lx}$ [0.1 to $0.9 \mathrm{fc}$ ] were measured at grade in the center of the street, with $1.1 \mathrm{~lx}$ [0.1 fc] measured vertically on faces $32 \mathrm{ft}$ from the pole. (Observers 
actually thought this level of illuminance and module brightness was still a bit high, but understood that some lumen degradation over time was to be expected, so this level was accepted even though it was slightly higher than ideal.) All observers agreed the visual comfort from this dimmed system was superior to other options they had seen. See Figure 41 and Figure 42.

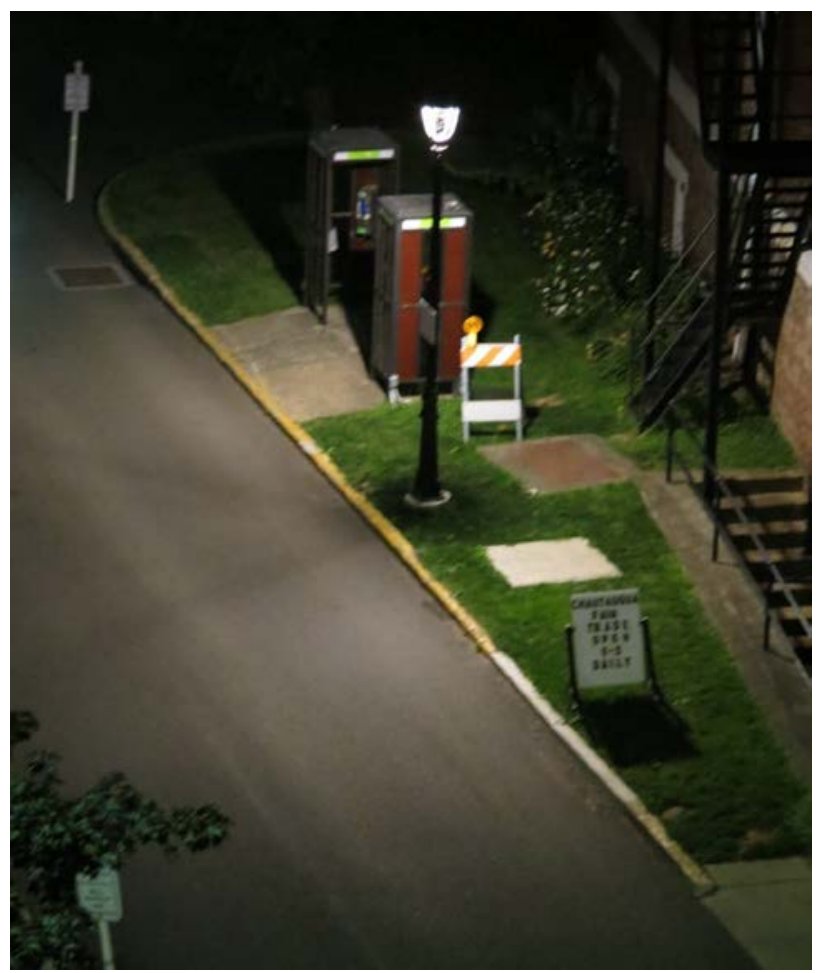

Figure 41. Neri post-top LED luminaire with 1800 lumen output, viewed from above to show light pattern on street. (Photo: Dr. William Neches.)

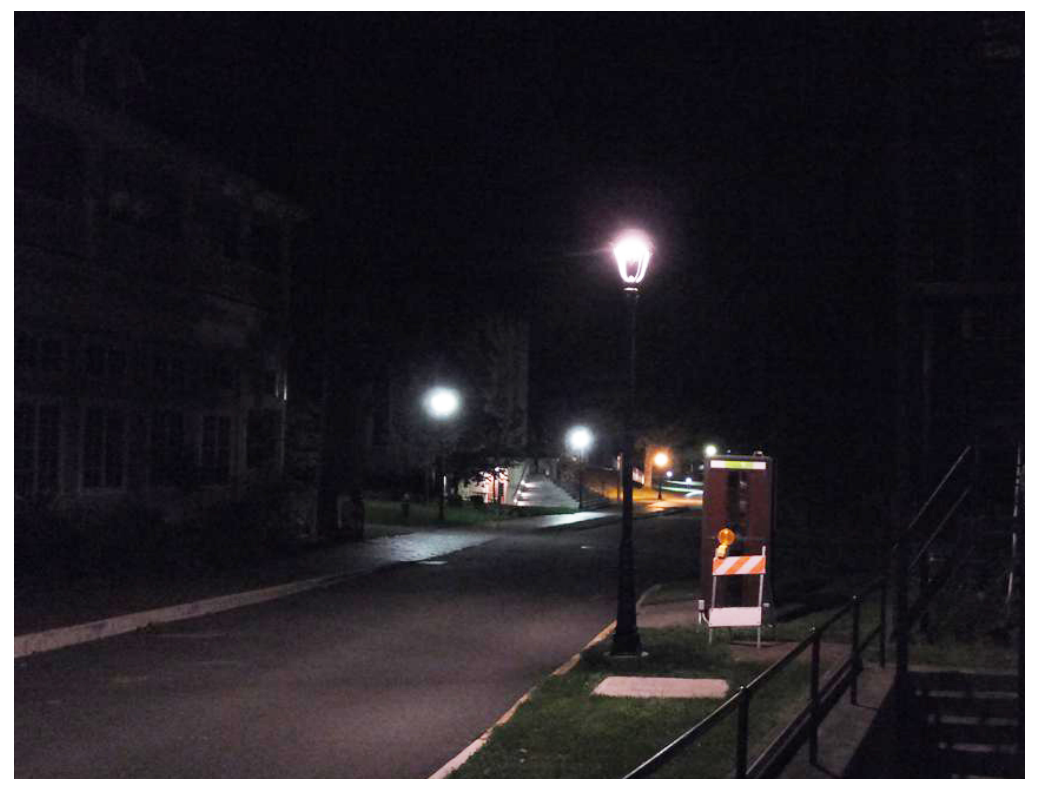

Figure 42. Photo of Chautauqua street with dimmed Neri 804 luminaire on mockup pole in the foreground, right. (Photo: Terry McGowan.) 
The outdoor lighting committee issued a community survey slightly modified from the 2012 survey (Appendix C) on August 15 for feedback on both this solution and the AAL indirect option. Although the survey was issued late in the summer season, and fewer people were able to see the new luminaire and complete the survey, there was generally positive response for the dimmed Neri 804 post-top on the two final questions among the 32 individuals who did respond:

- Positive responses $=75 \%$ (Strongly Agree and Agree)

- Neutral $=15 \%$

- Negative responses $=10 \%$ (Disagree and Strongly Disagree)

\subsection{Results of the Five Demonstrations at Chautauqua Institution}

Since the Neri "804" post-top lantern with linear LED module is available with a 24W, 1800 lumen LED module in the same Philips Fortimo module family, the committee agreed to order the Neri post-top luminaire with that modification for a larger mockup of nine poles and luminaires for 2014. The final product draws only $27 \mathrm{~W}$ including driver, and will be supplied with a fixed output, not a dimming, driver because when the starting wattage is that low, the savings from dimming is not expected to result in a practical payback period.

\subsection{Chautauqua Demonstration Illuminance Measurements}

Illuminance measurements were taken at the Chautauqua demonstration sites for the luminaires that the outdoor lighting committee considered acceptable in terms of glare, based on resident feedback. Vertical and horizontal illuminance values were measured by a portable Meterman LM631, color and cosine corrected meter with a minimum sensitivity of 0.1 lux [0.01 fc]. All measurements were made on the same night (August 9, 2013), 1 hour or more after sunset, except for the Acuity/Tersen luminaire, which was measured June 25, 2013 before it was removed. The sky was overcast with no apparent moonlight. Stray light was not controlled and is described for each measurement site (Figure 43). 


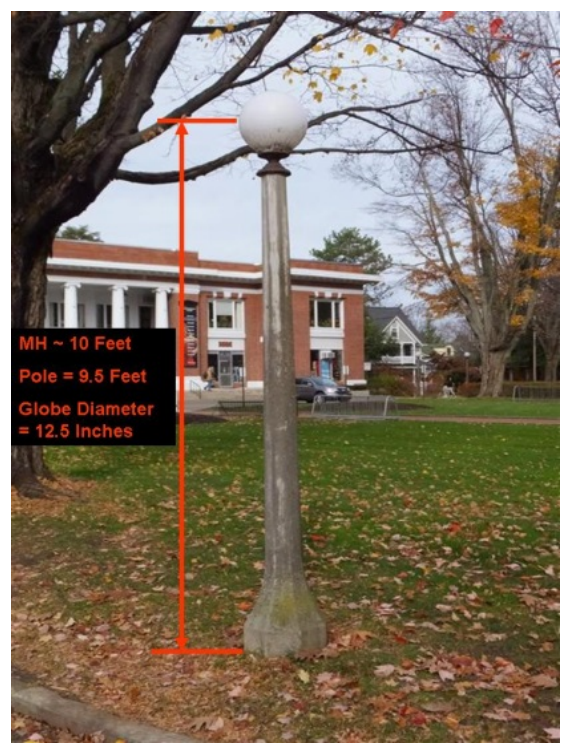

(a) Existing decorative globe luminaire in nearby area of Chautauqua Institution grounds for comparison.

- Mounting height of $10 \mathrm{ft}$ (to center of globe) lamped with a 23W CFL integral lamp.

- Avg. illuminance measured at a radius of $10 \mathrm{ft}$ from pole: $1.0 \mathrm{~lx}$ [0.1 fc].

- Stray light: No lighted windows or other outdoor lighting within $100 \mathrm{ft}$.

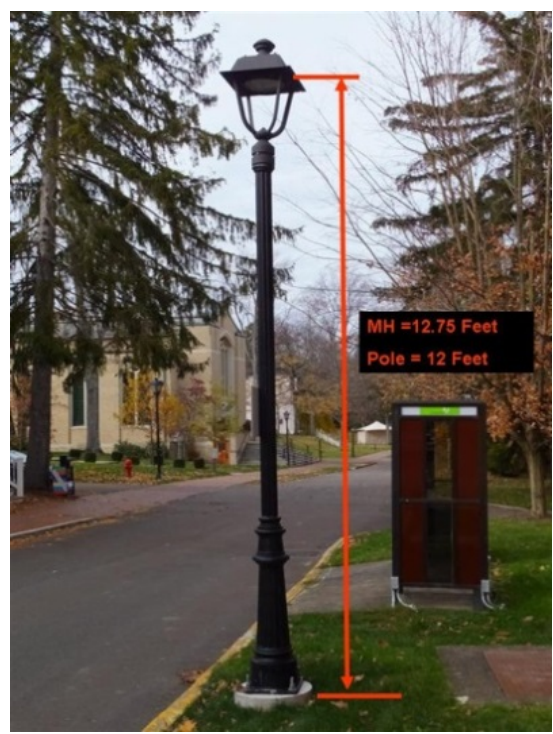

(c) Neri 804 lantern style post-top luminaire using 37W

Philips "Fortimo" LED module rated at 3000 lumens, but dimmed to 1800 lumens.

- Avg. illuminance measured at a radius of $12.75 \mathrm{ft}: 4.7$ lx [0.44 fc]. 1 to $10 \mathrm{~lx}(0.1$ to $0.9 \mathrm{fc}$ ) measured in center of street within $37 \mathrm{ft}$ of pole.

- Stray light: Lighted windows $20 \mathrm{ft}$ away; a $175 \mathrm{~W}$ refractor cobrahead mercury streetlight $\sim 50 \mathrm{ft}$ away. Stray light, measured by shielding meter from direct light of the test luminaire was $0.54 \mathrm{~lx}[0.05 \mathrm{fc}]$.

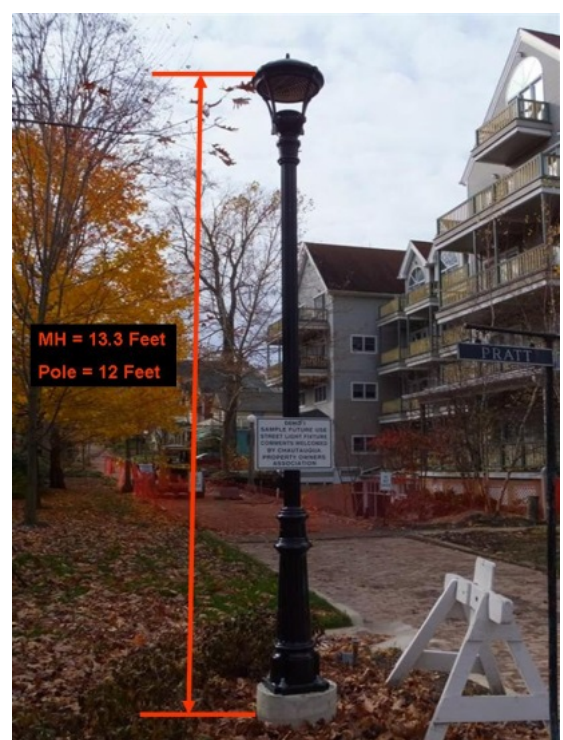

(b) AAL Providence Indirect luminaire with Philips $60 \mathrm{~W}$ "Cosmowhite" CMH lamp.

- The indirect reflector is mounted at $13.3 \mathrm{ft}$.

- Avg. illuminance measured at a radius of $13.3 \mathrm{ft}$ : $5 \mathrm{~lx}$ [0.5 fc].

- Stray light: Lighted windows and decorative lighting located 75-100 ft away, producing $0.9 \mathrm{~lx}$ [0.08 fc], measured by shielding meter from the direct light of the test luminaire.

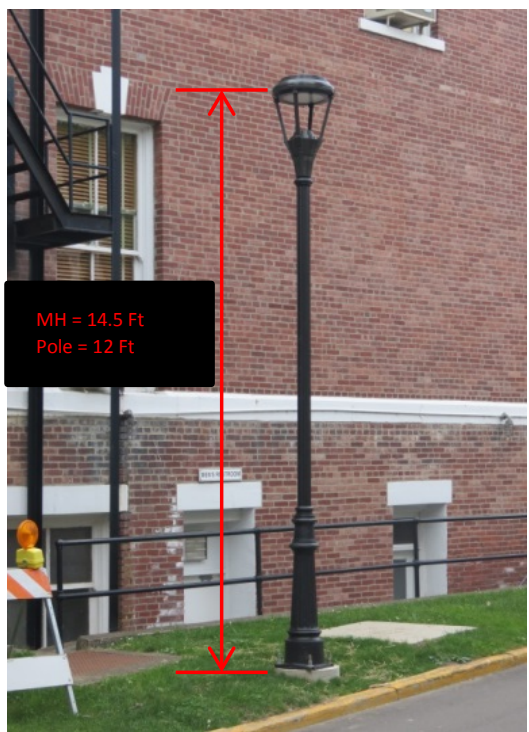

(d) Acuity/Tersen "Resonance" luminaire using 58W LED array in cap of luminaire.

- The plane of the LEDs is $14.5 \mathrm{ft}$ above grade.

- Avg. illuminance: $16 \mathrm{~lx}$ [1.5 fc] near the base of the pole; 4 to $11 \mathrm{~lx}$ [0.4 to $1.0 \mathrm{fc}$ ] at a $29 \mathrm{ft}$ radius from pole.

- No stray light measurement.

Figure 43. Nighttime illuminance measurements at Chautauqua Institution. 


\subsection{Chautauqua Luminaire Luminance Measurements}

Luminance readings were taken using a Minolta LS-110, which has a $1 / 3^{\circ}$ acceptance angle over a $9^{\circ}$ angle of view calibrated in candelas per square meter to $+/-2$ digits of displayed value and color corrected to within $8 \%$ of the International Commission on Illumination (CIE) spectral luminance efficiency function $(\mathrm{V} \lambda$ ). The luminances of the luminaire's light-emitting surface were measured from an approximate height of $6 \mathrm{ft}$ above grade and a position $20 \mathrm{ft}$ from the pole along the street edge (roughly $22^{\circ}$ above horizontal for the pedestrian; or $68^{\circ}$ from luminaire nadir).

Measurements of the Providence/Cosmowhite luminaire (Demonstration 1) are representative of the actual luminance of the luminaire's reflecting surface; but the values for the Acuity/Tersen Resonance LED luminaire (Demonstration 2) and the AAL Providence LED Microcore (Demonstration 3) are misleadingly low because even the $1 / 3^{\circ}$ measuring aperture of the meter "sees" both the bright LEDs and the darker surrounding area of the LED optical system. As a result, the very high luminance of the LED chip is averaged over the larger surface area, reducing the maximum value. The spot luminance doesn't capture the maximum luminance, nor is it necessarily capturing an accurate average luminance.

Luminance values shown for the Neri "804" (Demonstration 4) are more accurate since the light from the LEDs is evenly diffused by the remote phosphor surface of the LED module, but the higher value listed in the table is likely the flashed area of the reflector. Overall, the luminance measurements (Table 1) are useful for reference; but should not be used to indicate or compare intensity or potential for glare.

Table 1. Measured luminaire luminance values from Chautauqua mockup luminaires.

\begin{tabular}{|c|c|c|c|c|c|c|c|}
\hline Mockup & \#1 AAL & \#2 Acuity & \#3 AAL & \#4 Neri & \#5 Neri 804 & Reference: & Reference: \\
\hline Luminaire & Providence & Tersen & Providence & 804 LED & LED Linear & $175 W$ & $175 W$ \\
\hline & Indirect & Resonance & Microcore & Linear & Module & Mercury & Mercury \\
\hline Reference & $60 \mathrm{~W}$ CMH & LED & LED & Module & (frosted & Cobrahead & Post-Top $^{(\mathrm{a})}$ \\
\hline Luminaire & & & & $\begin{array}{l}\text { (frosted } \\
\text { lens) }\end{array}$ & $\begin{array}{l}\text { lens), } \\
\text { dimmed to } \\
60 \% \text { output }\end{array}$ & & \\
\hline $\begin{array}{l}\text { Measured } \\
\text { spot } \\
\text { luminance } \\
\left(\mathrm{cd} / \mathrm{m}^{2}\right)\end{array}$ & $1300-5100$ & $\begin{array}{l}27,000- \\
50,000\end{array}$ & $\begin{array}{l}29,000- \\
34,000\end{array}$ & $\begin{array}{l}68,500- \\
115,500^{(b)}\end{array}$ & $\begin{array}{l}41,000- \\
69,300 \\
\text { (calculated) }\end{array}$ & $3300-3500$ & $6500-8500$ \\
\hline \multirow{2}{*}{\multicolumn{8}{|c|}{$\begin{array}{l}\text { (a) The reference } 175 \mathrm{~W} \text { mercury post-top can be seen in the distance in Figure } 42 \text {. } \\
\text { (b) The low luminance measurement is an accurate measurement of the LED remote phosphor panel in the light } \\
\text { module; the high luminance value is likely the capture of the reflected and concentrated light from the specular } \\
\text { reflector. }\end{array}$}} \\
\hline & & & & & & & \\
\hline \multicolumn{8}{|c|}{$\begin{array}{l}\text { (c) The luminance values are derived from those listed in the previous column, with a } 0.6 \text { multiplier applied to } \\
\text { account for the reduced output due to dimming. }\end{array}$} \\
\hline
\end{tabular}

\subsection{Lessons from Chautauqua}

The process of exploring pedestrian lighting at Chautauqua has been unusual, in that the CPOA outdoor lighting committee worked diligently to communicate with the community about nighttime lighting issues in non-technical terms. They asked questions of residents, listened carefully to the responses, and used those responses and comments to inform the decisions about the next products for mockup. The lessons from this series of demonstrations were similar to those of Stanford University. 
Daytime appearance matters to the residents, the residents are interested in duplicating the warm appearance of incandescent lighting with a more efficacious source, glare really matters to the pedestrian, and horizontal illuminance can be at the low end of the Illuminating Engineering Society (IES) recommendations and still be perceived acceptable, as long as luminaire glare and light trespass are reduced. Chautauqua is an unusual community with low levels of crime and an expressed policy of making cars and trucks subordinate to pedestrians, but these lessons may also apply to other neighborhoods and campuses.

\subsection{A Note on Spider Webs and Dirt}

Both the Chautauqua Institution and Stanford University demonstration luminaires exhibited spider webs and accumulated dirt during warm weather months, as is visible from the nighttime photographs. These do not significantly affect the daytime appearance, but they do attract dirt and are visible at night. Periodic rainstorms help wash these out, but the spiders return after only a few days. In areas where there are prolonged periods without rain, and where appearance is important, it may be advisable to schedule a crew to hose down luminaires once or twice a year. More importantly, if long-life LED products are expected to last for many years without maintenance, luminaire optical enclosures should be sealed with high-quality gasketing to reduce dirt infiltration that can block light and reduce efficacy. Ingress Protection (IP) ratings can help the specifier identify luminaires better able to resist dirt and water vapor infiltration, since more resistant products have higher IP ratings (usually IP65 or greater). They are listed on product specification sheets.

\subsection{Discussion on Outdoor Luminaire Glare}

\subsection{Metrics Related to Glare Perception}

Traditionally, the following factors have been considered for glare metrics such as Veiling Luminance Ratio (VLR) for outdoor roadway lighting, and Visual Comfort Probability (VCP) and Unified Glare Rating (UGR) for interior lighting:

1. Luminance of the glare source from the vantage point of the viewer

2. Size, in solid angle, of the glare source from the vantage point of the viewer

3. Background luminance of the area beyond or flanking the glare source

4. Viewer's adaptation luminance

5. Angular deviation of the glare source relative to the viewer's line of sight

6. Number of glare sources within the field of view

These factors are not easily quantified because they are difficult to measure or characterize. For example, consider the following:

- The source luminance is virtually impossible to measure directly, since a luminance meter collects light within a fixed size collecting angle (such as $1^{\circ}$ or $1 / 3^{\circ}$ ), and the arc tube or LED may fill only a portion of that angle, thereby diluting the maximum absolute luminance. Average luminance can be 
calculated if the intensity emitted at a specific angle is known, but the projected area of the luminous source must also be known. Does the flashed area of a reflector, the arc tube, the luminaire aperture, or the summed area of LED sources constitute the luminous area?

- Similarly, how does one calculate the size in solid angle of the glare source? Unless it is an evenly luminous aperture or globe, calculations will vary widely. Which elements count toward the total luminaire luminance, and what should be done with luminance variation within that area?

- Is the background luminance the immediate area beyond the LED or arc tube (such as the luminance of the reflector or the luminance of the surface surrounding the LED), or is it the black night sky (or building facades or tree canopies) surrounding the luminaire?

- How is the viewer's adaptation luminance determined? Does it include the glare source and some weighting of luminances within the full field of view? (VLR, for example, calculates adaptation luminance as the average luminance of the pavement ahead and includes no contribution from the luminaire.) And because the retina exhibits spatial adaptation to different luminances in the field of view, is the adaptation level averaged over the whole field of view? How do head and eye motion affect this? Does spectral adaptation affect this?

- The angular deviation of the glare source is often resolved into the Guth Position Index, a multiplier of luminance that gets smaller as the angle from the line of sight increases. The Guth Position Index assumes that when the luminaire is above the natural cutoff of the human facial features (approximately $53^{\circ}$ above the line of sight, depending on the face), and is therefore not in the visual field, that it is no longer contributing to the glare sensation. Work on overhead glare (see Ngai and Boyce 2000; Boyce et al. 2003) has shown that subjects report discomfort from sources located at angles up to $85^{\circ}$ above the line of sight in interior applications. The same is likely true for outdoor applications as well.

- The number of luminaires within the field of view may contribute to the sensation of glare, but it is not clear whether additional luminaires increase the glare response because more luminaires are contributing high-contrast light to the visual system, or whether the additional luminaires decrease the glare response because the additional luminance they produce in the field of view increases the adaptation level of the viewer. Furthermore, some individuals have observed that it feels as though one experiences the glare from one luminaire at a time, unless the multiple luminaires are clustered very close together in the visual field. It may be that additional points of high luminance in the field of view multiply the glare response only if they are projected closely together on the retina.

The GATEWAY pedestrian lighting demonstrations support luminance as a glare factor, in that higher lumen output luminaires were generally perceived as more glaring. However, luminance as measured using a spot luminance meter was not predictive because spot luminance does not reliably capture the maximum luminance or average luminance of the luminaire. Table 1 shows the measured luminance values of the five options, using a 1/3 degree Minolta meter as described above, handheld and aimed toward the luminaire from $20 \mathrm{ft}$ away. Note that the luminaires rated most comfortable do not necessarily exhibit the lowest measured values.

Calculated luminance of the luminaire is also not necessarily related to the pedestrian response to glare because that uses the candela value emitted from the luminaire toward the viewer, divided by the projected area of the aperture. This assumes all lumens are spread uniformly across the luminaire aperture. Instead, some LED luminaires, for example, have multiple bright points of light, each very 
bright but with very dark space in between each point. Average luminance may work better for the interior-frosted glass refractor post-top luminaires on the Stanford campus because the lantern glass is more uniform in luminance.

\subsubsection{The IES Luminaire Classification System, or BUG (Backlight, Uplight, and Glare)}

The IES Luminaire Classification System (LCS) for Outdoor Luminaires (IES Technical Memorandum TM-15-07) groups pedestrian glare and driver glare into a single category, and it is based on the number of lumens emitted between $80^{\circ}$ and $90^{\circ}$ from a single luminaire's nadir. The number of lumens emitted in that zone dictates whether a luminaire is classified as G0, G1, G2, G3, G4, or G5. G0 means a luminaire emits very few lumens in that zone, and it is considered very low glare and appropriate for use in light-sensitive areas such as national parks or astronomical observatories. G1 suggests that the luminaire is suitable for rural areas or communities very sensitive to glare, light trespass, and the natural environment. This continues up to G5, which is a classification of very high glare potential. A G5 luminaire exceeds the lumen output recommended for use in areas of high ambient lighting (Lighting Zone 4), such as central business districts in urban areas. Figure 44 provides a 3D illustration of the LCS model.

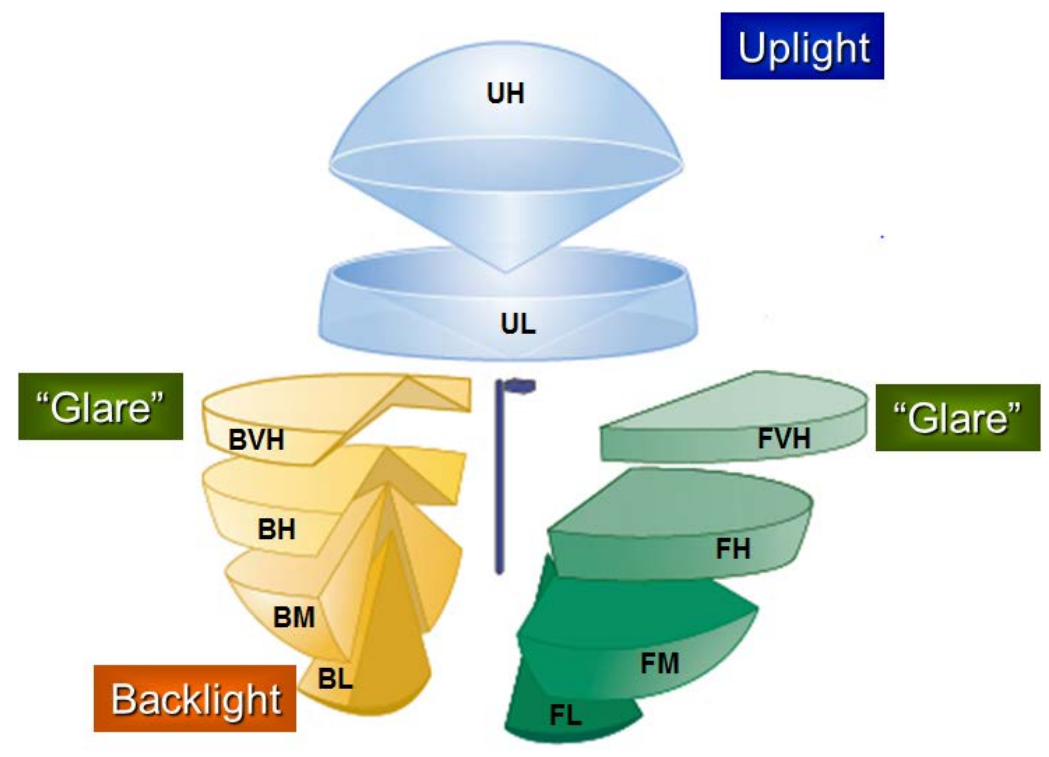

Figure 44. Three-dimensional illustration of the LCS model.

Figure 44 shows forward light zones in green, backlight zones in yellow, and uplight zones in blue. IES TM-15-07 defines the zones as contributing to backlight, uplight, and glare (BUG) in outdoor luminaires. The backlight very high $(\mathrm{BVH})$ and forward very high $(\mathrm{FVH})$ zones are defined as the glare zones, and comprise lumens emitted from $80^{\circ}$ to $90^{\circ}$. This pair of GATEWAY pedestrian lighting demonstrations does not support the glare zones as defined by the IES BUG system (TM-15-07) because the pedestrian's response to glare seems more closely linked to the luminaire emissions between $0^{\circ}$ and $75^{\circ}$, rather than $80^{\circ}$ to $90^{\circ}$ from luminaire nadir. The lower and larger range of angles seems to be critical for the pedestrian, even though much of the zone affecting the pedestrian's glare response seems to be coming from "overhead” (i.e., above the pedestrian's technically defined field of view). 
Do outdoor glare calculations and classification systems predict pedestrian glare? Judging by the results of these two demonstrations, no. It is perhaps time for the IES to reexamine pedestrian glare and develop metrics that are more predictive.

\subsubsection{Factors that DO Affect Pedestrian Glare}

Both of these demonstrations raise questions about how glare has traditionally been measured and calculated. They further raise questions about optical systems and what principles need to be followed to address glare for pedestrians. Although these two demonstrations were not rigorous experiments, the results seem to point to several areas of investigation for future glare research:

- Viewing angle for pedestrian. Although glare from a bright pedestrian-scale luminaire viewed from a distance of more than $40 \mathrm{ft}$ may be a source of disability glare, in these demonstrations, pedestrians complained more about the glare when they were closer to the pole. Designers and engineers can no longer dismiss excessive brightness at angles above the classically defined field of view (about $53^{\circ}$ to $60^{\circ}$ above horizontal for the viewer). Nor is it appropriate to assume that pedestrians will not move their gaze above horizontal in the scene ahead. Therefore, for visual comfort, the luminance and luminance distribution of the luminaire need to be considered, from $0^{\circ}$ to approximately $75^{\circ}$ from luminaire nadir for the pedestrian's discomfort glare, and from $75^{\circ}$ to almost $90^{\circ}$ for disability glare.

- Luminance of luminaire relative to viewer adaptation luminance. Visual comfort and the visibility of terrain, objects, and people to the pedestrian are inextricably intertwined. A very bright luminaire shifts the viewer's adaptation level. The visual system is able to see details in a very wide range of luminances, but not at both extremes at the same time (Boyce 2003). At night, if the luminance of a luminaire dictates the upper end of that adaptation luminance range, then details (i.e., luminance contrasts) may not be immediately visible if those luminances are below $1 / 500^{\text {th }}$ of that maximum luminance. Of course, the pedestrian's visual system is changing its adaptation level constantly, depending on which luminances are in the field of view, and there can be different adaptation levels within the field of view as well. However, at low light levels, the eye adapts more slowly, and details may not be visible as quickly as the viewer needs to see them. Reducing the maximum luminance value within a field of view may help the pedestrian see in the range necessary to detect important features in the scene, in time to react appropriately.

- Luminaire's spatial luminance distribution. Traditionally, glare calculations have relied on metrics of luminous intensity toward the viewer (i.e., candela value toward the viewer's eye), or average luminance toward the viewer (i.e., the average luminance of the bright aperture or surface as projected toward the viewer). Neither of these metrics would predict that viewers would object to odd or distracting luminance patterns on lenses, nor that the luminance of a single LED optic out of a larger group of LEDs aimed in multiple directions would be seen as excessively glaring, nor that sand-etching glass refractors could tip the scales between unacceptable and acceptable brightness. The principles that seem to apply in these two demonstrations are as follows:

- Spreading luminous intensity over a larger area can reduce maximum luminance and perceived glare.

- Small, intense patches of luminance, such as individual LEDs, may appear more glaring than the equivalent luminance spread more uniformly over a larger area. Conversely, a high average luminance from a remote-phosphor LED module may be perceived as less glaring than a spot luminance measurement of its surface would suggest. 
- Outdoor luminaire optics that feature dramatic distributions (such as a "flashed reflector" that delivers a sharp edge of luminous punch, followed by a sudden drop in luminance), may increase the pedestrian's response to glare, as he or she walks into, and then out of, the punch of intensity. Pedestrian luminaire optics may be deemed less glaring if the change of luminance with viewing angle is more gradual.

- Higher correlated color temperature (CCT) sources are usually perceived as brighter. Higher CCT sources may make outdoor areas appear to be more brightly lighted than illuminance and luminance measurements may suggest; however, it also means pedestrians may find the luminaires more unacceptably glaring than those same measurements might suggest.

\subsection{Pedestrian Lighting Concerns, Issues, and Tradeoffs}

Pedestrian-friendly lighting that is warm in color, soft in the gradients of light it produces, and lower in output and glare may necessitate some tradeoffs. For example:

- Efficacy losses due to lenses and diffusers can be significant: $10 \%$ to $20 \%$ or more.

- Warm-color 2700K to 3000K LED packages are less efficacious than 6500K LED packages. 4000K LED packages may deliver $8 \%$ to $10 \%$ fewer lumens than cooler $6500 \mathrm{~K}$ packages, and 3000K LED packages may deliver $20 \%$ fewer lumens than $6500 \mathrm{~K}$ in equivalent wattages.

- Lower lumen output luminaires produce lower illuminances and probably reduce visibility as well, although the better CRI among all mockup luminaires may compensate by improving color contrast compared to HPS.

- In general, warm-color light sources slightly reduce a pedestrian's ability to identify colors compared to high-CCT sources (i.e., the color gamut is smaller). The Stanford University security office would have preferred a higher CCT for visibility and for color identification, but the Stanford architects office insisted on the warm color. Note that both the $2700 \mathrm{~K}$ and $3000 \mathrm{~K}$ options are expected to improve pedestrian color discrimination compared to the existing HPS.

- Light distribution on the ground. Doesn't diffusion turn a precise optical pattern to mush? Yes. Diffusion in its most common forms will reduce peaks of candlepower, and reduce valleys of candlepower, making the photometric distribution closer to an unsophisticated cosine distribution. The resulting light pattern is likely to produce poorer maximum-to-minimum uniformity ratios on the ground. However, the gradient of light at the edge of that light pattern may be more gradual, and the smear of light that is spread by the diffusion into higher angles may produce an unintended benefit of actually increasing vertical illuminances on faces of pedestrians.

- Warm-color lighting delivers lower scotopic/photopic (S/P) ratios, which may lead to lower off-axis visibility at very low light levels.

These need to be weighed against the benefits of pedestrian-friendly outdoor lighting. 


\subsection{Conclusions}

Every outdoor lighting project is different. The needs vary according to the project client, the users, and their activities, and therefore the best lighting solution will also vary from project to project. There is no glare metric that works reliably for pedestrian lighting, so specifiers should organize full-scale mockups wherever possible and gather feedback from users. Not every neighborhood is suited for pedestrian-friendly approaches, but where communities are receptive, the following may help mitigate glare, improve visual comfort and visibility, and make outdoor spaces more inviting:

- lower lumen output luminaires and lower illuminances, if luminaire brightness can be controlled

- luminaires that spread luminance (“brightness”) over a larger area, including luminaires that use indirect optics

- luminaires with less optical punch and less sharp cutoff in candlepower

- luminaires delivering warmer color light, usually lower than 4000K, and often below 3000K CCT.

The problems of pedestrian lighting occur with all technologies, but LEDs offer optical options and opportunities the industry has never had before. This report is meant to stimulate discussion among specifiers, users, energy specialists, and industry in hopes that new approaches, metrics, and standards can be developed to support pedestrian-focused communities.

\subsection{References}

American National Standard Practice for Roadway Lighting, 2000. ANSI/IES Recommended Practice 8 (RP-8-00). Illuminating Engineering Society, New York.

Boyce P, C Hunter, and C Inclan. 2003. “Overhead glare and visual discomfort,” Journal of the Illuminating Engineering Society, Illuminating Engineering Society, New York, NY.

Boyce P. 2003. Human Factors in Lighting, $2^{\text {nd }}$ Edition, pp. 404-405. Lighting Research Center, Rensselaer Polytechnic Institute, Troy, New York.

Gibbons RB, CJ Edwards, R Bhagavathula, P Carlson, and DA Owens. 2012. “Development of Visual Model for Exploring Relationship Between Nighttime Driving Behavior and Roadway Visibility Features." Transportation Research Record: Journal of the Transportation Research Board 2298:96103. DOI 10.3141/2298-11.

Luminaire Classification System for Outdoor Luminaires, IES Technical Memorandum 15 (TM-15-07 Revised), 2007. Illuminating Engineering Society, New York, NY.

Ngai P and P Boyce. 2000. "The effect of overhead glare on visual discomfort," Journal of the Illuminating Engineering Society, Illuminating Engineering Society, New York, NY. 


\section{Appendix A: Stanford Community Residential Leaseholders (SCRL) Lighting Survey}

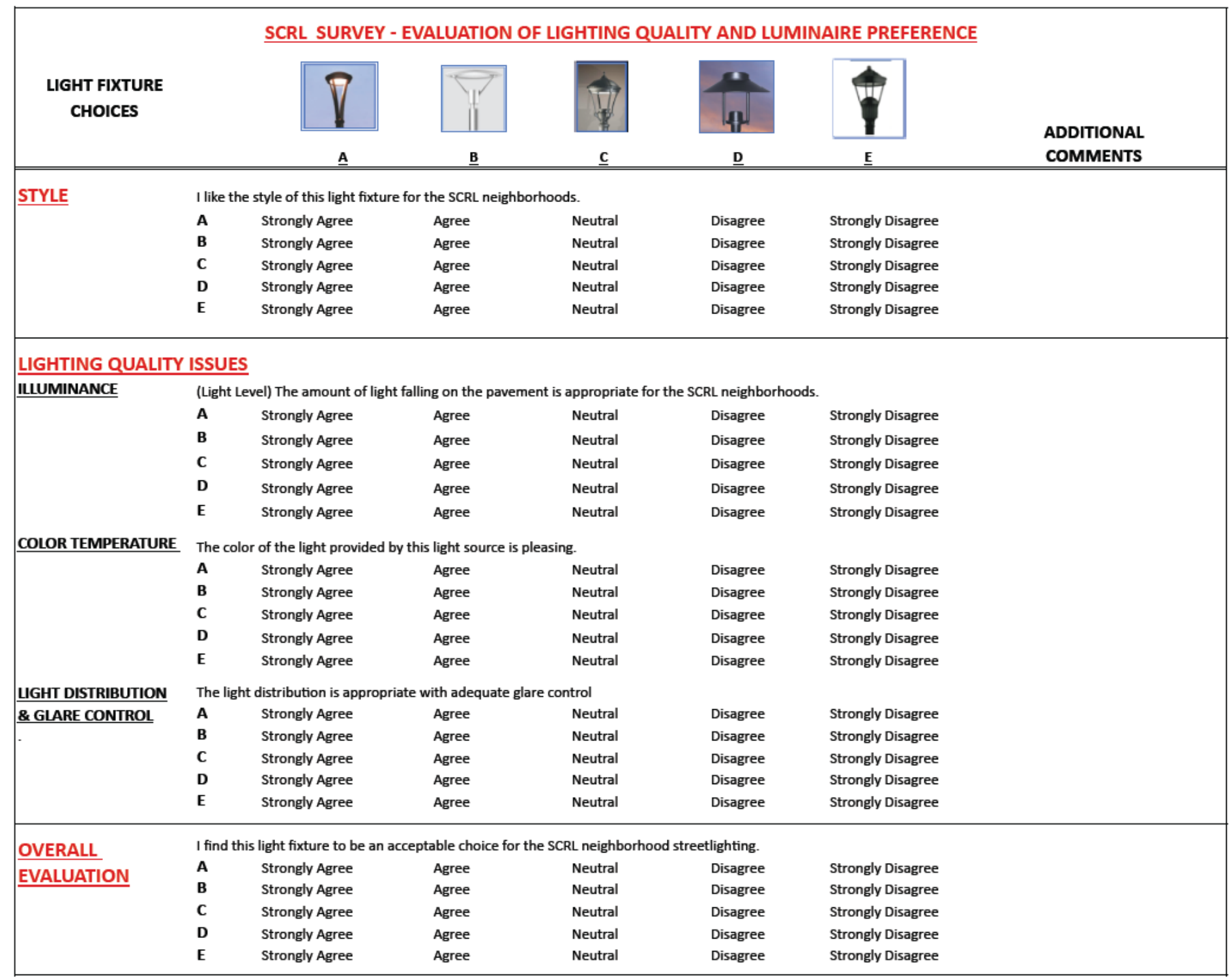





\section{Appendix B: Chautauqua Property Owners Association Outdoor Lighting Survey, 2012}

\section{CHAUTAUQUA PROPERTY OWNERS ASSOCIATION STREET LIGHT SURVEY 2012}
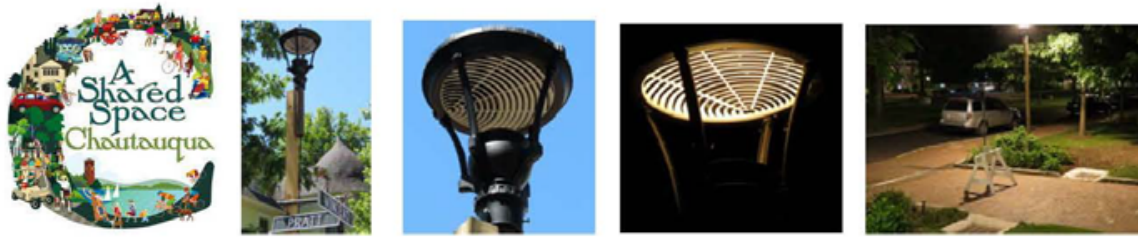

The CPOA demonstration street light has been installed at the bottom of the Vincent brick walk, on the Logan Dormitory side (opposite the St. Elmo), on the corner of Pratt Avenue. If there is a consensus among Chautauquans that this is the street lamp that should be used for replacement of existing lighting, then we can explore the possibility of replacing the Institution owned post-top globes in Bestor Plaza and on the Vincent Brick Walk. In addition, we would hope to be able to convince National Grid, the owner of the majority of street lighting in Chautauqua, to add this street light to their catalog and to use it for the hundreds of street lights that will need to be replaced in the next few years. You can help by filling out the survey below. Please indicate your selection by checking the appropriate response.

Style: I like this light fixture for Chautauqua street lights.

Strongly Agree

Agree

Neutral

Disagree

Strongly Disagree

\section{LIGHTING QUALITY ISSUES}

\begin{tabular}{|l}
\hline Illuminance (Light level): \\
The amount of light falling on \\
the pavement is appropriate. \\
$\square$ Strongly Agree \\
$\square$ Agree \\
$\square$ Neutral \\
$\square$ Disagree \\
$\square$ Strongly Disagree
\end{tabular}

Illuminance (Light level): The amount of light falling on the pavement is appropriate.

Strongly Agree

Agree

Disagree

Strongly Disagree

\begin{tabular}{|l|}
\hline Light distribution is appropriate \\
(dark sky friendly) with adequate \\
glare control. \\
$\square$ Strongly Agree \\
$\square$ Agree \\
$\square \quad$ Neutral \\
$\square$ Disagree \\
$\square$ Strongly Disagree
\end{tabular}

Light distribution is appropriate glare control.
Strongly Agree
Agree
Disagree
Strongly Disagree

\section{OVERALL EVALUATION}

This light fixture is an excellent choice for the Chautauqua street lighting.
$\square$ Strongly Agree
- Agree
$\square$ Neutral
$\square$ Disagree
- Strongly Disagree

Color Temperature: The color of the light provided by this light source is pleasing.

$\square$ Strongly Agree

Agree

Neutral

Disagree

Strongly Disagree

Please return survey to Bill Neches: Porch at 21 Ramble, Survey boxes in the Colonnade or in the Library (on table near the copier). Send e-mail comments to: cpoalighting@gmail.com 



\section{Appendix C: Chautauqua Property Owners Association Outdoor Lighting Survey, 2013}

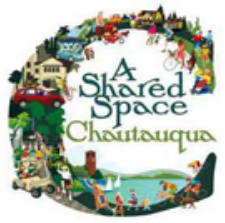

\section{CHAUTAUQUA PROPERTY OWNERS \\ ASSOCIATION \\ STREET LIGHT SURVEY 2013}
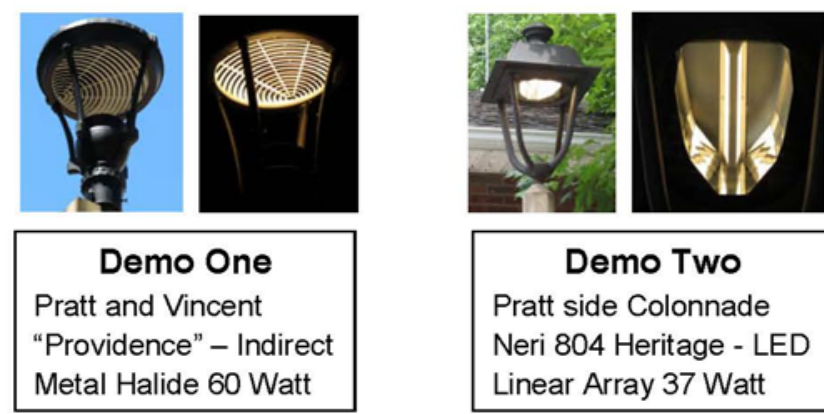

\begin{tabular}{|l}
\multicolumn{1}{c|}{ Demo Two } \\
Pratt side Colonnade \\
Neri 804 Heritage - LED \\
Linear Array 37 Watt \\
\hline
\end{tabular}

This year the CPOA has 2 demonstration street lights. Demo One is the light from last Summer. Demo Two is a new LED light. Next year we are planning a Street Light Demonstration Project with the US Department of Energy to evaluate LED street lighting in Chautauqua. If National Grid agrees, we plan to replace the 9 post top lantern lights on Pratt between Ramble and Hurst. We also would remove the existing old street lights on 2 wooden utility poles nearby and replace them with an LED lantern style light.

Since lighting requirements differ with location, it is important to compare the 2 demo lights above as possible replacements for lighting on streets with vehicles, as well as on pedestrian only walkways.

Therefore please consider:

Style: I like the appearance of this light fixture for Chautauqua street lights:

\begin{tabular}{|c|c|}
\hline $\begin{array}{c}\text { Agree } \\
\text { Neutral } \\
\text { Disagree }\end{array}$ & Agree \\
Neutral \\
Disagree
\end{tabular}

Light Level and Glare: There is enough light and glare is adequately controlled:

\begin{tabular}{|c|c|}
\hline Agree & Agree \\
Neutral & Neutral \\
Disagree & Disagree \\
\hline
\end{tabular}

For Chautauqua street lighting: I find this light fixture to be an excellent choice:

\begin{tabular}{|c|c|}
\hline Agree & Agree \\
Neutral & Neutral \\
Disagree & Disagree \\
\hline
\end{tabular}

For Chautauqua pedestrian walkways: I find this light fixture to be an excellent choice:

\begin{tabular}{|c|c|}
\hline $\begin{array}{c}\text { Agree } \\
\text { Neutral } \\
\text { Disagree }\end{array}$ & $\begin{array}{c}\text { Agree } \\
\text { Neutral } \\
\text { Disagree }\end{array}$ \\
\hline
\end{tabular}

Comments:

Name (Optional): 



\section{Appendix D: Photometric Performance for Luminaires on Stanford University and Chautauqua Institution projects}

\begin{tabular}{|c|c|c|c|c|c|c|c|c|c|c|c|c|c|c|c|c|c|}
\hline & 宸 & 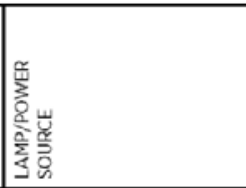 & 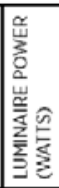 & 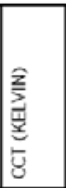 & $\bar{y}$ & 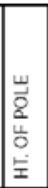 & 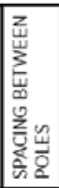 & 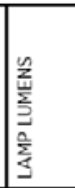 & 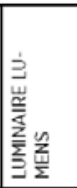 & 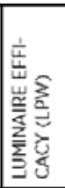 & 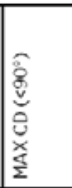 & 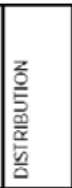 & 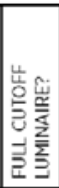 & 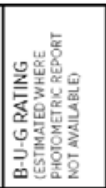 & 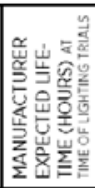 & 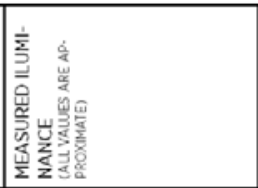 \\
\hline \multirow{7}{*}{\multicolumn{2}{|c|}{ 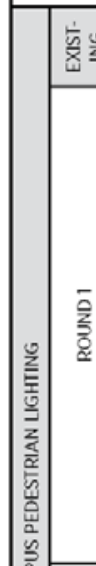 }} & $\begin{array}{l}\text { Acuity/Holophane RSL-350: } \\
\text { utility series post-top }\end{array}$ & $\begin{array}{l}\text { 100W HPS and magnetic } \\
\text { ballast }\end{array}$ & 122 & 2200 & 22 & 10 & $\pi$ & 9500 & 6220 & 51.0 & 4935 & $\begin{array}{l}\text { Type } \\
\text { III }\end{array}$ & No & B3-U3-G3 & $24,000+$ & \begin{tabular}{|l|}
$16.51 \times(1.53 \mathrm{I} \mathrm{lc}) 6^{\prime}$ from pole: \\
$5.8 \mathrm{1}(0.54 \mathrm{fc})$ between \\
poles
\end{tabular} \\
\hline & & $\begin{array}{l}\text { New Acuity//Holophane RPE } \\
\text { (LED luminatre identical in } \\
\text { appearance to the RSL-350): } \\
\text { utility series LED post-lop }\end{array}$ & 70W LED and driver & 70 & 4000 & 70 & 10 & $73^{\prime}$ & N/A & 4174 & 59.6 & 3910 & $\begin{array}{l}\text { Type } \\
\text { III }\end{array}$ & No & B1-U3-G2 & 50,000 & $\begin{array}{l}111 \times(0.98 \mathrm{fc} \text { ) average } 6 \\
\text { from pole: } 7.81 \times(0.72 \mathrm{fc}) \\
\text { between poles }\end{array}$ \\
\hline & & $\begin{array}{l}\text { Acuity/Holophane RSL-350: } \\
\text { utility serles post-top }\end{array}$ & $\begin{array}{l}\text { 85W QL Induction and elec- } \\
\text { tronic power supply }\end{array}$ & 85 & 3000 & 80 & 10 & $70^{\circ}$ & 6000 & 3928 & 46.2 & 317 & $\mathrm{~N} / \mathrm{A}$ & No & N/A & 60.000 & \begin{tabular}{|l|}
$10 \mathrm{~lx}(0.97 \mathrm{fc})$ average $6^{\prime}$ \\
from pole; $3.6 \mathrm{Ix}(0.33 \mathrm{fc})$ \\
between poles \\
\end{tabular} \\
\hline & & $\begin{array}{l}\text { Acuity/Holophane RSL-350: } \\
\text { utilty series post-top }\end{array}$ & $\begin{array}{l}\text { 900W "Cosmowhite" CMH } \\
\text { with electronic ballast }\end{array}$ & 99 & 2800 & 70 & $10^{\circ}$ & $62^{\circ}$ & 10450 & 6842 & 69.1 & 5428 & $\begin{array}{l}\text { Type } \\
\text { III }\end{array}$ & No & B3-U3-G3 & 18,000 & $\begin{array}{l}28.8 \times\left(2.68 \mathrm{fc} \text { ) average } 6^{\circ}\right. \\
\text { from pole: } 9.01 \times(0.84 \mathrm{fc}) \\
\text { between poles }\end{array}$ \\
\hline & & $\begin{array}{l}\begin{array}{l}\text { Acuity/Holophane RSL-350: } \\
\text { utlity serles post-top }\end{array} \\
\end{array}$ & $\begin{array}{l}100 \mathrm{~W} \text { CMH with efectronic } \\
\text { ballast }\end{array}$ & 110 & 4000 & 85 & $10^{\prime}$ & $\mathrm{N} / \mathrm{A}$ & 9000 & 5892 & 53.6 & 4675 & \begin{tabular}{|l}
$\begin{array}{l}\text { Type } \\
\text { III }\end{array}$ \\
\end{tabular} & No & B3-U3-G3 & 20,000 & $\begin{array}{l}25.6 \mathrm{1} \times(2.38 \mathrm{fc}) \text { average } 6^{\prime} \\
\text { from pole (only } 1 \text { pole) }\end{array}$ \\
\hline & & \begin{tabular}{|l} 
New Acuity/Holophane PUL: \\
utility series with frosted flat \\
glass (")
\end{tabular} & 70W LED and driver & 70 & 3000 & N/A & 10 & $41.5^{\prime}$ & N/A & 4889 & 69.8 & 2160 & $\begin{array}{l}\text { Type } \\
\text { vs }\end{array}$ & Yes & B3-U0-G1 & 50,000 & $\begin{array}{l}28.2 \mathrm{IX}(2.62 \mathrm{fc}) \text { average } 6^{\prime} \\
\text { from pole; } 8.1 \times(0.75 \mathrm{fc}) \\
\text { between poles }\end{array}$ \\
\hline & & $\begin{array}{l}\text { Acuity/Holophane PTU: util- } \\
\text { ties ser ies post-top }\end{array}$ & $\begin{array}{l}100 \mathrm{~W} \text { CMH with electronic } \\
\text { ballast }\end{array}$ & 110 & 3000 & 85 & 10 & $63^{\prime}$ & 9000 & 5029 & 45.7 & 1514 & $\begin{array}{l}\text { Type } \\
\text { ve }\end{array}$ & Yes & B2-UO-Gl & 20.000 & 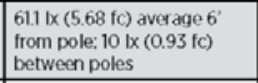 \\
\hline$\frac{2}{5}$ & \multirow{4}{*}{ 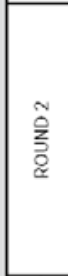 } & $\begin{array}{l}\text { Acuity/Holophane RSL-350: } \\
\text { utility series post-top }\end{array}$ & $\begin{array}{l}\text { 60W "Cosmowhite" CMH } \\
\text { and electronic ballast }\end{array}$ & 67 & 2800 & 70 & $10^{\prime}$ & $95^{\prime}$ & 6900 & 4517 & 67.4 & 3584 & $\begin{array}{l}\text { Type } \\
\text { III }\end{array}$ & No & $B 2-U 3-G 3$ & 18,000 & \begin{tabular}{|l}
$15.7 \mathrm{I} \times(1.46 \mathrm{fc}) 6^{\prime}$ from pole: \\
$0.9 \times(0.08 \mathrm{fc}$ between \\
poles
\end{tabular} \\
\hline$\sum_{\bar{y}}^{\bar{m}}$ & & $\begin{array}{l}\text { Acuity/Holophane RSL-350: } \\
\text { utility series post-top }\end{array}$ & $\begin{array}{l}\text { 45W LED retrofit kit from } \\
\text { Xeralux/Sensity }\end{array}$ & 45 & 4000 & $\mathrm{~N} / \mathrm{A}$ & 10 & $\mathrm{~N} / \mathrm{A}$ & 4050 & N/A & $\mathrm{N} / \mathrm{A}$ & $\mathrm{N} / \mathrm{A}$ & N/A & No & N/A & $\mathrm{N} / \mathrm{A}$ & N/A \\
\hline 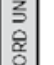 & & \begin{tabular}{|l|} 
Acuity/Holophane RSL-350: \\
utility series post-top
\end{tabular} & $\begin{array}{l}67 \text { WLD and driver retrofit } \\
\text { from CREE } \\
\end{array}$ & 67 & 2700 & $70+$ & 10 & $62^{\prime}$ & N/A & $\begin{array}{l}3800 \\
\text { approx }\end{array}$ & 56.7 & $\mathrm{~N} / \mathrm{A}$ & $\mathrm{N} / \mathrm{A}$ & No & $\mathrm{N} / \mathrm{A}$ & $\mathrm{N} / \mathrm{A}$ & $\mathrm{N} / \mathrm{A}$ \\
\hline $\begin{array}{l}\frac{1}{2} \\
\frac{1}{4} \\
\frac{1}{n}\end{array}$ & & $\begin{array}{l}\text { Acuity/Holophane RSL-350: } \\
\text { utility series post-top }\end{array}$ & $\begin{array}{l}\text { 50W LED optical replace-- } \\
\text { ment kit from Holophane }\end{array}$ & 51 & 3000 & 70 & 10 & $70^{\prime}$ & $\mathrm{N} / \mathrm{A}$ & 3349 & 65.7 & 2866 & $\begin{array}{l}\text { Type } \\
\text { IIII }\end{array}$ & No & B1-U3-G2 & 50,000 & $\begin{array}{l}\text { no measurements taken until } \\
\text { glass lantern was frosted- } \\
\text { see Round } 3 C\end{array}$ \\
\hline \multirow{4}{*}{\multicolumn{2}{|c|}{$\mid \begin{array}{c}n \\
\hat{z} \\
0 \\
0 \\
\alpha\end{array}$}} & $\begin{array}{l}\text { Acuity/Holophane PSL-350: } \\
\text { utlity series post-top }\end{array}$ & $\begin{array}{l}\text { 60W "Cosmowhite" CMH } \\
\text { with electronic ballast }\end{array}$ & 67 & 2800 & 70 & 10 & $95^{\circ}$ & 6900 & 4517 & 67.4 & 3584 & $\begin{array}{l}\text { Type } \\
\text { IIII }\end{array}$ & No & B2- $-43-63$ & 18.000 & \begin{tabular}{|l|}
$15.7 \mathrm{l} \times(1.46 \mathrm{fc})$ average $6^{\prime}$ \\
from pole. $0.9 \times(0.08 \mathrm{fc})$ \\
between poles
\end{tabular} \\
\hline & & $\begin{array}{l}\begin{array}{l}\text { New Acuity/Holophane PUL: } \\
\text { utility series with frosted flat } \\
\text { glass (") }\end{array} \\
\end{array}$ & 70W LED and driver & 70 & 3000 & $\mathrm{~N} / \mathrm{A}$ & $10^{\prime}$ & $41.5^{\prime}$ & $\mathrm{N} / \mathrm{A}$ & 4889 & 69.8 & 2160 & $\begin{array}{l}\text { Type } \\
\text { vs }\end{array}$ & Yes & B3-U0-G1 & 50.000 & \begin{tabular}{|l}
$28.1 \mathrm{l} \times\left(2.62 \mathrm{fc}\right.$ average $6^{\prime}$ \\
from pole: $8.1 \mathrm{1} \times(0.75 \mathrm{fc})$ \\
between poles \\
\end{tabular} \\
\hline & & \begin{tabular}{|l} 
Acuity/Holophane RSL-350: \\
utilty series post-top with \\
interior frosted lantern glass"
\end{tabular} & $\begin{array}{l}\text { 50W LED optical replace- } \\
\text { ment kit from Holophane, } \\
\text { 3000K } \\
\end{array}$ & 51 & 3000 & 70 & $10^{\circ}$ & $70^{\prime}$ & $\mathrm{N} / \mathrm{A}$ & 3182 & 62.4 & 2723 & $\begin{array}{l}\text { Type } \\
\text { III }\end{array}$ & No & B1-U3-G2 & 50,000 & \begin{tabular}{|l}
$10.11 \times\left(0.94 \mathrm{fc}\right.$ ) average $6^{\circ}$ \\
from pole; $3.21 \times(0.30 \mathrm{fc})$ \\
between poles
\end{tabular} \\
\hline & & $\begin{array}{l}\text { Acuity/Holophane RSL-350: } \\
\text { uttity series post-top with } \\
\text { inter ior Irosted lantern glass" }\end{array}$ & $\begin{array}{l}\text { 50W LED optical replace- } \\
\text { ment kit from Holophane. } \\
2700 \mathrm{~K}\end{array}$ & 51 & 2700 & 73 & 10 & $60^{\circ}$ & N/A & 2948 & 57.8 & 2522 & $\begin{array}{l}\text { Type } \\
\text { III }\end{array}$ & No & B1-U3-G2 & 50.000 & $\begin{array}{l}71.5 \mathrm{Ix}\left(1.07 \mathrm{fc} \text { ) average } 6^{6}\right. \\
\text { from pole; } 2.7 \mathrm{I} \times(0.25 \mathrm{fc}) \\
\text { between poles }\end{array}$ \\
\hline
\end{tabular}




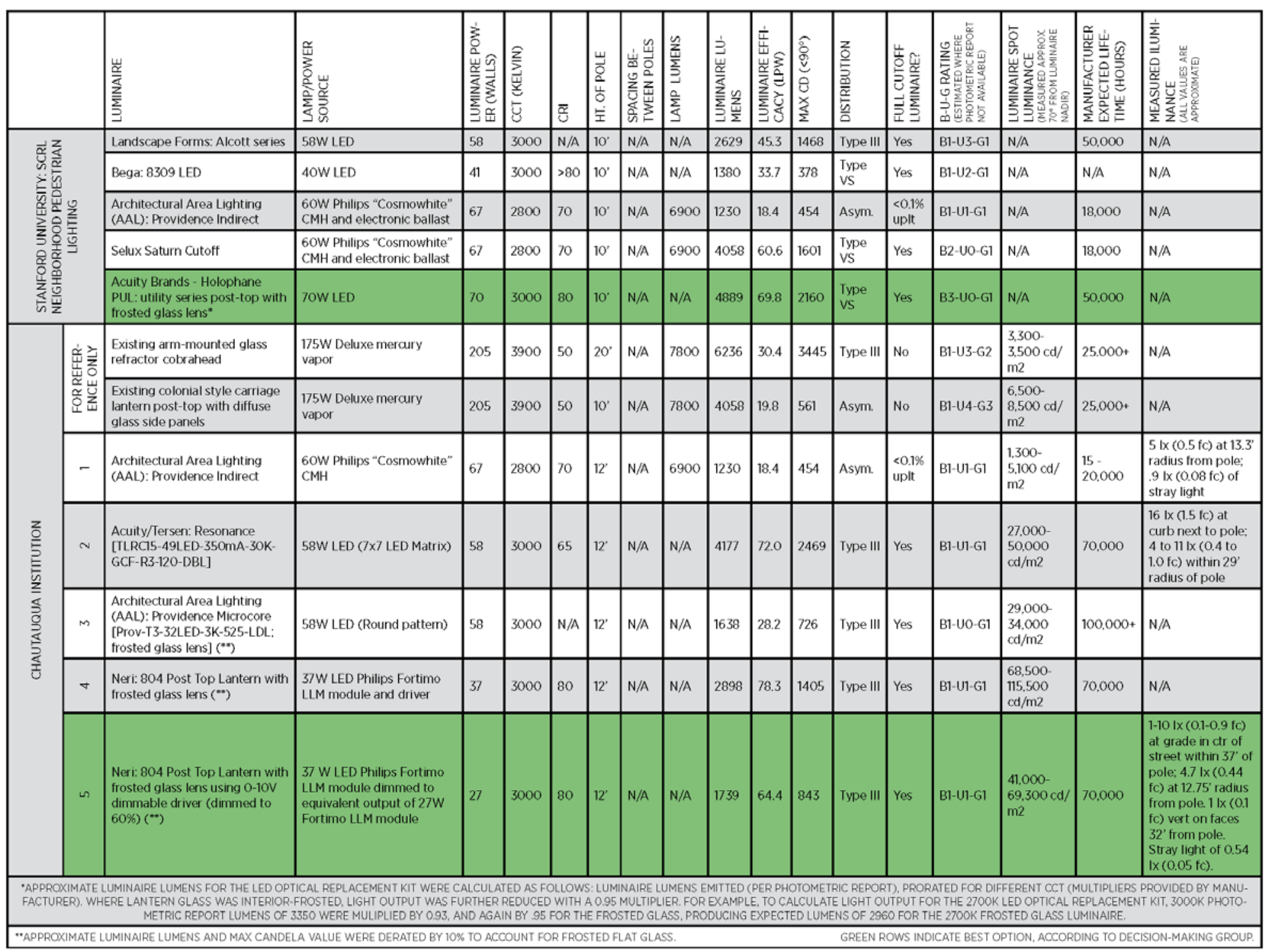





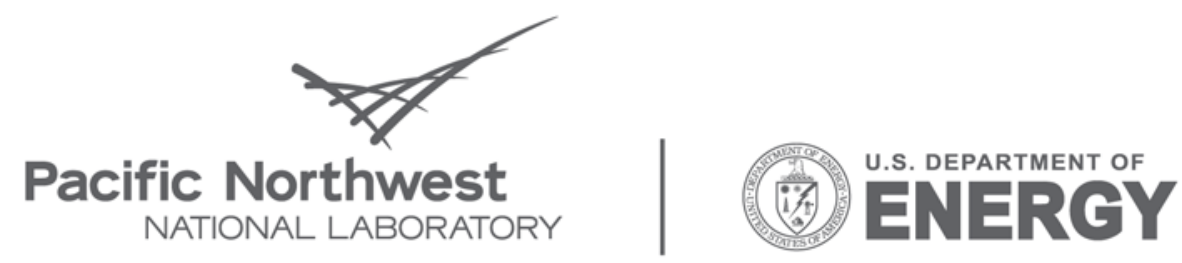

Proudly Operated by Battelle Since 1965

902 Battelle Boulevard

P.O. Box 999

Richland, WA 99352

1-888-375-PNNL (7665)

www.pnl.gov 